\title{
QUELQUES PROBLEMES RELATIFS A LA RESPONSABILITE CIVILE EN DROITS ALLEMAND, SUISSE ET FRANÇAIS (*)
}

\author{
Dr. Halûk TANDOĞAN
}

Professeur de droit civil à la Faculté de droit d'Ankara

\section{CHAPITRE II \\ ILLICEITE, RAPPORT D'ILLICEITE, OBJECTVATION DE LA FAUTE}

\section{Section I - Illicéité comme élément constitutif de la} responsabilité extracontractuelle

25. Droits des pays du Marché Commun qui admettent l'illicéité comme une condition indépendante de la responsabilité délictuelle. - L'illicéité est expressément mentionnée comme une condition indépendante de la responsabilité à base de faute, dans les Codles allemand, suisse, italien, néerlandais, grec et turc. Par contre, les Codes civils français, belge et luxembourgeois, se contentant de la faute, ne font pas figurer l'illicéité parmi les éléments constitutifs de la responsabilité.

Le BGB allemand, comme nous l'ạvons décrit plus haut (125), a essayé, aux paragraphes 823 et sv., de déterminer les conditions ( Tatbestände) dans lesquelles un comportement dommageable doit être considéré illicite. En d'autres termes, dans l'esprit du législateur allemand, la conformité d'un comportement à ces conditions (Tatbestandsmässigkeit) permettrait de le qualifier en principe d'illicite, à moins qu'il n'existe un fait justificatif (Recht-

(*) L'introduction et le premier Chapitre de cette étude ont paru dans les «Mélanges publiés par la Faculté de droit d'Ankara à l'occasion Ju quarantième anniversaire de l'adoption du Code civil turc et de la fondation du Faculté de droit d'Ankara», Ankara 1966, pp. $317-357$

(125) Cr. supra No. 7. 
fertigungsgrund) dans les cas concrets (126). Ainsi, en droit allemand, la loi elle-même tendait à fixer les catégories des conduites illicites. A ces catégories sont venues s'ajouter plus tard les conduites dont l'illicéité est déduite du droit non écrit par la jurisprudence (127). Le BGB parle dans le $\S 823$ al. 1 er d'une atteinte portée d'une manière illicite (widerrechtlich verletzt) à certains droits et biens juridiques. Le second alinéa du mêmı para. graphe vise les contraventions aux lois ayant pour but la protection d'autrui (welcher gegen ein den Schutz eines anderen bezzeckendes Gesetz verstösst). Les actes dommageables contraires aux bonnes mœurs, commis dans l'intention de nuire à autrui, constituent en vertu du $\S 826$ une autre catégorie d'atteintes illicites. Selcr le $\S 831$, la responsabilité du maître n'est engagé que pour les, dommages causés par son employé d'une manière illicite ( $w i-$ derrechtlich zufügt).

En droit suisse, conformément à l'art. 41 al. 1er du CO, «ceỉuj qui cause, d'une manière illicite, un dommaga à autrui, soit intentionnellement, soit par négligence ou imprudence, est tenu de le. réparer.» Le second alinéa de cat article emprunté au $\$ 826$ du BGB dispose: «Celui qui cause intentionnellement un dommage à autrui par des faits contraires aux mours, est également tenu de le réparer.» Le CO turc a reproduit intégralement le texte de l'art. 41 du CO suisse.

Le CC italien, dans son art. 2043, dont la note marginale est «réparation pour fait illicite», statue que «toute fauta qui cause injustement un dommage à autrui, oblige celui qui l'a commise à le

(126) Cf. Larenz, t. II, pp. 377-378; Esser. Schuldrecht, pp. 189, 838 et 840. Toutefois, selon Esser (Schuldrecht, $\S 5.2,2$ ), on doit d'abord fixer la conformité de l'acte aux conditions légales et décider ensuite de la question de l'illicéité. R. Bienenfeld (Die Haftungen ohne Verschulden, Typenlehre und System der aussergeschaeftlichen Obligationen im deutschen, österreichischen und schweizerischen Recht, Berlin 1933, p. 404) est d'avis que la conformité aux conditions légales ne constitue même pas un indice pour l'illicéité et que les paragraphes 823 et sv. du BGB contiennent des normes en blanc (Blankettnormen) dont le contenu est à remplir par le juge, comme part. 41 du CO suisse. of. supra No. 9 . 
réparer». Il est affirmé dans la doctrine (128) que «l'illicéité du fait et l'injustice du dommage sont des termes corrélatifs.» D'ailleurs, les articles 2044 et 2045 du CC italien sont consacrés à la réglementation des faits justificatifs, tels que légitime défense et état de nécessité qui ôtent à l'acte dommageable son caractère illicite.

On rencontre la condition d'illicéité également dans l'art. 1401 du CC néerlandais ainsi rédigé (129): Tout acte illicite par lequel un dommage est causé à autrui, oblige celui par la faute duquel il est arrivé à le réparer». La même condition est maintenue dans le Projet dư nouveau CC néerlandais qui contient la disposition suivante (130): «Celui qui accomplit à l'égard d'un autre un acte illicite qui lui est imputable, est obligé de réparer le dommage qui en résulte pour cet autre». Il est à remarquer que la définition de l'illicéité donnée dans ce Projet s'approche de la doctrine moderne allemande qui préconise la théorie de "Sozialadäquanz" (131). En effet, d'après ce Projet, «peut être considéré comme acte illicite une atteinte à un droit, un acte ou une ommission en contradiction avec un devoir légal ou avec ce qu'il convient de faire en société selon le droit non écrit, le tout sous la réserve d'un fait justificatif» (132).

Le CC grec (133), dans son art. 914, semble restreindre le domaine de l'illicéité seulement aux actes contraires à la loi, lorsqu'il déclare: «tenu i réparation celui qui, par sa faute, a causé contrairement à la loi (134), un dommage à autrui». Pour remédier ;: cette restriction, une clause générale renvoyant au droit non écrit

(128) Cf. A. De Cupis, «Fatti illeciti», dans le Trattato di diritto civile de G. Grosso et F. Santoro _ Pascarelli, 1961, No. 9, p. 18.

(129) Cf. Limpens, dans Mélanges Savatier, p. 563; le même auteur, La faute et l'acte illicite en droit comparé, dans Mélanges en l'honneur de Jean Dabin, t. II, Paris 1963, p. 724.

(130) Cf. Limpens. Mélanges Savatier, p. 565.

(131) Cf. infra. Sect. II. no. 44.

(132) Cf. Limpens, Mélanges Savatier, p. 565.

(133) Traduction de l'Institut héllenique de droit international et étranger P. Mamopoulos, Athènes 1956; Cf. aussi X. Savidis, Le nouveau Code civil hellénique, Athènes 1940, p. 198.

(134) Toutefois, selon J. Déliyannis (La notion d'acte illicite considéré en sa qualité d'élément de la faute délictuelle, Paris 1952, p. 15) le texte grec contient' lexpression kcontraire au droit». 
est ajoutée à l'art. 919, à l'instar du $\S 826$ du BGB; d'après cet article, «celui qui a causé intentionnellement un dommage à autrui en agissant contrairement aux bonnes mœurs, est tenu i réparation». Toutefois, comme nous l'avons remarqué plus haut (135), le champ d'application d'une telle disposition qui exige la preuve de l'intention de nuire, reste également assez limité.

26. Rôle de l'illicéité dans les responsabilités sans faute. - La question de savoir si l'illicéité doit être prise en considération comme un élément constitutif ou comme fondement des responsabilités sans faute donne lieu à des controverses, même dans les droits qui l'admettent en tant que condition indépendante de la responsabilité à base de faute.

Si l'on considère l'illicéité comme une qualification du résultat dommageable, donnée par l'ordre juridique en vue de désapprouver ce résultat et d'y attacher l'obligation de réparer (136), on peut constater l'existence d'une telle qualification dans chaque cas de responsabilité sans faute.

Mais si l'on part du point de vue selon lequel l'illicéité est une qualification de la conduite de la personne responsable, des difficultés surgissent lorsqu'il s'agit d'expliquer la présence d'un comportement illicite de la personne responsable dans certains cas de responsabilité sans faute.

D'abord, selon les partisans d'une théorie dite subjective de l'illicéité (137), cette dernière notion n'a de sens que là où existe la possibilité subjective de se conformer aux injonctions de l'ordre juridique que l'on transgresse. Si l'on voit dans ces injonctions des impératifs adressés seulement à des hommes qui peuvent les coniprendre et qui ont la possibilité de s'y conformer, l'illicéité fait défaut, lorsque les normes en question sont violées sans faute. II en est ainsi dans les cas de responsabilité objective qui apparaissent même si la personne responsable est privée de la capacité de dis-

(135) Cf. supra No. 7.

(136) Cf. Bienenfeld, pp. 425 et sv.; Enneccerus-Nipperdey, t. I. $\S 203$, note 6 et $\S 209$. texte relatif à la note 11 .

(137) Cf. sur cette théorie Oftinger, Schweizerisches Haftpflichtrecht. $t$. I. p. $\mathbf{1 1 7}$ 
cernement ou si elle a observé la diligence nécessaire pour éviter le résultat dommageable.

Actuellement, c'est la théorie objective de l'illicéité qui domine en droits allemand et suisse (138). Selon cette théorie, l'illicéité consiste simplement dans la violation d'une norme, sans qu'il soit nécessaire de rechercher si l'auteur de cette violation avait la possibilité d'agir conformément à la norme en question. Certains auteurs suisses (139), en se fondant sur cette théorie, affirment que l'illicéité est aussi un élément constitutif des responsabilités sans faute. Toutefois, cette affirmation ne serait pas exacte pour toutes les responsabilités objectives, si l'illicéité était considérée comme la violation d'une norme de conduite. En effet, dans les responsabilités pour risque créé au sens technique, l'exploitation d'une installation ou l'activité à laquelle est rattachée la responsabilité n'est pas illicite en elle-même (140) étant autorisée dans l'intérêt social; d'ailleurs, il n'existe pas en dehors de cette activité une action de la personne responsable qui pourrait constituer la cause du dommage. En outre, les responsabilités en question ne supposent pas un comportement, une action humaine précise (141) ; le responsable est déterminé par la maîtrise qu'il exerce sur la source du risque; il répond même des cas fortuits. C'est pourquoi, en Allemagne, selon la doctrine et la jurisprudence récentes (142), l'illicéité ne peut être ni un élément constitutif, ni le fondement de responsabilités pour risque créé au sens technique. Ces responsabilités ne sont pas fondées sur la violation d'un devoir imposé par les rapports sociaux, mais elles reposent sur une considération de justice commutative suivant laquelle celui qui tire les profits d'une activité dangereuse, mais autorisée dans l'intérêt social, doit en supporter également les risques.

(138) Cf. sur cette théorie Oftinger, Schweizerisches Haftpflichtrecht. t. I, p. 118

(139) Cf. Oftinger, Schweizerisches Haftpflichtrecht t. I, p. 117, note 33.

(140) Dans ces cas, von Tuhr (t. I, p. 360) constate l'illicéité dans la mise en péril des biens d'autrui.

(141) Cf. Enneccerus-Nipperdey, t. I, § 20:8, II, 1, p. 1273.

(142) Cf. Larenz, t. II, pp. 455-456; Esser, Schuldrecht, pp. 189, 190, 830; BGHZ, 24, 26; 34,361 . 
D'autre part, il est évident que, lorsqu'il s'agit de responsabilités pour des interventions autorisées (143), il n'est pas possible de parler de l'existence d'un comportement illicite.

Parmi lé responsabilités causales ordinaires, dans celles qui dérivent de la violation d'un devoir de diligence objective, on peut constater l'existence d'une omission illicite de la personne responsable. Cette constatation conduit certains auteurs (144) à admettre l'illicéité non seulement comme élément constitutif, mais en même temps comme fondement de ces responsabilités. En outre, la responsabilité du propriétaire foncier qui excède son droit de propriété implique également un comportement illicite (145).

Pour certaines responsabilités causales ordinaires un acte illicite de la personne elle-même responsable, ou des personnes dont elle répond des faits, est exigé par la doctrine ou par la loi. Ainsi selon la majorité des auteurs allemands et suisses (146), la responsabilité pour les motifs d'équité d'une personne incapable de discernement suppose un acte illicite de celle-ci. Les auteurs qui hésitent de considérer l'attitude de la personne incapable de discernement comme une action (Handlung) au sens juridique, exigent une attitude qui aurait été déclarée «illicite», si cette personne avait été consciente de ses actes (147).

(143) Cf. supra No. 24.

(144) Cf. A. Hombenger. Haftpflicht ohne Verschulden, ZSR, N. F. 49 (1930). pp. 22a-27a.

(145) Cf. toutefois pour les troubles licites causés par le propriétaire foncier à ses: voisins, supra note 120 .

(146) Cf. Larenz, t. II, p. 381; Esser, pp. 864-855; von Tuhr, $\S 47$, tex relatif à la nate 35 ; Oser-Schönenberger, art. 54 no. 4.

(147) D'après sa définition juridique (cf. Larenz, t. II, pp. $376-377$ l'action (Handlung) est tout fait humain maitrisable par la volonié (vom Willen beherrschbar); il n'est pas nécessaire, dans le cas concret que l'agent soit toujours conscient de son attitude ou qu'il l'ait voulue, mais il suffit qu'il existe d'après les prévisions humaines la possibilité de se rendre compte des effets d'une telle attitude. Ainsi un enfant ou un dément peuvent commettre un acte objectivement illicite bien qu'on ne puisse leur imputer aucune faute. Toutefois s'il manque à lagent toute maitrise de volonté ou s'il cause un dommage en état d'inconscience totale, on ne peut plus parler d'une action et la responsabilits d'équite devient dans ces cas une responsabilité pour risque créé (cf. Larenz, i. II, p. 382; Esser, Schuldrecht. p. 865). 
D'autre part, en droit suisse, les employeurs et les chefs de famille ne sont responsables que des dommages causés par un acte illicite de leurs employés ou des personnes qui sont soumises à leur autorité (148).

Pour conclure, il est à remarquer que parmi les conditions des responsabilités causales qui sont réglementées d'une façon plus casuiste que la responsabilité basée sur la faute, celle de l'illicéité du comportement de la personne responsable ne se trouve jamais expressément mentionnée par la loi. A part les responsabilités des incapables de discernement, des employeurs, des chefs de famille et des propriétaires fonciers, la question de' savoir si l'illicéité est un élément constitutif de la responsabilité et s'il existe des faits justificatifs qui l'excluent, ne présenta pas un intérêt pratique même si l'on répond à cette question d'une façon affirmative (149).

Dans d'autres responsabilités causales que celles qu'on vient de mentionner, surtout dans les responsabilités pour risque créé au sens technique, l'un des faits justificatifs, le cas de nécessité peut parfois se présenter; mais il peut être pris en considération comme la faute d'un tiers ou comme un cas de force majeure qui rendent inadéquat le lien de causalité entre le fait générateur de la responsabilité et le dommage. Il en est ainsi, par ex. lorsqu'un automob:liste, pour éviter une autre voiture ou un éboulement de roches fait un accident.

Section II - La détermination de l'illicéité en droit allèmand.

27 - Critères servant à déterminer l'illicéité d'un comportement. - En droit allemand, pour déterminer l'illicéité d'un compor. tement, des critères de diverse nature sont utilisés. On considère, en principe, comme illicites les comportements (150) :

i) Portant atteinte aux droits absolus et aux biens personnels visés par le $\S 823$ al. 1 du BGB, ou,

(148) Cf. supra No' 16.

(149) Cf. Oftinger, Schweizerisches Haftpflichtrecht, t. I, p. 116; Cf. aussi Limpens (dans Mélanges Jean Dabin, pp. 729-732) qui essaie de démontrer l'inutilité en droits français et belge' d'un recours de la notion d'allicéité dans les 'cas de responsabilité présumée, c'est - à - dire les cas de responsabilité objective.

(150) Cf. Larenz, t. I. pp. $219-222$; t. II. pp. 379 et 399 et sv. 
2) Impliquant la transgression d'une norme protectrice de ia loi, ou,

3) Violant le devoir général de diligence, ou,

4) Contraires aux bonnes moeurs et commis dans l'intention de nuire à autrui.

Le premier de ces critères prend en considération plutôt ic résultat de l'acte dans la sphère juridique de la victime, dans le domaine soumis à la maîtrise de celle-ci. Par contre, les autres critères visent directement la conduite de l'agent, la mıánière dont il a agi; c'est la non-conformité de cette conduite à une norme de l'ordre juridique qui permet de la qualifier d'illicite. On se place donc au point de vue de l'auteur du résultat dommageable lorsqu'on se sert de ces derniers critères; on recherche si l'agresseur est sorti du cadre d'activité qui lui est réservé. Nous retrouverons cette dualité de nature des critères utilisés pour apprécier l'illicéité éga. lement dans les droits suisse et français. En réalité, l'illicéité s'apprecie toujours d'après une règle de conduite; mais parfois cette conduite est définie par son résultat, lorsque la norme de conduite est exprimée par la reconnaissance des droits subjectifs absolus; en effet, le côté négatif de ces droits se présente comm: un devoir universel, devoir de ne pas leur porter atteinte. Dans cette perspective, la lésion de droits subjectifs apparaît comme un effet reflexe de la violation d'une norme de comportement (151).

D'autre part, les deux premiers critères qu'on vient de citer plus haut, renvoient, en principe, au droit écrit; tandis que les deux derniers comportent un renvoi au droit non écrit. D'ailleurs, parmi les droits absolus, le droit général de la personnalité est un droit dont le contenu et les limites sont déduites du droit non écrit.

Exception faite de la violation du devoir général de diligence qui est un critère apporté par la jurisprudence, les autres critères sont prévus par la loi. Mais aussi en utilisant le critère d'atteinte aux droits absolus, la jurisprudence use de son pouvoir créateur

(151) Cf. E. Kânzig. Die Widerrechtlichkeit nach Art. 41 Abs. 1. des schweizerischen Obligationenrechts, thèse Berne 1939, p. 52; Oftinger, Schweiz. Haftpflichtrecht, t. I, $\$ 4$, note 22; J, Darbellay, Théorie générale de l'illicéité, Fribourg, 1955, p. 61. 
en reconnaissant certains droits, teḷ que le droit général de la personnalité ou le droit à l'exploitation d'une entreprise organisée, qui n'étaient pas envisagés par le législateur.

Lorsque le juge recourt au droit non écrit pour déterminer l'illicéité d'un acte, il emploie d'autres critères élaborés par la doctrine et admis également par la jurisprudence. On peut citer comme exempies (152), la conformité à la conduite sociale correcte (Soziadäquanz), l'adéquation des moyens employés au but poursuivi (153), la proportionnalité du préjudice causé et le but recherché, le caractère normal ou anormal de l'acte. Le juge tiendra compte aussi de l'échelle de valeurs exprimée par l'ordre juridique, dans les diverses normes que celui-ci présente pour résoudre d'autres questions que le cas incriminé. Toutefois, ces critères (154) ne servent qu'à faciliter le jugement de valeur que le juge doit prononcer en pesant les intérêts contradictoires de la victime et de l'auteur de l'atteinte; mais ils ne peuvent pas se substituer à ce jugement de valeur même (155).

28 - Atteintes aux droits absolus. - D'après l'opinion do. minante en droit allemand, un comportement qui a pour effet la violation d'un droit absolu ou de l'un des biens personnels énumérés expressément par le $\S 823$ al. 1 du BGB, doit être con. sidéré comme illicite, à moins qu'il n'existe un fait justificatif en faveur de l'agent (156). Le $\S 823$ al. 1 du BGB sur lequel $\approx e$ fonde cette opinion siatue comme suit: «Celui qui, intentionnellement ou par néglizerce, porte atteinte d'une manière illicite à ia vie, au corps, à la santé, à la liberté, à la propriété ou

(152) Cf. H. Hubmann. Grundsaetze der Interessenabwaegung, Archiv für die civilistische Praxis, 155 (1956), pp. 85 et sv.; J.M. Grossen, La protection de la personnalité en droit privé, ZSR, N.F. 79 (1960), p. 30 a, no. 40.

(153) Si l'acte en question ne constitue pas un moyen juste pour une juste fin (rechtes Mittel zu rechtem Zwecke) il ser'a qualifié d'illicite.

(154) On rencontre aussi ces critères dans l'appréciation de l'abus des droits. D'ailleurs. cette dernière notion joue un rôle important dans la détermination de l'illicéité et elle comporte également un renvoi au droit non écrit.

(155) Cf. P. Jäggi, Fragen des privatrechtlichen Schutzes der Persönlichkeit, ZSR N. F. 79 (1960), pp. 213a-214a.

(156) Cf. Larenz, t. II, p. 399. 
à un autre droit ( ein sonstiges Recht) d'une autre personne, est. tenu envers celle-ci de réparer le dommage qui en résulte.» Or, la majorité des auteurs allemands sont d'avis que le législateur qui avait l'intention de définir les éléments matériels (la matérialité) de l'illicéité, voyait en principe, déjà dans l'atteinte aux droits et aux biens personneìs énumérés la nature d'un critère permettant d'établir l'illicéité (157); il n'avait ajouté l'expression «d'une manière illicite» (widerrechtlich) que pour faire allusion aux faits justificatifs.

On constate que dans le $\S 823$ al. 1 sont mentionnés. d'une part, le droit de propriété et d'autres droits qui ne sont pas définis, d'autre part, certains biens personnels n'ayant pas le qualificatif de droit. Cette distinction, provenant de la subtilité parfois trop poussée de la pensée allemande, ne présente actuellement aucune valeur pratique.

Avant d'examiner (158) les atteintes portées aux quatre bjens personnels mentionnés expressément dans le $\S 823$ al. 1, arrêtons - nous sur les lésions concernant le droit de propriété el les autres droits.

La lésion du droit de propriété peut consister aussi bien dans la destruction ou l'endommagement d'une chose appartenant à * autrui que dans les troubles entraînant la dépréciation de la valeur de cette chose sans préjudice à sa substance (159), ainsi que dans la simple utilisation de la chose sans y être autorisé ou dans la soustraction de celle-ci à son propriétaire soit matérielle. ment (actes d'usurpation ou de trouble de la possession), soit par un acte juridique (aliénation par un acte de disposition non autorisé, mais valable).

La question de savoir ce qu'il faut entendre par les autres droits ( sonstige Rechte) est controversée. D'après la doctrine dominante, l'expression d'autres droits ne signifie que les droits subjectifs absolus qui présentent une analogie avec le droit de

(157) Pour des points de vue différents v. infra no. 43.

(158) Cf. infra no. 29

(159) Cf. Esser, Schuldrecht, $\S 202$, 1. b. aa; Larenz, t. II, pp. $383-334$;

H. Stoll; Unrechtstypen bei Verletzung absoluter Rechte, Ac P, 162, pp. $218-227$. 
propriété par leur caractère exclusif $(160)$. En d'autres termes, ce sont des droits qui, à l'instar du droit de propriété, permettent à leurs titulaires d'exiger de tous l'abstention de toute atteinte à l'objet de leur droit. Suivant la classification récente des drnits subjectifs (161) du point de vue de leur contenu, de la nature du pouvoir juridique qu'ils comportent, on distingue les droits de maitrise ( Herrschaftsrechte ou Beherrschungsrechte), les droits. do la personnalité, les droits de créance et les droits formateurs (162).

Les droits de maîtrise confèrent à leurs sujets un pouvoir de domination direct, en règle générale sur un objet (une chose ou un bien patrimonial immatériel,) et, exceptionnellement sur une personne, mais seulement en liaison avec une position juridique du droit de la famille qui est considérée en mêmę temps comme un devoir (p. ex. la puissance paternelle, surtout en ce qui concerne les rapports personnels) (163). A part le droit de propriété, qui accor-

(160) Cf. Esser, Schuldrecht, $\S 202,1$, b, bb; Larenz, t. II, pp. 384 et sv.; R. Reinhardt, Das Subjektive Recht in $\S 823$, I BGB, JZ, 1961, pp. 713 et sv. Pour les différents points de vues sur la notion des autres droits, cf. F. Fabricius, Zur Dogmatik des «sonstigen Rechts» gemaess $\S 823$ Abs. I BGB, Ac P. 160, pp. 273 et sv. Autrefois, on rencontrait des auteurs comme von Liszt (cité par Fabricius. $p$. 274), qui entendaient par les autres droits tout intérêt protégé juridiquement. Selon Fabricius (pp. 290-295), si l'intérêt attaché par le sujet d'un droit à un bien faisant l'objet de ce ơroit est reconnaisable comme nécessitant la protection juridique, d'après la réflexion faite par une personne moyemne selion les conceptions sociales et culturelles qui règnent dans la société, on doit admettre la protection de ce bien comme sun autre droit» prévu par le $\S 8.23$ al. 1. Le critère de «sozialtypische Offenkundigkeit» du bien juridique atteint, que propose Fabricius, a lut-méme besoin d'être concrétisé et n'est d'aucun secours pratique pour déterminer la notion des autres droits. Cf. Larenz, t. $\Pi$, p, 385. note 1.

(161) Cf. Larenz, p. 384; Enneccerus-Nipperdey, t. 1, \& 73, I.

(161) Cr. Larenz, p. 384; Enneccerus-Nipperdey, t. 1. para. 73, I.

(162) Des auteurs plus anciens comme von Tuhr (Der allgemeine Teil des deutschen bürgerlichen Rechts, t. I, Leipzig 1910, § 6, classaient les droits de la personnalité et les droits de créance parmi les droits de maîtrise. Même actuellement la doctrine dominante considère les droits de la personnalité comme des droits de mâ̂trise. Cf. H. Coingó (Zur Geschichte des Begriffs «subjektives Recht», Frankfurt-Beri.. 1959 , p. 22), à qui la définition d'un droit de créance comme un droit de maitrise, semble artificielle.

(163) Cf. Larenz, t. II, p. 384.

Forma : 22 
de la maîtrise la plus étendue sur une chose, les droits réels limités (servitudes, droits de gage, charges foncières) et les droits sur les biens patrimoniaux immatériels (164) (tels que le droit d'auteu:, les droits sur le brevets d'invention, les marques de fabrique, la raison commerciale les dessins et modèles industriels) appartiennent à la catégorie des droits de maîtrise sur un objet. Lorsqu'on est en présence de ces droits, dans les limites de ia maîtrise reconnue pa.r ceux - ci, toute intervention d'une autre personne est exclue et $r$. prouvée en principe par l'ordre juridique, à moins qu'elle ne soit ex ceptionnellement justifiée.

Les droits expectatifs de la propriété, tels que le droit de l'acheteur avec réserve de propriété (165), les droits d'appropriation exclusive, comme le droit de chasse ou de pêche (166) (bien que ces derniers dérivent d'un rapport d'obiigation quí est le bail à ferme de la chasse ou de la pêche), sont aussi considérés comme des droits absolus qui rentrent dans la catégorie des «autres droits; du $\S 823$ al. 1.

La possession est également classée par la doctrine dominante (167) et la jurisprudence (168), parmi les «autres droits». Pourtant, on remarque que ce n'est pas un droit, mais un fait social auquel le droit attache certains effets juridiques. Selon les auteurs qui font catte remarque (169), ce n'est pas la possession elle même, mais le droit à la possession que l'on peut qualifier de droit de maîtrise; car, ce droit, même s'il découle d'un rapport d'obligation, tel que le bail ou le prêt, peut être opposé aux tiers, bien qu'il doive céder devant un meilleur droit à la possession (comme la propriété ou l'usufruit); il a donc une fonction d'exclusion comme les autres droits de maîtrise.

La doctrine dominante fait rentrer le droit général et les droits particuliers de la personnalité dans la catégorie des droits

(164) En droit français, pour désigner ces droits on emploie le terme de «droits intellectuels». Cf. Marty - Raynaud, Droit civil, t, I. Paris 1961, No. 145, p. 250 .

(165) Cf. Larenz, t. II, p. 384, note 2; RGZ, 170, 6; Esser, Schuldrecht, p. 845 .

(166) Cf. Esser, Schuldrecht, p. 845; Fabricius, pp. $299-300$.

(167) Cf. Enneccerus - Nipperdey, t. I, $\S 80$, I, 1; Fabricius p. 298.

(168) RGZ 91, 65.

(169) Cf. Larenz, t. II, p. 386; Fabricius p. 303. 
de maîtrise, mais dans les études récentes (170) il est souligné que les sujets des droits de la personnalité ne peuvent pas disposer de leurs biens personnels comme d'une chose ou d'un bien patrimonial immatériel. En d'autres termes, il n'est pas passible de parler d'une maîtrise exercée par les titulaires de ces droits sur leurs biens personnels par exemple sur leur honneur. La seule analogie qui existe entre les droits de la personnalité et les droits de maîtrise réside dans le fait que leurs sujets peuvent exiger de tout le monde le respect de ces droits.

Le contenu et l'étendue des droits de la personnalité, surtout du droit général de la personnalité ne sont pas bien précisés. Par conséquent, on ne peut pas déclarer sans réserve que toute atteinte à l'objet de ces droits est illicite. D'autre part, on émet encore des doutes sur la nécessité de la reconnaissance de tels droits et de l'introduction de ceux-ci sous la rubrique des «autres droits» pour assurer la protection civile de la personnalité. C'est pourquoi nous allons les examiner séparément (171), ainsi que le droit à l'installation et à l'exploitation d'une entreprise (172) et le droit au travail (173) dont la nature personnelle ou patrimoniale est contestée et qui n'ont pas un contenu précis.

Par ailleurs, la doctrine et la jurisprudence ont tendance à faire bénéficier certaines situations juridiques relevant du droit de la famille, de la protection accordée aux «autres droits» par le $\S 823$ al. 1. Nous avons déjà signalé que la puissance paternelic était considérée comme un droit de maîtrise figurant parmi ces «autres droits»; cependant, il existe des divengences de vue sur la manière dont on peut porter atteinte au droit de la puissance paternelle. Mais c'est surtout la protection de l'union conjugale contre les troubles des tiers qui donne lieu à de vives discussions en droit allemand. Certains auteurs sont enclins à reconnaître un droit a!ı maintien non troublé de l'union conjugale qui mériterait d'être protégé par le $\S 823$ aì. 1. Nous réserverons donc une place spécia.e.

(170) Cf. Larenz, t. II, p. 384; H. Hubmann. Das Persönlichkeitsrecht, Münster - Köln, 1953, pp. 105 et sv.

(171) Cf. infra nos. $30-38$.

(172) Cf. infra no. 39.

(173) Cf. infra no. 40 . 
à l'étude des troubles portés aux situations juridiques en question relevant du droit de la famille (174).

Les droits formateurs sont des droits qui accordent à leurs titulaires le pouvoir de créer, de modifier ou d'éteindre un rapport juridique au moyen d'un acte unilatéral (175). Par la nature même de ces droits, les tiers ne peuvent pas intervenir dans leur exercice d'une manière efficace. C'est la raison pour laquelle il n'existe aucun besoin de ranger ces droits parmi les «autres droits» du $\S 823$ al. 1 (176).

Selon l'opinion dominante, la nature relative des droits $d$ créance exclut aussi la possibilité pour les tiers de violer ces droits. Mais on constate dans la doctrine différents essais entrepris, afin d'étendre la protection du $\S 823$ al. 1 aux droits de créance. Cas essais méritent également un examen particulier (177).

29 - Atteintes aux biens personnels énumérés clans le $\S 823$ al. 1 du BGB. - Comme nous l'avons remarqué plus haut, quatre biens personnels sont mentionnés expressément dans ie $\S 823$ al. 1 et protégés d'une manière absolue, contre toute sort, d'atteintes. Ce sont la vie, le corps, la santé et la liberté. Toute atteinte portée à ces biens est considérée par la doctrine dominante comme illicite, à moins qu'il n'existe un fait justificatif (178).

Deux questions viennent à l'esprit en ce qui concerne la manière dont le législateur a réglementé la protection des biens précités :

La première est de savoir pourquoi on a choisi seulement ces quatre biens personnels parmi tant d'autres, pour leur accorder

(174) Cf. infra nos. s. $41-42$

(175) Pour la notion du droit formateur cf. Enneccerus - Nipperdey, t, I, s 73, I, 3; von Tuhr, Allg. Teil, t. I, pp. 161 et sv.; L'Huillier, La notion du droit formateur en drolt sutsse, thise Geneve 1947.

(176) Cf. Larenz, t. II p. 386.

(177) Cr. Infra no. 3 .

(178) Co principe est exprimé dans le Projet de Lol sur la réglementation nouvele de la protection civile de la personnalite et de l'honneur, d'une fason plus claire que dans le BGB. Selon le $\S 13$ du Projet, les atteintes portées à la vie, au corps, à la santé ou à la liberte d'autrui, sans y être autorisé, sont considérées comme une violation fllicite de la pereonnalite. 
une protection absolue. Certains auteurs expliquent (179) le choix du législateur par le souci de protéger la personne dans son existence extérieure immédiate (in ihren unmittelbaren äusseren $D a$ sein). Selon d'autres, la poursuite pénale n'assurant pas la réparation des dommages qui résultent de la lésion de ces biens pour la victime ou pour ses proches, le législateur a voulu leur accorder une protection civile absolue (180) et a réglementé d'une façon dé taillée dans les paragraphes 843 à 847 le genre et l'étendue des dommages à réparer en pareils cas. Mais cette considération serait aussi valable pour d'autres biens personnels protégés contre certaines atteintes par des dispositions spéciales du Code pénal tel que par exemple l'honneur (181). Le traitement particulier dont jouit les quatre biens personnels mentionnés expressément par la loi provient, à notre avis, plutôt du fait qu'ils ont un contenu plus précis que les autres biens personnels protégés seulement contre des atteintes déterminées. D'ailleurs le législateur allemand voulait limiter la réparation du dommage moral ( $\S 847$ ) aux cas où l'un de ces quatre biens personnels était lésé et à certains autres cas bien définis.

La seconde question qui se pose à propos de la protection absolue dont bénéficient les biens personnels prévus au $\S 823$ al. 1 est la suivante: Pourquoi le législateur allemand n'a pas érigé ces biens en droits subjectifs, puisqu'il a reconnu à leurs possesseurs un pouvoir d'exclusion à l'égard de tout le monde. L'explication en est qu'au moment de l'élaboration du BGB, les théories sur les droits de la personnalité n'étaient pas bien développées et il y avait des controverses sur l'opportunité de l'admission de tels

(179) CF. Larenz, t. II, p. 387 .

(180) Cr. Esser, Schuldrecht, p. 843; Retnhardt, JZ, 1961, p. 713. Tout dabord on a voulu protéger la liberté aussi contre les attelntes par négligence, ce qui n'étalt pas envisagé par le Code pénal; ensuite, pour que l'énumération soit complete on y a ajouté les trois autres biens personnels, malgré qu'il était possible de leur accorder protection par le détour du $\S 823$ al. 2 appliqué en relation avec les dispositions du Code Pénal (Procès - verbaux de la deuxième Commission, pp. 573 et sv.)

(181) La deuxième Commission travaillant sur le Projet de BGB a refusé de mentionner l'honneur parmi les biens cités au $\S 823$ al. 1 (Procès - verbaux II, pp. 573 et sv.) 
droits (182). II est vrai que la vie, la santé et le corps ne sont pas des droits, mais des biens qui existent indépendamment d'un ordre juridique; toutefois, si l'on prend en considération la protection civile accordée à ces biens contre toutes sortes d'atteintes et la re connaissance par la jurisprudence d'un droit général et de droit particuliers de la personnalité, il faut admettre aujourd'hui aus l'existence de droits subjectifs au respect de la vie, de l'intégrité corporelle, de la santé et de la liberté (183).

Le contenu des quatre biens personnels visés au $\$ 823$ al. 1 a des limites assez précises en comparaison avec d'autres biens personnels. En cas d'atteinte à la vie, la mort peut être causée directement ou être la suite d'une atteinte à l'intégrité corporelle, ov: à la santé (184). Dans cette dernière éventualité, il faut distinguer l'action en dommages - intérêts de la victime pour les lésions corporelles qu'elle a subies et l'action des personnes qui ont été privées du soutien de la victime décédée par la suite.

Les atteintes au corps et les atteintes à la santé sont des notions qui se complètent. Les premières consistent en les interventions extérieures à l'intégrité corporelle, les secondes en troubles des fonctions internes de nature physiologique ou psychique (185). Ainsi, des affections nerveuses causées par une peur excessive ou par les insultes continues seront considérées comme une atteintc

(182) Selon l'Exposé des Matifs de BGB (t. II, p. 728), on pouvait douter de la possibilité de qualifier ces biens comme des droits, mais ils nécessitaient aussi une protection.

(183) Larenz, t. II, p. 388. Selon Esser (Schuldrecht, § 232, 1. p. 843) is sens de la protection accorciée par le $\S 823$ al. 1 aux droits subjeutif et aux biens personnels qu'il vise est différent dans les deux cas. c'est une protection suppléméntaire pour les droits subjectifs qui confèrent déjà à leurs titulaires d'autres actions, en permettant d'exiutu les interventions des tiers, telles que l'action en revendication t l'action négatoire; tandis que pour les biens personnels en question la protection civile n'est établie pour la première fois que par le ; 823 al. 1 sous la forme de l'action en dommages-intérêts. Cf. R. Nerson (Les droits extrapatrimoniaux, Paris 1939, pp. 379-380) au s'ijet de l'évolution d'un bien juridique qui tend à devenir un droit subjectif. Nerson (p. 501) n'admet pas, en droit français, l'existence d'un droit à la vie, à l'intégrité eorporelle ou à l'honneur.

(184) Cf. Esser, Schuldrecht, p 843.

(185) Cf. Esser, Schuldrecht, p. 843; Larenz. t. IT, p. 387. 
à la santé. Dans ces derniers cas l'existence du lien de causalité est souvent problématique. Les interventions médicaies constituent des att:intes à l'intégrité corpcrelle qui ne seront justifiées que par le consentement réel ou présumé du patient ou de son représentant légal. Une abondante jurisprudence s'est formée sur la question du consentement du patient et sur le devoir du médecin de renseigner celui-ci au sujet des risques de son intervention (186). En matière d'atteintes à la santé, un arrêt intéressant du Bundesgerichtshof (187) donnant lieu à de vives discussions, a accordé une action en dommages - intérêts à un nouveau-né atteint d'une syphilis congénitale acquise de la mère qui avait été contaminée par le défendeur avant la conception de l'enfant; certains y voient (188) un précédent pour les risques atomiques de mutation qui pourraient éventuellement faire l'objet d'actions de la part des futures générations.

On entend seulement par atteintes à la liberté celles qui entravent la liberté de mouvement corporel (Körperliche Bewegungsfreiheit) (189) et non les atteintes à la liberté intellectuelle ou économique. La grève, le lock - out et le boycott ne constituent donc pas en principe une atteinte à la liberté dans le sens du $\S 823$ al. 1. Peu importe que l'atteinte à la liberté corporelle provienne d'une pression physique (emprisonnement, attachement) ou psyshique (menaces) ou d'une autre cause indirecte (189a).

(186) V. pour cette jurisprudence: Esser, Schuldrecht, pp. 843-844.

(187)' BGHZ, 8, 243.

(188) Cf. Esser, Responsabilité et garantie dans la nouvelle doctrine allemande des actes illicites, Revue Internationale de Droit Comparé, 84 (1961). p. 485 .

(189) RGZ, 102, 134.

(189a) Cf. pour les atteintes indirectes à la liberté: H. Stoll, Unrechtstypes bei Verletzung absoluter Rechte, AcP 1962, pp. 214-215. P'ar exemple, un médecin après un examen superficiel donne un rapport qui cause l'internement d'un personne saine dans un asile d'aliénés (RG dan: Warneyers Rechtssprechung 1910, no. 279, p. 288; -ou par un témoignage dont l'inexactitude est. due à la négligence une personne innocente est condamnée;- ou des mineurs sont bloqués sous l:: terre par un éboulement provenant du fait que les étançons n'éta:-srt pas posés selon les règles de l'art. 
30 - Atteintes aux autres droits particuliers et au droit gi. néial de la personnalité. - Outre les quatre biens personnels expressement mentionnés dans le $\S 823$ al. 1, la doctrine et 13 juris. prudence allemandes avaient reconinu encore quelques droits particuliers de la personnalité avant l'entrée en vigueur de la nouvelle Constitution fédérale (190). Ceux-ci étaient définis par lo BGB ou par d'autres lois, ou bien leur contenu et ćtendue étaient déterminables dans une certaine mesure. On les a fait rentrer dans la catégorie des «autres droits» du $\S 823$ al. 1. Parmi les droits particuliers de la personnalité ainsi protégés se trouvaient le droit au nom réglementé par le $\S 12$ du BGB (191), certains dioitミ đéduits de la législation spéciale relative aux droits intellactuels, telo que le droit moral de l'auteur d'une cuvre littéraire ou artistique, sultout le droit prohiber toute altération de l'œuvre (192), le droit de l'inventeur à la citation de son nom dans le brevet (193), le droit à sa propre image dont les limites étaient fixées par les paragraphes 22 à 24 de la Loi concernant le droit de l'auteur sur lâs ceuvres artistiques st photographiques, L'aämission d'nin droit $n$ l'honneur défendue par quelques auteurs (194) n'a pas €u la faveur de la doctrine et surtout de la jurisprudence. L'honneur n'était protégé que par le $\S 823$ al. 2 du BGB, appliqué en re. lation avec les dispositions protectrices du Code Penal ( $\$ \S 185$ et sv.) En outre, le BGB réglementait dans ses paragraphes 824 et 825 les atteintes au crédit et les atteintes à l'honneur sexuel d'une femme. A côte des droits particuliers de la personnalité b:sés plus ou moins directement sur un texte légal, il y avait le droit à l'exploitation d'une entreprise, qui était une pure création de la jurisprudonce (195) et considéré pai certains comme une expres-

(190) Cf. Larenz, t. II, p. 388; W. Siebert, Zur allgemeinen Problematik dus Persönlichkeitsrechts, NJW. 1959, p. 370.

(191) RGZ, 69, 4103;91, 350; 119, 47.

(192) RGZ, 79, 397; 102, 134.

(193) Cf. Siebert, NJW. 1958, p. 1370.

(194) O. v. Gierke. Deutsches Privatrecht, t. III, p. 888; Müllereisert, Die Ehre im deutschen Privatrecht, Berlin, 1931, p. 333.

(195) RGZ. 60, 6; $61366 ; 102,225 ; 116,151 ; 126,96$.

(196) Cf. infra no. 39. 
sion de la personnalité dans la vie économique (196). Il est à remarquer enfin, que le Reichsgericht avait refusé constamment de reconnaître un droit général de la personnalité, en invoquant l'absence des dispositions légales sur lesquelles on pouvait le forder (197).

La protection civile de la personnalité, ainsi limitée à quelques droits ou biens particuliers et à des normes spéciales protégeant certains biens personnels contre des atteintes déterminées, se révélait à plusieurs égards comme insuffisante (198). Il est vrai que le Reichsgericht essayait de compléter ce système en recourant parfois au $\S 826$ du BGB et en déclarant contraire aux bonnes mœurs certains actes intentionnels qui nuisent aux intérêts personnels. Il a assuré ainsi la protection de la liberté morale et de la liberté économique de décision (199). Ii a considéré comme cortraire aux bonnes mours le fait de propager consciemment d'une façon légère des affirmations portant atteinte à l'honneur sans connaître leur inexactitude et même dans certaines circonstances, la diffusion des affirmations exactes de ce genre (200). D'autre part, les tribunaux avaient étendu, par analogie, la protection de l'image à la représentation d'un personnage sur la scène ou dans un film sous les traits d'un acteur plis ou moins ressemblant (201); mais cette extension ne visait pas la représentation du caractère (l'image morale) d'une personne dans une pièce de théâtre, un roman ou un reportage. D'ailleurs, selon la Loi concernant le droit d'auteur sur les ouvres d'arts et de photographie. seulement la diffusion et l'exploitation au public de l'image d'autrui étaient interdites, mais non la prise d'une photographie sans consentement. Il existait encore d'autres lacunes dans le

(197) RGZ. 79, 398; 82, 334; 94, 1; 102, 134; 107, 281; 113, 414;123, 320. Dans la doctrine, seuls, Glerke (Grundzüge des deutschen Privatrechts, t. 1, 1914, p. 218) et Kohler (Bürgexliches Recht, t. I, 1914. p. 587) admettalent l'existence d'un droit général de la personnalité.

(198) Cr. Larenz, t. II, pp. 3888 - 389.

(199) Cf. RGZ, 104, 327; 109, 37; 140, 392; Siebert NJW, 1958, p. 370.

(200) Ce. RGR, T2, 175 (l'affirmation inexacte d'un médecin que le demandeur est attelnt d'une maladie mentale et a besoin d'être interné); RGZ. 115, 416 (renseignement exact, mais sous une forme sans ménagement sur une condamnation antérieure); $R G Z, 162,7$ (compte rendu inexacl sur les capacités d'un artiste débutant); Esser, Schuldrecht, p. 846.

(201) Dans co sens KG, JW, 2*, 363. 
système de la protection de la personnalité: L'auteur d'une lettre missive ou d'un journal intime n'était pas protégé contre la pub. lication non autorisée de ceux-ci, lorsqu'ils ne présentaient pas une valeur littéraire et ne bénéficiaient pas, par conséquent, des dispositions de la Loi concernant le droit d'auteur. Pour faire cesser la diffusion des faits relatifs à la vie privée, l'intéressé ne pouva: intenter une action en interdiction de trouble, si les faits en question n'étaient pas inexacts ou déshonorants. Enfin, il n'y avait aucun moyen de défense relevant du droit civil contro l'enregistrement clandestin des paroles d'autrui et contre leui diffusion ainsi que contre l'emploi des tables d'écoute et des appareils servant à suivre en secret les conversations des autres.

Après la deuxième guerre mondiale, l'insuffisance de la protection accordée à ia personnalité jusqu'alors par le droit civil s'est fait sentir d'une façon plus prononcée. Avant tout. deux raisons rendaient urgente l'amélioration de cette protection (202): D'abord, les articles 1 et 2 de la nouvelle Constitution soulignaient l'importance attribuée à la dignité humaine et à la liberté personnelle, en tenant compte de la sombre expérience faite sous une dictature qui n'avait aucun respect pour ces valeurs. Ensuite, le développement des moyens techniques permettant d'intervenir dans la sphère personnelle d'autrui, l'augmentation des possibilités de la diffusion en masse des images ainsi que des nouvelles inexactes ou des affirmations déshonorantes par la presse, le cinéma et la radio, exposaient la personnalité à des dangers particulièrement graves. C'est pourquoi le 42 ème Congrès des juristes allemands, réuni en 1957, après avoir constaté ces dangers dans une résolution qu'il a prise, a salué les efforts de la jurisprudence et de la doctrine en vue d'assurer une protection renforcée de la personnalité par les moyens du droit civil (203). Il a vu la base légale d'une telle protection dans les articles 1 et 2 de la Constitution et dans l'art. 8 de la Convention du Conseil de l'Europe pour la sauvegarde des droits de l'homme, qui lie aussi la Répub-

(202) Cr. Larenz, t. II, p. 389; iSiebert, NJW, 1958, p. 1369.

(2013) Il est intéressant de noter que le Congrès de la Société suisse des juristes, tenu en 1960, a pris également une résolution appuyant fermement la tendance d'une protection renforcée de la personnalité humaine par les moyens du droit civil. V. ZSR, NF. 79 (1960), p. 661 a. 
lique fédérale allemande. La résolution contenait en outre le voelı d'une réglementation légale étendue pour rendre la population consciente du devoir juridique du respect de la personnalité. Enfin, l'adoption des dispositions légales, permettant l'octroi d'une indemnité en argent également pour le dommage moral de la victime, y était recommandée.

Conformément à cette résolution, le Ministère de la Justice fédéral a soumis en 1959 à l'Assemblée fédérale un Projet de Loi sur la nouvelle réglementation de la protection civile de la personnalité et de l'honneur (204). Ce Projet substitue, d'une part, all $\S 12 \mathrm{du}$ BGB concernant le droit au nom, les paragraphes 12 à 20, qui accordent à la victime d'une atteinte à la personnalité une action préventive et une action en cessation da trouble, et qui définissent les atteintes illicites aux divers biens personnels; d'autre part, il modifie l'al. $1 \mathrm{du} \S 823$. Selon le $\S 13$ apporté par le Projet, la vie, le corps, la santé et la: liberté sont protégés d'une façon absolue contre toutes sortes d'atteintes comme c'est le cas actuellement; tandis que dans les paragraphes suivants l'honneur, l'image, l'intimité, les lettres missives, les mémoires personnels, les paroles secrètes ne bénéficient que d'une protection contre des atteintes déterminées. La nouvelle version du $\S 823$ al. 1 est la suivante: «Celui qui à dessein ou par négligence, porte atteinte d'une manière illicite à la personnalité ou à la propriété ou à un autre droit d'autrui, est tenu envers celui-ci de réparer le dommage qui en résulte». Comme on le voit, dans ce texte, les quatne biens personnels sont remplacés par la personnalité en général. Le projet modifie aussi le $\S 847$ du BGB concernant la réparation du dommage moral, de sorte que cette réparation n'est plus limitée aux cas d'atteintes aux quatre biens personnels, mais qu'elle peut être réclamée dans d'autres cas de violation de la personnalité. Le Projet n'a pas encore pris force de loi. Mais l'essentiel de sor contenu a été déjà introduit dans le droit en vigueur par le Bundesgerichtshof (le Tribunal fédéral allemand) en usant de son pouvoir de création jurisprudentielle (richterliche Rechtsfortbildung) Toutefois, selon les auteurs allemands (205), la nécessite d'une réglementation légale garde encore sa justification; car, il est

(204) V. Bundestags Drucksache 1237/1959.

(205) CP. Larenz, t. II. pp. $389-390$. 
difficilement concevable que le BGB, le Code de base du droit civil, réglemente une matière aussi importante que la protection de la personnalité d'une façon insuffisante qui ne correspond pas à l'état actuel du droit. De plus, on fait remarquer que la création de nouvelles règles par la voie jurisprudentielle comporte un facteur d'insécurité; cette insécurité ne peut être surmontée qu'après longtemps, lorsqu'un grand nombre de décisions sont intervenues. Cependant, jusqu'à l'adoption de la nouvelle réglementation légale, c'est la jurispmudence du Bundesgerichtshof qui doit être prise en considération.

Or, le BGH, dans sa jurisprudence constante, reconnaît l'exi:3tence d'un droit général de la personnalité (allgemeines Persönlichkeitsrecht) comme partie intégrante de l'ordre juridique allemand (206). Ce droit assure à la personnalité une protection non seulement dans certains domaines ou dans certaines formes sous lesquelles elle se manifeste, mais dans toute son étendue. Selon le $\mathbf{B G H}$, le droit général de la personnalité appartient à la catégorie des «autres droits» méntionnés au $\S 823$ al. 1. Les droits particuliers de la personnalité reconnus jusqu'alors ne sont que certaines formes d'apparition de ce droit étendu. Quand la protection accordée par un droit particulier de la personnalité ne paraît pas suffisante au BGH, celui-ci a recours au droit général. D'autre pait, le BGH déduit du droit général de la personnalité de nouveaux droits particuliers; on peut citer comme exemple le droit à l'honneur (Recht auf die Ehre) (206a).

Le droit général de la personnalité est fondé par le BGH, en principe, sur la Constitution fédérale. Mais il n'est pas toujours très clair de voir comment le Tribunal procède, en se fondant sur la Constitution. Selon une théorie (207) le BGH applique les

(206) Cf. BGHZ, 13,$338 ; 15,257 ; 24,76 ; 24,208 ; 26,349 ; 27,285 ; 30,7 ; 31$, $308 ; 33,22 ; 155,363 ; 39,124$.

(206a) Cf. BGHZ, 39, 128-129; Enneccerus-Nipperdey, t. I, 14 e éd. p. 365; Larenz, t. II, p. 388 ( 7 e éd. p. 414). Selon E. Helle (Der Schutz de: persönlichen Ehre und des wirtschaftichen Rufes im Privatrecht, Tübingen 1957, pp. 5-6), le contenu d'un droit à l'honneur ne peut pas être déterminé avec précision; c'est pourquoi, l'honneur ne doit être protégé, comme un bien juridique qui n'est pas érigé en drcit subjectif, que contre des atteintes déterminees.

(207) Cf. pour cette théorie et pour sa critique Larenz, t. II, p. 390. 
articles 1 et 2 de la Constitution directement aux relations entre les particuliers et considère le droit général de la personnalití comme un aspect du droit fondamental du libre développement de la personnalité qui se présente dans le domaine du droit privé. En d'autres termes, le droit général de la personnalité ne serait en réalité qu'un effet reflexe, un effet entre les particuliers (Drittwirkung) $\mathrm{du}$ droit fondamental qui lui correspond. D'après une autre opinion (208), le BGH, en s'inspirant de l'appréciation des valeurs (Wertung) exprimée aux articles 1 et 2 de la Constitution qui est valable aussi pour les autres domaines du droit, comble une lacune du $\mathrm{Co}^{-}$ de civil par la voie de la création du droit par le juge (209) et reconnaît ainsi un nouveau droit privé subjectif, précisément le droit général de la personnalité. Le contenu et la fonction die ce droit sont différents de ceux du droit fondamental au libre développement de la personnalité; cela n'empêche pas que les deux droits reposent sur le même critère de valeur.

La reconnaissance d'un droit général de la personnalité comme «un autre droit» protégé par le $\S 823$ al. 1, a suscité de vives critiques dans la doctrine (210). Ces critiques sont dues surtout au manque de précision du contenu et des limites du droit en question. En effet, le droit général de la personnalité, contrairement aux droits particuliers de la personnalité, vise à protéger la personnalité dans tous ses aspects et dans ses divers reflets; or, ces derniers échappent à une énumération exhaustive et à une définition complète en raison des diverses possibilités qui sont contenues dans la personnalité; cette diversité se manifeste, d'une part, dans les biens personnels à protéger, d'autre part, dans les manières de leur porter atteinte. C'est pourquoi il manque au droit général de la personnalité la précision du contenu que l'on constate dans les droits absolus et les biens personnels qui étaient

(208) Cf. Larenz. t. II, p. 390; Esser, Schuldrecht, § 202, 1, b, ee. p. 847; Siebert, NJW, 1958. pp. $1372-1373$.

(209) Ainsi, le BGH n'interprète pas, comme certains le prétendent, la Constitution fédérale, mais il crée une nouvelle règle pour combler une lacune du BGB.

(210) Cf. Esser, Sichuldrecht, p. 847; Larenz, t. II, p. 391; K. Michaelis Persönlichkeitsbegriff in seiner Eignung als Rechtsbegriff, dans Heckel, Person und Recht 1962. Contre les critiques en question cf. Hubmann, pp. 105 et sv. Siebert, NJW, 1958, p. 1371. . 
prévus à l'origine par le $\S 823$ al. 1. En édictant le premier et le second alinéas du $\S 823$, l'intention du législateur était d'établir un catalogue bien défini des comportements illicites at de n'apporter un complément à ce système que par le $\S 826$ concernant les dommages causés par les actes intentionnels, contraires aux bonnes mours. L'introduction du droit général de la personnalité qui présente la nature d'une clause générale, a détruit ce système dans ses fondements (211). Tout au plus, le système envisagé à l'origine ne peut se maintenir que pour les atteintes aux biens patrimoniaux (212).

On explique l'importance pratique du droit général de la personnalité en droit allemand, justement par sa nature de clause générale (213) qu'on lui reproche. En effet, il permet d'accorder la protection de la loi aux multiples aspects changeants de la personnalité sans la resserrer dans des cadres étroits fixés à l'avance (214). C'est le système casuiste du BGB qui a conduit la jurisprudence allemande à reconnaître un droit général pour assurer une protection efficace de la personnalité. Si le système de responsabilité délictuelle allemande contenait une norme générale comme en droits français et suisse, il n'y aurait plus, tout au moins, un besoin pratique de reconnaitre un tel droit. En effet en droit français, on «refuse à admettre l'existence de ce droit général de la personnalité dont tous les droits particuliers dériveraient, comme les rayons dérivent d'un même centre... Le droit français qui a la possibilité d'assurer la protection de tous les droits atteints (droits de la personnalité ou autres) par les dispositions de l'art. 1382 du Code civil, permet au juge et à l'interprète d'étendre sans cesse le nombre des droits protégés si de nouvelles formes de la vie sociale font apercevoir la nécessité

(211) Cf. supra no, 9 et note 40 .

(212) Larenz, t. II, p. 391.

(213) Cf. Siebert, NJW, 1958, p. 1371.

(214) Selon Hubmann (op. cit. p. 88), à côté des droits particuliers de 1 a personnalité un droit général est nécessaire pour protéger les éléments de la pensonnalité qui ne sont pas encore réglementés par la lol et qui ne sont pas encore arrivés à un stade de clarté suffisante. Par contre, certains auteurs comme Esser (ISchuldrecht, $\S 202,1$, b. ee. p. 847) se demandent si l'on ne peut pas assurer une protection efficace de la personnalité sans recourir à la fiction de considérer le droit général de la personnalité comme un autre droit du $\S 823$ al. 1. 
de protéger de nouveaux aspects de notre personnalité» (215). C'est probablement pour ces motifs que l'Avant-Projet du Codz Civil, préparé par la Commission de réforme, dans le chapitre destiné aux «droits de la personnalité», ne donne pas place à un droit général $(215 \mathrm{a})$; mais après avoir réglementé différents droits particuliers, il dispose dans son article 165 que «toute atteinte illicite à la personnalité donne à celui qui la subit le droit de demander qu'il y soit mis fin, sans préjudice de la responsabilité qui peut en résulter pour son auteur». En droit suisse, si la doctrine dominante admet l'existence d'un droit général de la personnalité (216), c'est plutôt pour des considérations théoriques. Elle recourt à celui-ci comme à une notion supérieure (Oberbegriff) pour en déduire les différents droits particuliers de la personnalité; en d'autres termes, elle utilise cette notion devant la difficulté de classifier les droits particuliers qui s'entremèlent parfois et qui ne sont pas séparés par des cloisons étanches (217). Toutefois, du point de vue pratique, l'admission d'un droit général de la personnalité n'est pas indispensable en droit suisse; car, d'après le système suisse «le nombre des intérêts personnels juridiquement protégés n'est pas clos» et «le juge ne se heurte pas à un catalogue légal exhaustif ${ }(218)$.

(215) Amiaud, Les droits de la personnalité, Travaux de l'Association Henri Capitant, t. III, 1947, p. 298. Dans le même sens Nerson: Les droits extra patrimoniaux, Paris 1939, pp. 350 et sv; L. Martin, Le secret de la vie privée, Rev. Tr. de droit civil, 1959. p. 242. Cf. aussi A. Weill, dans Travaux de l'Association Henri Capitant, t. II, pp. 321-322.

(215a) Pourtant Lyon-Caen avait présenté à la Commission de Réforme, l'idée d'un droit reposant sur le respect de la valeur humaine, Travaux $1950-1951$, p. 58.

(216) Cf. J. M. Grossen, La protection de la personnalité en droit privé, ZSR. N. F. 79 (1960), no. 4, pp. 5a-6a; A. Egger. Kommentar zum sichweiz. ZGB, t. I, Das Personenrecht. 2e éd. Zurich 1930, art 28. no. 47; K. Specker, Die Persönlichkeitsrechte mit besonderer Berücksichtigung des Rechts auf die Ehre im schweiz. Privatrecht, thèse de Zurich 1911, p. 48; Simonius, Travaux de l'Association Henri Capitant, t. $\Pi$, p. 305. D'un avis contraire surtaut M. Regamey, La protection de la personnalité en droit civil, thèse de Lausanne 1929, pp. 45 et sv.

(217) Cf. Simonius, dans les Travaux de l'Association Fenri Capitant, t. II, p. 308

(218) Grossen, p. 6a. 
31 - Essais de limitation du contenu du droit général de la personnalité. - Le BGH a reconnu (219), à juste titre, que la limitation du droit général de la personnalité ne pouvait se faire par une formule générale. Il faudrait plutôt procéder à une appréciation des biens et des intérêts contradictoires dans chaque cas particulier. En effet, bien souvent, le droit de la personnaliti. de la victime se trouve en conflit avec celui de l'agresseur ou avec d'autres intérêts juridiquement protégés. C'est pourquoi, dans chaque cas particulier où l'on prétend qu'un droit de la personnalité est violé, il faut apprécier toutes les circonstances de ce cas et évaluer le bien lésé par rapport aux intérêts qui lui sont opposís par l'agresseur. Par conséquent, chaque atteinte à la personnalite ne constitue pas nécessairement un indice en ce qui concerne 'a violation illicite du droit général de la personnalité. Au contrairc, c'est après avoir fixé l'iilicéité de l'atteinte qu'on peut conclu've à. la violation $d u$ droit de la personnalité (220). Ainsi, ce droit ne peut pas remplir la fonction attribuée par le $\S 823$ al. 1 du BGB aux droits absolus qui y sont prévus. En d'autres termss, toute intervention dans le cercle juridique déterminé d'une façon reconnaissable par les droits absolus en question, comporte on soi l'illicéité de cet acte; il n'est pas nécessaire, en principe, de recourir ̀̀ d'autres critères pour apprécier l'illicéité de l'artu. Tandis que les limites du droit de la personnalité, qui ne sont pas fixées à l'avance, se précisent lorsqu'une atteinte a ou licu. Le juge déterminera ces limites d'après les circonstances ciu cas particulier, en pesant les intérêts contradictoires; dans son appréciation, il aura recours parfois au critère de la conduite sociale correcte; parfois, il recherchera, si le comportement de l'agresseur est conforme à l'usage ou s'il dépasse la limite de ce qu'on doit supporter inévitablement dans la vie en commun. Il pourrait déduires également de l'ensemble de l'ordre juridique et de l'ordre moral, la valeur supérieure de certains intérêts en comparaison avee d'autres.

Selon certains auteurs (221), les critères en question comportent un facteur d'insécurité, en laissant une marge considè-

(219) Cf. BGHZ, 24, 80

(220) Ct. Larenz, t. II, pp. $399-400$.

(221) Cf. Enneccerus - Lehmann. 15. Bearb. (1958), p. 937. 
rable de liberté au juge qui apprécie les circonstances du cas particulier, ce que justement le législateur voulait éviter. Mais, il est invoqué contre cette critique, que les limites des autres droits absolus prévus par le $\S 823$ al. 1 ne sont pas non plus toujours très précises (222). A titre d'exemple, on rappelle les limites apportées à la propriété immobilière par le voisinage. D'ailleurs, même une réglementation légale détaillée de la personnalité ne pourrait entièrement écarter la marge laissée au pouvoir d'appréciation du juge. Il suffit d'examiner à cet égard le Projet do loi préparé par le Ministère de la Justice fédéral. Ainsi, dans divers paragraphes de ce Projet, on se réfère encore au critère d'intérêt légitime du lésé ( $p$. ex. $\S 17$ dernier alinéa) ou on ordonne au juge de rechercher si la violation de la personnalité a été effectuée dans le but de sauvegarder un intérêt légitime public ou privé (p. ex. $\S 15$ al. 2). En outre, conformément à ia version du $\S 12$ al. 1 prévue par le Projet, les atteintes à la personnalité qui doivent être tolérées raisonnablement dans la vie en commun, ne seront pas prises en considération. Du reste, le BGH, en se fondant sur le droit général de la personnalité, a établi certaines règles qui précisent les limites des différents aspects de ce droit, sous réserve d'appréciation des biens et intérêts réciproques dans chaque cas particulier (223). Nous donnerons un bref aperçu de ces règles en les comparant avec les dispositions correspondantes du Projet du Ministère de la Justice fédéral ainsi qu'avec les droits français et suisse.

32 - Règles déduites du droit général de la personnalité, relativement aux lettres missives et aux mémoires intines. - D'après la jurisprudence du BGH (224), les lettres missives et les mémoires intimes, même s'ils ne bénéficient pas de la protection des disposi-

(222) Cf. Hubmann, pp. 130 et sv.; 'Siebert, NJW, 1958. p. 374.

(223) Cf. Larenz. t. II, pp. 392-394.

(224) BGHZ, 13, 334 (dans ce cas, l'avocat du Dr. Schacht, exerçant son droit de réponse, avait demandé à un hébdomadaire de publier une certaine mise au point; au lieu de donner suite à cette demande, l'hébdomadaire s'était contenté dé publier la réponse de l'avocat dans la colonne réservée aux lettres des lecteurs et, de surplus, il avait coupé un passage important); BGHZ, 15, 249 (ce cas concernait la publication di Journal intime de Cosima Wagner). 
tions légales relatives au droit d'auteur, ne peuvent êtrel publiés qu'avec le consentement de l'auteur et de la manière autorisée par celui-ci. Toute publication qui n'est pas approuvée ou qui comporte des modifications, constitue une ingérence dans la sphère déterminée par le droit de la personnalité de l'auteur; car le public peut tirer de la façon dont ces écrits sont rédigés ou du mode de leur publication, certaines déductions sur la personnalité de celui-ci.

En vertu du $\S 15$ al. 2, que le Projet de loi concernant la protection de la personnalité veut introduire dans le BGB, celui qui publie sans y être autorisé le contenu confidentiel de lettres missives ou de notes personnelles, porte atteinte à la personnalité d'une manière illicite; la publication n'est permise que si l'auteur, et dans le cas de lettres missives, également le destinataire, y consentent, ou lorsque cette publication est destinée à sauvegarder d'une façon équitable un intérêt légitime public ou privé. Comme on le constate, le Projet n'a pu non plus se dispenser de l'appréciation des intérêts réciproques.

En droit français, suivant la jurisprudence constanta (225), la publication d'une lettre sans le consentement de son auteur ne

(2.25) Req. 11.5.1887, D.P. 1887.1.332 «En aucune matière, il ne peut êt: porté atteinte au principe de l'inviolabilité du secret des lettres au moyen des procédés délictueux, ce principe de haute moralité intéressant l'ordre public. Et, notamment, on ne peut invoquer à l'appui d'une poursuite discipinaire dirigée contre un avocat la lettre par. lui écrite à son client contenant des imputations diffamatoires à l'encontre d'un magistrat, lorsque cette lettre n'est parvenue aux mains du plaignant que par un véritable abus de confiance».; 20.10.1903, D.P. 1909.1.46; Cass. civ. 9.6.1883, D.P. 1884.1.89; Rouen, 5.4.1939, D.H. 1939.380. «e commerçant, destinataire d'une lettre contenant des renseignements confidentiels sur un autre commerçant, est tenı au secret envers l'expéditeur. Il ne peut, ni faire personnellement usage de la lettre, ni en disposer au profit de personne; il serait en faute, si par lui - même ou par un préposé, il en révélait l'existere? ou les termes; le tiers au profit duquel il contreviendrait ainsi à ses obligations, ne pourrait pas plus que lui-même, se prévaloir de la lettre et l'invoquer en justice. Une lettre confidentielle adressée à un tiers ne peut être produite en justice sans le consentement de l'auteur et du destinataire.» Cass, civ., lère, 26 octobre 1965, JCP, 1965 Ir, 14445. «S'agissant d'un échange de lettres confidentielles, la Cour a pu en déduire qu'elles ne pouvaient ètre portées à la connaissance des tiers sans l'assentiment de l'expéditeur et du destinataire». 
constitue un acte illicite que si la lettre revêt un caractère confidentiel. Le droit au secret des lettres missives est considéré par l'opinion dominante (226) comme un droit de la personnalité (227). En vertu de l'art. 163 du Projet de réforme du CC :

«Le destinataire d'une lettre missive ne peut en divulguer le contenu sans le consentement de son auteur.

Il peut toutefois la produire en justice s'il justifie d'un intérèt sérieux.

En cas de décès du destinataire, et à défaut d'accord amiable, l'auteur de la lettre ou ses héritiers ayant droit aux souvenirs de famille peuvent demander au tribunal d'en ordonner la restitution, la destruction ou le dépôt entre les mains d'une personne qualifiée, ou de prendre toute autre mesure appropriée».

En droit suisse, la doctrine admet (228) des règles analogues à celles des droits allemand et français pour la protection du drcit de la personnalité relatif au secret des lettres missives (229).

(226) F. Geny, Des droits sur les lettres missives, Paris 1911, t. 1, pp. 196 et sv.; Nerson, p. 172; Planiol et Ripert, Traité pratique de droit civil français 2 éd. t. III, Paris 1952, no. 485; Marty - Raynaud, Droit clvil, Paris 1961, p. 482; L. Martin, Rev. trim. de dr. ^iv. 1959, p. 248.

(227) La publication des lettres et des mémoires fictifs attribués à une personne qui ne les a pas écrits et qui n'a pas consenti à cette pubrication, constitue aussi une atteinte illicite au patrimoine moral (au droit de la personnalité): cf. Paris 16.3.1955, Rev. trim. de dr. civ 1955, p. 501 (prétendus Mémoires de Marlène Dietrich).

(228) Cf. Grossen. ZSR. 79 (1960), pp. 96a et sv; Jäggi, ZSR, 79 (1963) pp. 236 a - 237 a; Cf. Jäggi, pp. 237a-241a, pour les questions relevnn: de l'analyse graphologique des écritures d'autrui à l'insu de l'intéressé ou contre sa volonté.

(229) En droit turc, conformément à l'art. 85 de la Loi relative aux cuvre: intellectuelles et artistiques, les lettres et les mémoires ainsi que les autres écrits analogues, même s'ils ne présentent pas le caractère d'une œuvre, ne peuvent être publiés sans le consentement de leur. auteur et, éventuellement, de leur destinataire. La loi détermine, en outre, les personness qualifiées pour donner l'autorisation de publication après le décès die l'auteur ou du destinataire; d'ailleurs, à l'expiration de dix ans après le décès, la publication est libre, sous réserve des dispasitions du $\mathrm{CC}$ concernant la protection de la personnalité. 
33 - Protection de la personnalité contre la fixation de l'image sans consentement. - Selon le BGH (230), ce n'est pas seulement la publication, mais aussi la fixation de l'image d'une personne àans le domaine de sa vie privée, qui constitue une violation iu droit de la personnalité à moins qu'elle ne soit justifiée par des intérêts supérieurs. L'intérêt du public à voir les images des personnes appartenant à l'histoire contemporaine ne suffit pas à justifier les tentatives pour les surprendre dans leur intimité afin de les photographier sans leur permission (230a). Le BGH a élargi ainsi la protection accordée à l'image par la Loi relative au droit d'auteur sur les œuvres d'art et les photographies, sans admettre l'argument tiré du fait que cette protection était exclusivement réglementée par la Loi précitée en tant que lex specialis. Cette jurisprudence du BGH a trouvé sa consécration dans le $\S 17$ al. 4 du Projet du Ministère fédéral de la Justice. En vertu de cette disposition, «il existe une atteinte illicite au sens du $\S 12$, lorsqu'on fixe l'image d'autrui contre sa volonté reconnaissable, excepté les cas prévus à l'al. 2 chiffres $1-3$ (231), eu lorsqu'un intérêt légitime du sujet est lésé».

(230) BGHZ, 24, 200.

(230a) NJW, 10, 1957, p. 1315 - 1316. Selon cet arrèt, la persone appartenant ả l'histoire contemporaine est celle qui est entrée à tel point dans lo champ d'observation du public que celui-ci a un intérèt légitime à recenoir des informations à son sujet, un intérêt qui ne tient pas simplement à la curiosité ou au gout de la sensation.

(231) Ce sont les cas ou la pubication de l'image d'autrui est admissible. Ils se napportent aux images appartenant à l'histoire contemporaine, concernant les assemblees, cortèges, ou autres manifestations publiques semblables, représentant des évènements et des lieux où le sujet n'apparait que comme une figure secondaire. La doctrine suisse reconnaît également l'admissibilité de la publication dans les mêmes circonstances. En droit français, dans de pareils cas, le consentement tacite de l'intéressé à la publication est présumé; toutefois, les pe"sonnes reconnaissables sont en droit d'exiger que leurs traits soient rendus non identifiables ('Stoufflet, J. C. P. 1957, I, 1374, no. 15; Trisi. civ. Yvetot, 2 mars 1932, Gaz. Pal. 1932, I. 855; P'dris 15e Ch. 24 mars 1965, J.C.F. 1965. II 14305: "S' agissant de personnes représentée: sur une photographie dans une tenue vestimentaire négligée prise : sur un lieu touristique (en tenue polynésienne devant la tour de Pis:), celles-ci ne peuvent faire grief au photographe de la publication do cette photographie dans une revue accompagnée de commentaires peir flatteurs. En stationnant en un lieu public, les personnes susvisjé 
La doctrine dominante suisse semble se rallier à la solution allemande, en ce qui concerne la reproduction de l'image d'autrui. Ainsi Grossen (232) écrit que «la fixation de l'image peut heurter un intérêt personnel digne de protection à raison de son objet (il s'agit par exempie d'une scène de la vie privée) ou à raisor: des moyens utilisés (les photographies clandestines, en particulier celles qui sont prises au téiéobj:ctif méritent (réprobation). Dans telles ou telles circonstances, le sujet peut ressentir un vif dépiais;: à être saisi par le photographe et il faut alors lui donner la poss: bilité d'un refus» (233).

Par contre, la doctrine française, tout en considérant le droit d'interdire la publication de l'image comme suffisant, ne reconnait pas au sujet le droit de s'opposer à la fixation de son image (233a), excepté les cas où il s'agit de fixer une scène äe

se sont exposées aux regards de tous et leur présence devant wii monument public ne saurait leur conférer le droit exorbitant d'empé cher toute prise de vue. Le droit de reproduire par voie de presiv une photographie est admissible dès lors qu'elle a été prise en un lieu public, qu'il s'agit d'une scène dont les personnages n'ont pas cherché à se dissimuler ou qui n'ètaient pas, momentanément, păr l'effet des circontances imprévues et contre leur gré, dans une situatio.? désagréable ou ridicule et que le cliché représentant une scèn. d'extérieur n'a pas été modifié dans la publication. En ne prenant aucune disposition pour que les personnes susvisées ne puissent être reconnues, l'éditeur de la revue a manqué à la prudence que, en dépit de la faute de goût commise par les plaignants, elle avait l'obligation d'observer.»

(2312) ZSR, 79 (1960), p. 100 a.

(233) Dans le même sens Jäggi, ZSR, 79 (1960), pp. 230a-231a.

(233a) Cf. J. Stoufflet, La droit de la personne sur son image, JCP, 1957, I. 1374, no. 10; Nerson, pp. $383-384$; L. Martin, Rev. trim. dr. civ. 1959, p. 251-252; contra Trib. corr. de Grasse, 8.2.1950. D. 1950. 713 critiqué par Carbonnier. Récemment la Première Chambre du Tribur: 1 de la Seine a condamné (arret du 18 mars 1965. JCP 1965 II 14223) la Société éditrice de France - Dimanche à verser des dommages intérets à la veuve de Gérard Philippe pour la publication d'une phoio de son fils. Cf. aussi Trib. gr. inst. Seine 3e Ch. 24 nov. 1965, JCP 1966 II 14521 (une autorisation de la personnalité publique à la pubilcation de sa photographie est nécessaire, lorsque celle-ci a été pri.c au cours de sa vie privée; une simple tolérance même prolongée nc peut faire présumer ni une renonciation au droit de la personne sur 
la vie privée (233b). Les personnes se trouvant dans les lieux aecessibles à tous, en particulier celles qui circulent sur la voie publique ne peuvent pas se prévaloir de leur droit à l'image contre le photographe qui ne fait que fixer leurs traits sur la pellicule. Catte question a été débattue à propos de l'activité das photographes ambulants qui prennent les instantanés des passants dans l'espoir de leur vendre ensuite leur portrait. Le Conseil d'Etat n'a pas pris en considération le moyen tiré d'une atteinte illicite au droit à l'image et a statué exclusivement en fonction des exigences de la circulation sur la voie publique $(233 \mathrm{c})$.

L'art. 162 de l'Avant-Projet du CC relatif à la protection de l'image ne mentionne pas non plus la simple fixation. Selon cette Gisposition: «En cas de publication, d'exposition ou de l'utilisation de l'image d'une personne, celle-ci peut, à moins qu'il n'y ait consenti d'avance, demander qu'il y soit mis fin, sans préjudice us la réparation de tout dommage matériel ou moral. La même droit appartient au conjoint et aux parents en ligne directe au premier. degré d'une personne décédée dont l'image serait publiée, expcsée ou utilisée après son décès dlans des conditions de nature à porter atteinte à son ho:neur ou à sa considération».

34 - Protection de la personnalité contre l'enregistrement clandestin de la parole. -- La BGH estime (234), en principə, que l'enregistrement des paroles d'autrui, sans consentement, constitue une atteinte illicite au droit général de la personnalité.

son image, ni une assimilation de sa vie privée à sa vie publique. Spécialement doit etre condamné à des dommages - intérêts le journal qui, sans son autorisation a publié la photographie d'une artiste d. cinéma - dans l'espèce il s'agissait de Brigitte Bardot - prise a!n'"ú que ladite dame ne sé livrait à aucune activité professionnelle et était dans l'intimite de son existence et sans qu'elle' ait donné son consentement).

(233b) Stoufflet, no. 9.

(233c) Cf. Stoufflet, no. 10.

(234) BGHZ, 27, 284 (l'enregistrement clandestin d'une discussion destinée à éliminer certainsi désaccordis entre deux personnes); 33, 20 (l'enregistrement d'un opéra, réalisé sans le consentement des membrés de l'orchestre, en vue de sa diffusion radiophonique). 
Des exceptions ne sont admises à ce principe que dans deus sortes de cas:

D'une part, dans les affaires, l'enregistrement de certaines communications téléphoniques, relatives par exemple aux commandes passées ou à la transmission des nouvelles de la bourse, est d'un usage courant. Dans de pareils cas où la personnalité de celui qui parle n'est pas reflétée par les paroles qu'il a proncncées, l'enregistrement de ces paroles sans consentement ne porte pas atteinte à son droit de la personnalité (235).

D'autre part, un enregistrement clandestin peut êt: justifié dans les cas de légitime défense ou dans d'autres situations analogues, par exemple lorsqu'il s'agit d'établir la preuve cie menaces de chantage (236). Un motif de justification peut également être déduit de l'appréciation des intérêts réciproques; mais une talle déduction ne doit être faite que dans des c2.s très exceptionnels; car, l'enregistrement clandestin est entaché de supercherie et d'inconvenance. L'intérêt privé que présente la fixation du souvenir d'une conversation ou l'acquisition d'un moyen de preuve ne suffit pas à lui seul pour justifier l'enregistrement des paroles d'un interlocuteur à son insu. D'ailleurs, selon la jurisprudence constante du BGH (237), il est inadmissible d'utiliser comme moyen de preuve en procédure pénal, sans le consentement du défendeur, une bande magnétique sur laquelle on a fixé $\dot{a}$ son insu une conversation privée.

Le Projet de Loi relatif à la protection de la personnalite (§ 18), admet l'existence d'une atteinte illicite à la personnalité, «lorsque, sans y être autorisée, une personne enregistre les paroles d'autrui grâce à un procédé technique, ou les diffuse publiquement d'une façon directe ou par le moyen d'un microphone». Il dispose en outre: «Les paroles peuvent être enregistrées ou diffusées dans le cadre du compte rendu d'une assemblée, d'un cortége ou d'une autre manifestation publique semblable, à moins qu'un intérèi légitime d'autrui ne soit pas lésé.» D'autre part, le nouveau $§ 19$ du BGB prévu par le Projet, défend de prendre connaissance, saris

(235) BGHZ, 27, 286.

(236) BGHZ, 27, 290.

(237) Cf. BGH st. 14, 358, particulièrement p. 363. 
autorisation, par une installation d'écoute ou par tout autre procédé semblable, de propos destinés à autrui ou de faits et d'évènements appartenant à la vie privée ou familiale d'autrui.

En droit français, la question de la protection ${ }_{1}$ le la personna. lité contre l'enregistrement clandestin des paroles, s'est posée surtout du point de vue de l'admissibilité d'un tel enregistrement comm: moyen de preuve (238). La Cour de Cassation a décidé (239), que l'admission comme moyen de preuve d'un enregistrement à l'insu de l'intéressé de paroles injurieuses prononcées au téléphone $1:$ saurait empêcher celui - ci d'intentar une action en clommages - intérêts en raison de la violation du secret des conversations téléphoniques. Cette jurisprudence a été critiquée par la doctrina (240) qui, par analogie avec le secret des lettres missives, exclut la pro. tection pour les appels téléphoniques non confidentiels, en particulier pour les appels injurieux.

La doctrine suisse a dû choisir entre deux solutions opposées, l'une consistant à refuser simpiement les enregistrements clandestins comme moyen de preuvi, l'autre à admettre do teis moyers, quitte à renvoyer le lésé à intenter une action en dommagesintérêts fondée sur l'art. $28 \mathrm{du}$ CC. La préférence des auteurs suisses (241) šmble être allée à la première solution, suivant en cela la doctrine allemande. En dehors des questions de preuve, les auteurs suisses (242) voient également une violation illicite du droit de la personnalité, dans l'emploi d'appareils d'écoute ou ds bandes magnétiques destinés aux enregistrements clandestins.

(238) Cf. Mimin, La preuve par magnétophone, J.C.P. 1957, I, 370.

(239) Civ. 18.3.1955, D. 1955. 573.

(240) Note de Savatier, D. 1955. 573 - 575. Pourtant selon Mimin, «il n'y a done dans l'arrêt de cassation qu'une conséquence de l'interdiction aux juges et à leurs délégués de recourir à des modes d'instruction qui nếgligent les garanties de la défense en justice, mais qui ne seraient pas déplacés entre particuliers»; en effet, dans l'affaire jugée «les opér tions étaient dirigées par un Commissaire de police, délégué du jugr? a'instruction, au cours de l'information du chef d'injures ouvertes sur la plainte du récepteur».

(240a) Dans ce sens, Cour suprême du Canton de Berne, 2 Ch. pén. 21 févr. 1949, Rev. de crim. et de pol. techn. 1949, p. 224.

(241) Grossen, ZSR 79 (1960), p. 72 a.

(242) Grossen, ZSR 79 (1960), p. 107 a; Jäggi. ZSR, 79 (1960), pp. 234a-236a. 
Jäggi est d'avis que (243) la remise de ces bandes à d'autres personnes ou l'action de les faire entendre est encore plus grave que l'enregistrement lui-même.

35 - Protection de la personnalité contre la divulgation du contenu d'un certificat médical. - Selon le BGH (244), la divu: gation du contenu d'un certificat médical conoernant l'état de santé d'autrui, à des tiers auxquels il n'était pas destiné, viole le secret de la vie privée protégé par le droit de la personnalité; car, une teile révélation ne respecte pas la volonté de la personne de cacher son état de santé aux étrangers. Les certificats médicaux doivent être tenus secrets non seulement lorsqu'ils contiennent des constatations gênantes pour l'intéressé mais également dan: d'autres cas. Toutefois, il en est autrement, s'ils sont relatifs à des lésions sans importance ou à des syptômes des maladies courantes qui n'affectent pas l'état mental ou corporel et s'il n'existe aucun intérêt raisonnable pour les tenir cachées. D'autre part, des intérêts prépondérants peuvent justifier ì révélation du contenu d'un certificat médical.

En droit français, l'idée d'un droit au secret professionnel ou au secnet de la vie privée, bien que discutée par certains auteurs (245), tend à se répandre en jurisprudence et dans la doctrine (246). Dans les actions en petition d'hérédité et en reconnaissance de paternité, la question de la protection contre la violation du secret professionel par la production de certificats médicaux est souvent posée $(247)$ et de tels certificats sont écartés des débats.

(243) ZSR $79(1960)$, p. 235 a.

(244) BGHZ 24, 72 (la remise par un. médecin à l'auteur d'un accident. d'un certificat médical, relatif à la victime et qu'il avait établi à la suite d'un accident précédent subi par la même victimè).

(245) Cf. Nerson, nos. 87, 94, 177 (p. 384).

(246) Cf. Marty - Raynaud, t. I, p. 482; L cartin, Le secret do la vie privée, Rev. trim dr. civ. 1959 pp. 228 et sv. particulièrement p. 256.

(247) Cass, civ. 29.3.1927, S. 1928.1.5; 13.7.193̂,, Gaz. Pal. 1936.2.727, 22.1.1957, J.C.P. 1957, II. 9818; Paris, 6.2.1954, J.C.P. 1954, II, 8107 . (l'obligation de silence imposée aux médecins comme un devoir de leur état ainsi que le rappelle l'art. 4 du décret du 27 juin 1947 portant Code de déontologie médicale, ils ne peuvent s'en affranchir lorsqu'ils en sont régulièrement déliées; le juge civil ne peut admettre d'autres moyens de preuve que ceux admis par la loi et administrés ou mis en 
Le devoir de respect du secret professionnel impose aux médecins ne se limite pas seulement à l'obligation del ne pas divulguer le contenu d'un certificat médical. Un médecin qui écrit ses mémoircs se rapportant à sa carrière ou qui fait des publications médicales est tefiu également de garder le secret sur l'état de santé de ses clients. Il est à rappeler à ce sujet les mémoires du médecin de Churchill qui a fait beaucoup de bruit en Angleterre. M. Savatier (247a), fait les remarques suivantes à propos de la responsabilité du médecin écrivain: «Le médecin par exemple, quand il écrit pour le public, ne saurait, sans engager sa responsabilité, non seulement civile, mais pénale, présenter sous une clef déchiffrable, les observations faites en clientèle. Il n'est déjà pas sûr que les observations rap. portées dans une publication médicale n'exposeraient pas déjà bièn des médecins aux plaintes légitimes de leurs patients scientifiqucment déshabillés. S'il se fait écrivain, romancier, dramaturge, historien, la discrétion dont le médecin est tenu envers sa clientèle ș doit, en tout cas, d'être particulièrement rigoureuse.»

En droit suisse, la divulgation du contenu d'un certificat médical est citée (248) également parmi les exemples de la violation du droit au secret de la vie privée.

36 -.. Protection contre l'usage non autorisé du nom dans des. buts publicitaires. - La mention du nom d'une personne connue sans son consentement dans une annonce de publicité, est considérée par le BGH comme portant atteinte au droit général de la personnalité, même s'il n'existe pas une violation du droit au nom prévu par le $\S 12 \mathrm{du}$ BGB. Il en est ainsi tout particulièrement dans lca cas où le nom d'un artiste est associé d'une façon désagréable ou contraire au bon goût à une publicité commerciale susceptible de lui faire perdne l'estime du public et de gêner le développement

œuvre suivant les règles qu'elle prescrit. Doivert donc être rejetés des débats dans une instance en nullité de contrat de rente viagère fondée sur l'art. $1975 \mathrm{C}$. civ, des certificats èmanant du médecin traitant et précisant la nature de l'affection dont à son avis le crédirentier est décédé. Cf. aussi Grenoble 29 mai 1952, D. 1952. 729 (action en désaveu du mari).

(248) Cf. Egger, Art 28, Nr. 42; Sprecker, p. 78; Tribunal fédéral, RO 45 II $546 ; 44$ II 323. 
de sa personnalité artistique (249).

En droit suisse, il existe une jurisprudence semblable à celle du BGH en ce qui concerne la protection des personnes connues contre l'utilisation de leur nom dans les annonces publicitairez. Ainsi, on a décidé (250) qu'une vedette de cinéma est fondée à s'opposer à ce que son nom soit utilisé pour désigner une marque de cigarettes.

En droit français, le droit au nom est qualifié de droit de la personnalité par la doctrine dominante (251). Sielon la jurisprudence, l'attribution d'un nom patronymique à des personnages de roman, de pièces de théâtre ou de film, susceptible de créer une confusion préjudiciable avec la personne réelle (252), ou l'utilisation du nom d'autrui pour désigner des produits fabriqués (253), peuvent donner lieu à une action en dommages - intérêts. D'autre part, conformément à l'art. 221 de l'Avant - Projet du CC «l'usag du. nom, et des prénoms dans l'exercice d'une activité profession nelle ne doit avoir ni pour but ni pour effet de porter atteinte,

(249) BGHZ, 30,7, en particulier p. 13. On peut également citer un autre cas jugé par le BGH (BGHZ, 35, 363): celui d'un professeur de droit canonique dont le nom a été mentionné dans des prospectus et des annonces publicitaires qui le présentaient comme un savant se livrant a des rechertches sur les qualités d'un produit contenant des racines de ginseng et recommandé entre autres comme aphrodisiaque. Ce professeur avait rapporté de son voyage en Corée lies racines de cette plante sur la demande d'un de ses amis pharmacologues qui l'avait remercié dans un article scientifique. D'autre part, selon le BGH, la piblication sans consentement de la photographie d'une personne connue aux fins de réclame n'est pas contraire seulement au $\S 22$ de la Loi relative au droit d'auteur sur les oeuvres artistiques et photographiques, mais elle constitue également une atteinte au droit général de la personnalité: BGHZ, 20, 345 (affaire Paul Dahlke); 26, 349 (l'utilisation du portrait d'un cavalier amateur dans l'affiche réclame d'un remède contre l'impuissance).

(250) Tribunal supérieur de Zurich, 12.1.1923, BlZR 1924, no. 21 (affnire Douglas Fairbanks).

(251) Nerson, pp. 45-46; Planiol - Ripert-ISavatier, Traité pratique de droir civil français. t. I, 2 e éd. Paris 1952, no. 114; Marty-Raynaud, t. I, p. 482.

(252) En rendant surtout cette personne odieuse ou ridicule. Cf. les arrets cités par Planiol - Ripert - Savatier à la p. 144, note 2. Dans le mêm. 
à l'aide d'une confusion dommageable, au crédit ou à la répuî: tion d'un tiers».

37 - Protection de la personnalité contre les atteintes portées par la presse. - Le BGH a essayé également de fixer î: limites du droit général de la personnalité en ce qui concerne la protection contre les atteintes à l'honneur ou secret de la vie privée, portées par la presse. Pour déterminer ces limites, il s'est fondé (254) sur le principe de l'appréciation des biens et intérêts réciproques, tout en prenant en considération le droit reconnu a la presse par la Constitution (art. 5, al. 1, phrase 2) d'informer el public.

Selon le BGB (255), la presse, en apportant les faits et cin exerçant sa critique, dans la mesure où elle reste dans le cadre do sa mission officielle consistant à informer les citoyens et à coopérer à la formation d'opinions politiques, défend l'intérêt public; elle peut se prévaloir ainsi de la sauvegarde d'un intérêt légitime dans le sens du $\S 193 \mathrm{du}$ Code pénal (256). En appréciant l'existence d'un tel intérêt légitime qui justifierait l'atteinte portée à l'honneur d'autrui, on doit prendre en considération l'importance que présente pour la communauté, l'affaire examinée. D'autre part,

sens Reichsgericht dans JW 1939, 153, 154. Cf. aussi R. Lindrn, La responsabilité de l'écrivain envers un tiers victime d'une confusicn dommageable avec un personnage de roman, D. 1957, 622; Raynald ot Castelain, Le romancier et ses personnages, Rev. int. Dr. aut., jalivi=r 1963 , p. 3. Un certain M. Verdoux avait obtenu de Chaplin des dom. mages intérêts pour avoir ridiculisé son nom dans un film qui eût pu s'appeler Landru (Trib. Seine 18 mars 1948 inédit). Cf. aussi Paris 10 juillet 1957, JCP 1957 II 10266; Trib. Seine 22 oct. 1963. Rev, int. Dr. aut. sept. 1964; Trib. gr. inst. Seine 3e Ch, 13 mars 1962, D. 1963. Som. p. 21; Cour d'appel Paris, 1ère Ch. 22 nov. 1966, Le Monde 23 nov. 1966 (interdiction de l'emploi du nom de Sade dansi le titre d'une pièce').

(253) Cf. les arrêts cités par Planiol-Ripert-Savatier, à la p. 144, note 3

(254). BGHZ, 31, 312.

(255) BGHZ, 31, $312-313$.

(256) Autrefois, le RG ('RGZ 83 362; RG st. $56, \quad 380 ; 63,92 ; 64,10$ ) n'admettait un tel intérêt légitime que si l'affalre traitée présentait un rapport étroit avec l'auteur ou le rédacteur dans la meaure où elle touche les intérêts de ce dermier diune façon particulière. Cette jurisprudence n'était pas compatible, selon l'avis du $B G H$, avec la mission qui incombe à la presse dans un Etat démocratique. 
on doit tenir compte du fait que l'accusation portée par la presse aura des conséquenc:s particúlièrement graves pour l'intéressée, parce qu'elle la rendra accessible à un grand cercle de lecteurs, dont la majorité n'est pas en mesure de la soumettre à un examen ou à une appréciation critique. C'est déjà pour cette raison que la preše doit examiner soigneusement si ses sources d'information sont dignes de foi; elle doit s'abstenir d'empiéter injustement sur la vie privée et éviter les exagérations; elle doit, en outre, considérer s'il existe un rapport justifié entre le but poursuivi par la publication et le préjudice qui en résulte pour l'honneur de l'intéressé (257). Enfin, il est à rechercher si d'autres moyens moins spectaculaires que la publication dans la presse (tels l'action en justice ou le dépôt d'une plainte) ne se trouvaient pas à la dis position de celui qui a eu recours à cette voie (258). En pesant les intérêts défendus par la presse et les intérêts des particuliers qui leur sont opposés, on doit accorder plus de valeur à la liberté de la presse (259). Toutefois, le droit à la liberté de la presse prévu par la Constitution serait méconnu dans sa nature, si on considérait cette liberté comme dégagée de tcute responsabilité et propre seulement à attirer l'attention du public par des racontar.s, aux dépens de l'honneur d'autrui (260).

La presse est obligée, en principe, de rapporter des faits conforme: à la vérité; d'une part, la vérité ne doit pass être consciemment déformée, soit en omettant de rapporter certains faits importants,

(257) Dans les deux cas suivants le BGH a affirmé l'existence d'un tel rap port: 'BGHZ, 31, 313 (il s'agissait d'un reportage sur le rôle joú par lo demandeur dans une association d'étudiants, en vue de favoriser les idées nationales socialistes); BGHZ, 36, $82-83$ (dans cet arrét le BGH a déclaré que le public avait un intérêt particulier à s'informer sur la participation d'une banque au commerce des armes envo. yées à l'Afrique du Nord et au Proche Orient; la presse, en relatant ces faits, avait posé la question de savoir s'il n'était pasi nécessaire de prendre des mesures légales pour mettre fin à une situation qui présentait des dangers pour la securité intérieure et qui pouvait causer des difficultés en politique extérieure).

(258) RG St. 59, 414 (416). Cf. E. Helle, Der Schutz der persönlichen Ehre und des wirtschaftlichen Rufes im Privatrecht, Tübingen 1957, p. 121

(259) BGHZ, 39, 124 (132) (reportage offensant et contenant des indications inexactes sur la vie privée d'une speakerin de la télévision).

(260) BGHZ, 39, 124 (128). 
soit en recourant aux exagérations; d'autre part, des nouvelles dont l'exactitude n'est pas vérifiée, ne doivent pas être répandues à la légère (261).

La critique exercée par la presse doit être objective. Lorsque le public manifeste un intérêt particulier pour les faits rapportés, la critique sévère, mais objective de la presse doit être tolérée par la personne critiquée; cependant, n'est pas permis l'emploi de propos outrageux auxquels manque une base objective (262).

La relation par la presse d'évènements concernant la vie privée d'une personne, même si elle correspond entièrement à la réalitè et ne présente pas un caractère déshonorant, constitue en principe une atteinte illicite au droit de la personnalité. Toutefois, le récit d'évè nements relatifs à la vie privée peut êtrə justifié par un interêt səricux du public à être renseigné sur ces évènements. Iì $\in$ n est ainsi par exemple, lorsque la presse contribue par des informations de ce g:n' $\mathrm{E}$ a éclairer l'opinion sur une question d'importance politique. Les faits de la vie privée d'une personne ne font pas partie de la vie publiqu pour la seule raison qu'ils concernent une personnalité de la vie publique. De tels faits ne revêtent pas nécessairement un intérết public; il faut des circonstances particulières pour qu'ils puissent être reconnus comme tels. Cela peut être le cas, si la personne res. ponsable de la publication a été poussée par le souci de voir des postes publics importants occupés par des personnes dont la vie est irreprochable; mais il n'en est pas de même pour les rapports of les commentaires dont le but est de créer la sensation et le scandale (262a). D'autre part, celui qui fait de la vie privée d'autrui l'objo:

(251) BVerfGE 12, 113 ou NJW 61, 819.

(262) BGHZ, 39, 127.

(262a) L'arrêt rendu par le BGH le 15, janvier 1963, dans un cas où il s'agissait d'un article qui avait paru dans un journal au sujet d'un scan. dale de «call girls». Dans le contexte de ce scandale le journal avait mis en cause un ministre d'un Land. sans mentionner son nom, mais en donnant une description de la personne en question qui faisait apparaître clairement son identité à tout le monde. En réalité, il s'agissait d'une erreur d'identité. 
d'une campagne de presse doit tolérer également qu'on dévoile sa propre vie privée d'une manière conforme à la vérité (263).

Les principes ainsi posés par la jurisprudence, afin de fixer les limites de la liberté de la presse par rapport au droit général de la personnalité et au droit à l'honneur, auraient trouvé leưr consécration législative, si le Projet de loi sur la protection de la personnalité avait été adopté. Cependant, ce Projet a rencontré une opposition farouche de la part des journalistes qui lui ont reproché d'ignorer totalement la liberté de la presse et de corrmercialiser l'honneur (264). Or, un bref examen des dispositions du Projet en question suffirait à montrer qu'elles ne diffèrent pas des principes déjà acquis en jurisprudence (265). En vertu du $\S 14$ al. 2 prévu par le Projet, «la presse, la radio ou le cinématographe servent à sauvegarder un intérêt légitime, lorsque, dans les limites de leur mission officielle, ils informent le public et exercent la critique. Celui qui fait ou répand une affirmation relative à un fait portant atteinte à l'honneur en connaissant son inexactitude, ne peut se prévaloir d'un intérêt légitime $e_{k}$ Selon l'alinéa suivant, si dans une réunion publique quelqu'un fait ou répand au sujet d'une autre personne une affirmation déshonorante dont l'exactitude n'est pas prouvable, la personne incriminée ne peur. interdire à la presse de rapporter fidèlement les propos tenus, lor qu'il s'agit de sauvegarder d'une façon équitable un intérêt légitims public ou privé.

Le Projet contient également une disposition ( $\S 14$, al. IV) sur les limites du droit de critique. Conformément à cette disposition, un jugement désapprobateur sur une prestation ou sur un comportement d'autrui ainsi qu'une affirmation déshonorante au sujet d'un

(263) BGH, NJW, 64, 1471_ 1472 (dans cette affaire, le demandeur, éditeur d'un journal et d'un magazine avait attaqué, dans la presse qu'il dominait, certaines personnalités en vue de dénoncer leurs relations féminines et leur comportement contraire aux bonnes moeurs; une hébdomadaire avait démontré par la suite que ce publiciste qui s'était érigé en moraliste ne menait pais lui-même une vie privée exempte de reproche.

(264) Cf. à ce sujet: Grossen, ZaSR, N. F. Bd. 79 (1960), pp. 77a-78a.

(265) Cf. E. E. Hirsch, Maulkorb für die Presse? Berlin 1959; Larenz, t. II, p. 394 . 
tiers, fondée sur des faits dont l'exactitude peut être prouvée, ne constituent une atteinte illicite au droit de la personnalité çu si ce jugement ou cette affirmation par leur forme d'expression c"1 selon les circonstances se présentent comme la manifestation d'un miépris outrageant.

En droit français les dispositions pénales de la Loi sur in ' presse du 1881, modifiées par l'Ordonnance du 6 mai 1944, servent, bien qu'indirectement, à déterminer également du point de vue civil les limites de la presse (266). Cette liberté n'accorde aucuns immunité aux journalistes, leur permettant d'insérer dans lelui; articles des imputations de nature à porter atteinte à l'honneur et à la considération des personnes visées (267). Toutefois, la presse, ayant la mission d'informer le public, occupe une position particulière; le droit de rapporter des faits, accordé à une personne privée, est beaucoup moins étendu que celui accordé à la presso (268).

La presso, en renseignant le public sur les faits, doit respectir la vérité et les règles de la bonne foi (269). Depuis l'Ordonnance du 6 mai 1944, il est permis de relater même les faits diffamatoirez. à condition de pouvoir prouver leur exactitude; les exceptions à cette règle ne sont prévues que pour les imputations concernant

(266) Poun plus de détails cf. R. Savatier, Traité de responsabilité civiie, t. I, nos. 91, 94-97; le même auteur, Le droit de l'art et des lettres. Paris, 1953. nos. 213-218, 229-232, 244-252; Gutachten des Max-Planck Instituts über den zivilrechtlichen Persönlichkeits-und Ehrenschutz, Tübingen 1960, pp. $69-72$.

(267) Paris, 5 mai 1948, D. 1948. 351 et 492.

(268) Paris, 22 octobre 1957, Gaz. Pal, 1957. 26. 396 (commet le délit le diffamation, celui qui par plusieurs lettres, a attiré spécialement l'attention de ses correspondants sur un article d'une revue juridique ayant trait à des poursuites pénales dont son associé faisait l'objet, en les invitant à se procurer cet article et à le diffuser; il agit airıi avec une intention particulière de nuire à son associé).

(269) Cf. Savatier, Le droit de l'art et des lettres, p. 159. 
la vie privée des personnes (270), ou se référant à des faits anciens de plus de dix ans ou à des infractions couvertes par amnistie, prescription, ou réhabilitation. Ainsi, la vérité, même déplaisante ou pénible pour autrui, peut, en principe être révélée. Elle constituera pour le journaliste qui l'affirme un fait justificatif, le dispensant de toute responsabilité civile (271). La jurisprudence française nie la mauvase foi et écarte du même coup toute responsabilité, toutes les fois que la vérité est affirmée mêm a publiquement, dans un intérêt légitime (272). En particulier, lorsque les journalistes font connaître au corps électoral le passé inavoué ou inavouable du candidat qui sollicite ses suffrages, les tribunaux admettent que l'intérêt général justifie ce genre de publications (273). Cependant, la responsabilité du journaliste serait engagée, s'il exposait en même temps au public le passé des amis du candidat, désignant par exemple, au nombre de ses intimes, un homme qu'il présente comme un condamné de droit commun, privé de ses droits civiques (274).

Comme l'a écrit d'une façon pertinente M. l'Avocat Général R. Lindon dans une étude consacrée à «la presse et la vie privée» (274a), «selon la nature de la participation de l'individu à la vie politique, économique ou sociale du pays, les limites de la vie privée se déplacent et épousent des contours variables qu'il appartient aux tribunaux de fixer dans chaque cas. La seule règle qui paraît pouvoir être dégagée est que lorsqu'une personne sollicite la confiance

(270) V. Crim. 3 mars 1949, J.C.P. 1949.2.4978 (dans cette affaire, un journaliste racontant un attentat manqué contre un châtelain, avait indiqué que celui-ci avait été considéré dans le pays durant l'occupation allemande comme un collaborateur et que, pour cette raison, il lui était déjả arrivé d'être maltraité, ainsi que sa concubine. La Cour de Cassation n'a pas admss la preuve de la vêrité; parce que le journaliste faisant connaître à tout le pays que le châtelain avait une concubine, avait empieté sur le domaine de sa vie privée).

(271) Savatier, Le droit de l'art et des lettres, p. 158.

(272) 'Savatier, Le droit de l'art. p. 159.

(273) Savatier, Traité, p. 117; Le droit de l'art, p. 159; Trib. Seine 30.10.192: D.H. 1925. 698 .

(274) Crim. 18 julllet 1950, D. 1950, 281.

(274a) JCP 1965, I, 1887. 
et à fortiori les suffrages légaux du public, l'immunité de la vic privée doit céder devant l'exigence d'une information complète à l'égard de tout ce qui, chez cette personne, peut justifier ou, au contraire, détruire la confiance.»

On constate une certaine confusion dans la jurisprudence française entre la protection de l'honneur et celle de la vie privée (275). En d'autres termes, les tribunaux exigent de la victime de l'indiscrétion la preuve qu'elle a été ridiculisée. Ainsi, en droî́ français, à la différence des droits allemand et suisse, la vie privée ne bénéficie pas encore d'une protection pour elle même, bien distincte de celle de l'honneur et de la considération. Toutefois, certaines décisions récentes semblent accorder le protection civile contre les immixtions intolérables dans la vie privée, par la publication des clichés et des indications qui la concernent (275a), D'ailleurs, dans la doctrine récente $(275 b)$, on souligne de plus en plus l'importance de la protection de la vie privée pour elle-même. M. Lindon propose $(275 \mathrm{c})$ de lege ferenda l'adoption des règles suivantes à ce sujet qui pourraient, au demeurant, être prises en considération, dans une certaine mesure, par la jurisprudence: «Est fautive toute publication par le texte écrit ou parlé ou par l'image, lorsqu'elle donne, à propos de la personne qui en est l'objet, des informations autres que:

1) Celles qu'il est légitime de fournir à l'opinion publique, compte tenu des activités publiques ou professionnelles de cette personne, ou compte tenu de l'intérêt de toute nature que présentent pour cette opinion les évènements auxquels cette personne a été associée;

2) Celles qui sont justifiées par la nécessité d'informer le public sur les affaires judiciaires;

(275) Cf. L. Martin, Le secret de la vie privée, Rev, trim. dr. civ. 1959. pp. $232,254-255$.

(275a) Ainsi par exemple, Paris, 14e Ch. 13 mars 1965, Dame Philippe : France Editions publications, J.C.P. 1965, II, 14223; cf. aussi pour la publication des images concernant la vie privée d'un artiste: Trib. gi. inst. Seine, 24 nov. 1965, J.C.P. 1966, II 14521 (l'affaire Brigitte Bardot).

(275b) Cf. les études précitées de Martin et Lindon.

(275c) J.C.P. 1965, I, 1887. 
3) Celles qui ne sont que la suite de révélations auxquelles l'intéressé s'est volontairement prêté (275d).

Selon la jurisprudence française (276), «la critique des ouvrages de littérature, de musique ou de théâtre ne peut utilemeni remplir sa mission, qui est d'intérêt public, si ne lui est pas laissée une très large liberté d'opinion et d'expression. On ne saurait pārler d'abus fautif du droit du critique que si celui-ci au lieu d'exprimer, fût-ce avec vivacité, mais sincèrement et honnêtement, l'opinion favorable ou défavorable, l'admiration ou la répulsion que lui inspire le livre lu ou le spectacle contemplé, n'a visiblemert été mu que parti pris de dénigrement systématique et une volonté évidente de nuire. En ce qui concerne spècialement les œuvres pré sentées au théâtre, le comédien, le mime ou le danseur, en se produi sant publiquement, contraint le critique à se prononcer non seulement sur l'œuvre, mais: aussi sur tous les aspects de l'interprétation de l'acteur, et notamment sur les sentiments, impressions et influences que son comportement en scène est susceptible de produire sur les spectateurs». Par contre, il faut que le critique s'abstienne absolument de confondre avec l'art de la personne visée, le domaine de sa vie privée (277); il ne doit pas se laisser dominer par les passions partisanes et étrangères à l'art (278); il doit en outre être sincère (279) et éviter toute expression injurieuse et toute allusion outrageante $(280)$.

Les principes du droit suisse qui réglementent la protection

(275d) Cette dernière règle a été prise en considération par la Cour d'Appei de Paris (1ère Ch.) dans son arrêt du 22 novemore 1966 concernant l'affaire Gunther Sachs c. la Revue «Lui». Cf. Le Monde des 23 et 9 nov. 1966.

(276) Paris 6 janvier 1953, D. 1953, 198 (dans cette affaire, le critique avait exprimé sa désapprobation et son regret de ce qu'une danseuse sem. blait se complaire dans l'exhibition non exempte d'inconvenance, de sid beauté physique; il avait avoué en outre préférer, aux ballets dirigńspar cet artiste, les danses rurales africaines présentées dans un certain film; de plus, Il avait qualifié des épisodes d'un de ces ballets de «monstrueux plagiat» de l'œuvre d'un autre danseur).

(277) Savatier, Traite, no. 89, b; Le droit de l'art et des lettres, p. 192.

(278) Tr. Seine 20 mars 1928, D.H. 19128. 262.

(279) Paris 16 oct. 1955 (l'affaire d'Igore Markevitch: le critique n'est p?. sincère lorsqu'il n'a pas assisté au concert qu'il a critiqué et qu'il ca'a indiqué non plus ses sources d'information).

(280) Savatier. Le droit de l'art et des lettres, pp. $192-193$. 
de la personnalité contre les atteintes portées par la presse sont résumès très clairement dans les passages suivants que nous reproduisons d'un arrêt du Tribunal fédéral $(281)$; *... s'agissan: d'une atteinte portée aux droits de la personnalité par la voie de la presse, le juge considérera d'une part, les conditions particulières dans lesquelles travaille la presse et l'intérêt qu'elle peui avoir à renseigner le public sur un particulier et, d'autre part, l'intérêt de ce particulier à ne pas être objet d'articles publiés par la presse. En appréciant ces différents facteurs, le juge doit tenir compte du rôle que le législateur, notamment celui de la Constitution (art. 55), a reconnu à la presse.

...La presse peut porter atteinte de deux manières aux intérêts personnels: soit en publiant des faits, soit en les appréciant.

La presse ne doit relater que des faits exacts, cela va de soi, sinon ce ne sont précisément pas des faits qu'elle porte à la connaissance du public. L'auteur d'allégations inexactes ne saurait en aucun cas se réclamer de la mission dévolue à la presse. Une affirmation fausse n'ast donc jamais licite. Si elle est faite de bonne foi, elle n'en reste pas moins illicite, mais la faute disparait. Cela a une importance en droit civil, car dans une certaine mesure, la protection de la personnalité est accordée aussi contre des atteintes simplement illicites et non pas uniquement contre des actes impliquant une faute (action en cessation du trouble, art. 28 al. 1er CC) (282). Ii n'y a pas de motif d'exclure l'application de l'art. 28 al. 1er en cas d'allégations inexactes de la pressc qui sont faites de bonne foi. On sauvegarde suffisamment l'intérêt de la presse si l'on tient compte des conditions dans lesquelle. elle travaille Iorsqu'on apprécie sa faute, c'est-à-dire lorsqu'on examine si une allégation pouvait être avancée de bonne foi.

L'appréciation des faits est souvent liéa à leur communiration; elle constitue alors la conclusion que l'auteur en tire. Une telle appréciation est admissible en tant qu'elle cadre avec les faits exposés et ne revêt pas sans nécessité une forme blessante (283). Mais il peut arriver qu'une appréciation est émise sans

(281) RO 71 II 191 ou JdT, 1945, pp. $567-569$.

(282) Dans le même sens RO 58 Il 129 ou JdT 1942 I 629 ; RO 91 II ou JdT, 1966. pp. 514 et sv.

(283) Dans le même sens RO 50 I 205 et 218 ou JdT, 1924, pp. 541, 6?3; 
indication des faits sur lesquels elle repose et sans même qu'ćn puisse admettre qu'ils sont connus. Dans ce cas, il faut exiger que l'appréciation ne porte pas à des suppositions erronées quant à ces faits».

Selon la doctrine suisse (284), la presse ne doit pas rapporter, en principe, les faits concernant ia vie privée d'une personne, même si ces faits sont exacts et si liur rèvèlation ne porte pas atteinte à la considération. On ne reconnaît des exceptions à principe que lorsqu'il s'agit de titulaires de fonctions publics $e^{\prime}$ : de personnages appartenant à l'histoire contemporaine. Ainsi, lo Tribunal fédéral juge (285) qu'il est dans l'intérêt général que la presse donne des renseignements se rapportant à des personna lités en vue de la vie publique, autant que cela est utile pour apprécier leur rôle dans l'Etat. II estimie pu'à l'ègard des membres de l'Assemblèe rédèrale cette faculté de la presse va trés loin. Quant aux personnages célèbres appartenant à l'histoire contemporaine (286), les circonstances de leur vie privée ne peuvert être évoquées que dans la mesure où elles sont en rapport avcc l'activité à l'origine de leur célébrité ou nécessaires pour éclairer leur personnalité (287).

Il conviendrait ici de mentionner encore une résolution récente de la dernière Ȧssemblée consultative du Conseil de l'Europe (287a). Cette résolution, en constatant dans la Convention européenne des Droits de l'Homme l'existence de toute une série de dispositions relativa au rôle, aux droits et aux devoirs de la pressc, formule le souhait que ces dispositions trouvent une interprétation concordante dans les systèmes juridiques des pays - membres d 1 Conseil de l'Europe, alors qu'en réalité les dispositions législatives varient de pays à pays. D'autre part, d'après la même résolution, 'less facilités accrues de diffusion à travers les frontières appelient un

(284) Cf. J. Bourquin, La liberté de la presse, Lausanne 1950, pp. 206 - 206; Grossen ZSR, N.F. Bd. 79 (1960), pp. 83a-91a; Jäggi, ZSR, N.F.Bd. 79 (1960), pp. 244a-247a.

(285) JdT, 1945, p. 568; 1935, p. 296.

(286) Cf. supra note 230 a.

(287) Grossen, ZSR, N.F. Bd. 79 (1960) p. 87 a.

(287a) Adopté le 16 janvier 1967 (Doc. 2168). 
certain rapprochement des législations en ce domains et il sćrait souhaitabla que les réformes envisagées dans les lég slations sur la presse de certains pays - membres aille dans le sens d'une plus grande uniformité de droit.

38 - Droits particuliers de la personnalité correspondant $\grave{\varepsilon}$ certaines libertés garanties par la Constitution. -- D'après une rouvelle tendance de la doctrine allemande (288), à côte du droit génêral de la personnalité, on doit reconnaître des droits particuliers qui correspondent à certaines libertés garanties sous forme de droits constitutionnels. Ces droits sont reconnus dans la mesure où ces libərtés peuvent être entravées non seuiement par les autorités publiques, mais aussi, grâce à un rapport de dépendance ou à une supériorité économique, par des groupements ne disposani pas du pouvoir, ou par des particuliers. Il s'agit notamment de la liberté de conscience (art. 4 al. 1 de la Const. féd.), de la liberté d'expression (art. 5) et de la liberté d'association (Art. 9). Celui qui par intimidation ou par pression empêche autrui d'exercer l'ur: des droits constituant les corollaires des libertés en question Freheits:echte), se comporte d'une manière illicite; car, ces droits doivent être protégés conformément au $\S 823$ al. 1 du BGB, commi «autres droits» (sonstige Rechte). Cependant, il ne faut pas perdre de vue que le droit particulier de la personnalité peut avoir des limites plus étroit $ミ s$ que le droit constitutionnel correspondant, dirigś contra les pouvoirs publics; ainsi par exemple le droit privé à la sitions des lois générales (allgemeine Gesetze) et devant le droit à l'honneur (art. 5 al. 2 de la Const. féd,), mais aussi devant lto devoirs de discrétion et d'égards qui résultent d'un rapport de droit civil existant, tel le devoir de loyauté (289).

39 - Droit à l'exploitation organisée et exercée d'une entrep:ise (Recht am eingerichteten und ausgeübten Gewerbebetrieb). - L'énumération trop restrictive des droits et des biens juridiques susceptiblis d'être protégés par le $\S 823$ al. 1 contre les atteintes délictuelles, nə permettait pas en fait une protection efficace de l'entreprise commerciale et de l'exercice d'une industrie. Les tentatives pour trouver une base de protection pour l'entreprisa dans les $\S \S 824$ et 826 du

(288) Larenz, t. II, 7 ème éd. (1965), p. 240.

(289) Un tel devoir peut résulter, par exemple d'un rapport contractuel de travail. 
BGB et dans certaines lois accessoires, telle que la Loi sur la con currence déloyale se révélèrent également insuffisantes. En effet, toutes les atteintes dommageables portées à une entreprise n'étaient pas contraires aux bonnes mœurs, comme cela était exigé par lé $\S 826$ du BGB et par la clause générale du $\S 1$ de la Loi sur la concurrence déloyale. En outre, la condition d'intention de nuir a prévue par le $\S 826$ n'était pas toüjours réalisée. D'autre part, le $\S 824$ du BGB visant la protection du crédit et le $\S 14$ de la Loi sur la concurrence déloyale ne s'appliquaient qu'en cas d'affirma tions contraires à la vérité; tandis qu'on pouvait léser une entre. prise par d'autres sortes d'atteintes.

Par conséquent le RG a reconnu que, la manifestation de la volonté d'exercer une activité lucrative dans l'exploitation organisée d'une entreprise, justifie l'admission d'un droit subjectif à cette exploitation et que chaque intervention qui se dirige contre les bas?s corporolles de l'exploitation et qui atteint directement l'existence de celle-ci, constitue une violation de ce droit (290). Une telle violation existie lorsqu'on empêche matériellement les opérations d'exploitation ou qu'on nie juridiquement l'admissibilité de celle-ci en demandant sa cessation ou sa limitation. Au début. une simple diminution des bénéfices ou d'une expectative de bénéfices n'était pas considérée comme suffisante pour déclarer l'illicéité de l'aiteinte. Plus tard, le RG a admis (291) l'illicéité même pour leì atteintes directes au sphère d'activité de l'entreprise, qui sont susceptibles de menacer non son existence même, mais seulement ses revenus. Enfin, le BGH (292) a éiargi le domaine d'application de cette jurisprudence qui était réservé jusqu'alors par le $R G$ au droî́ des marques et au droit de concurrence. Dès lors, l'entreprise est protégée non seulement contre les atteintes de sess concurrents, mais aussi contre celles des autres personnes (293).

(290) IRGZ 58, 29; 76, 46; 77, 217;95, 340;101, 337; 1021, 225; 126, '96. Cf. Esser, p. 848 .

(291) RGZ 132, 316; 135, 395; 144, 52; 149, 332; 158, 379; 163, 32 .

(202) BGHZ. 3, 279

(293) Par exemple, dans le cas cité à la note précédente, une revue religieuse avait critiqué un magazine pour les femmes (Constanze) et avait recommandé aux croyants de lire d'autres revues qui. économi. quement, ne dépendaient pas d'elle. 
Le BGH entend par le droit à l'exploitation d'une entreprise, un droit au développement non troublé du cercle d'activité professionnelle, qui assure une protection contre les trouble; directs causés à l' exploitation organisée äune entreprise, soit dans son existence même, soit dans son activité (294). Afin de limiter le contenu de ce droit, le BGH recourt aux notions de «troubles» (Störungen) et d' atteintes directes. La notion de «trouble» est interprêtée d'une façon restrictive; par exemple, l'existence d'un trouble est niée, lorsque le fait en question a entraîné seulement un surcroît de travail (295). Quant au caras: tére direct des atteintes, il ne dépend pas selon le BGH (296), du fait que l'effet de l'atteinte a été produit sans que des causes intermédiaires soient intervenues; mais il doit être déterminé cn examinant si l'atteinte se rapporte à l'exploitation (betriebsbezogen) (297); les atteintes qui ne sont pas dirigées contre l'exploitation comme telle, mais contre les droits et biens juridiques séparebles facilement de celle-ci, ne sont pas de nature directe (29?). Il en est ainsi, par exemple, lorsque les attsintes portées aus personnes indispensables pour la continuation de l'entreprise (299). N'est pas considérée non pius comme une atteinte directe, l'endommagement d'un cable conduisant l'électricité à l'entreprise, qui entraîne une interruption de courant (300). On ne peut voir

(294) BGHZ, 3, 280.

(295) BGHZ, 23, 56. Dans ce cas, la cession des salaires avait causé un surcrolt de travail pour la comptabilité de l'entreprise.

(296) BGHZ, 29, 70.

(297) BGHz, 29, 74. Selon Larenz, (t. II 7e éd., p. 423), un acte est in rapport avec l'exploitation, si son influence sur celle-ci svait ete aperçue par celui qui le commet, ou au moins s'il était un moyen objectivement susceptible d'avoir une influence sur l'exploitation.

(298) BGH, NJW, 1959. 479.

(299) BGHZ 7, 30.

(300) BGHZ 29, 65. Car, d'après le BGH, la livraison de l'électricité et lu créance qui tend à obtenir cette livraison ne sont pas ces particu. larites propres à la nature de l'exploitation de l'entreprise Par contre OLG Munich (BB 64, 661) a affirme l'existence d'une atteinte directs dans un cas où le cable se trouvant sur l'emplacement même d'une construction et conduisant l'électricité aux machines de construction, avait été détruit et par ce fait avait causé l'interruption des travaux; ici, la destruction du cable se rapportait à l'exploitation de l'entr. preneur. 
non plus une atteinte directe dans la destruction par un tiers de machines importantes pour l'exploitation, achetées par l'entreprise, mais non encore délivrées, même s'il était possible de prévoir. le préjudice que devrait en subir l'entreprise (301). Certains auteurs (302) qualifient de violation illicite du droit à l'exploitation d'une grève inadéquate du point de vue social et qui paralyse l'exploitation en question.

Les tribunaux allemands essaient également de préciser le contenu du droit à l'exploitation d'une entreprise en pesant dans chaque cas particulier les intérêts réciproques du titulaire de ce droit et de celui qui porte atteinte à l'exploitation (303). Ils examinent, pour déterminer l'illicéité de l'atteinte, si elle est effectuée dans un but légitime et si elle constitue un moyen approprié et nécessaire pour arriver à ce but ou encore s'il existe! une proportion admissible entre l'avantage recherchée par l'auteur de l'atteinte et le dommage subi par l'entreprise. D'autre part, le fait d'empêcher l'exploitation d'une entreprise dans un immeuble dont on a la propriété, n'est pas jugé illicite (304).

Les principaux cas dans lesquels la jurisprudence a reconnu l'existence d'une atteinte illicite au droit à l'exploitation d'une entreprise peuvent être groupés dans les catégories suivantes (305):

a) La première catégorie renf $\in$ rme les cas où une personne, $€ n$ alléguant un droit de protection industrielle (tel qu'un brever. d'invention ou un droit sur les modèles), demande et obtient la cessation de l'activit'́ d'une entreprise ex où, dans la suite, ii se révèle qu'un tel droit n'existait pas et que l'allégation de ce drnit provenait pour le moins d'une négligence (306).

b) Dans la deuxième catégorie, on classe les jugements de valeur dommageables, ajoutés souvent à l'affirmation de certains faits, pouvant être vérifiés. Il s'agit ici des déclarations qui déprécient la situation d'une entreprise (Verhaeltnisse eines gewerblichen Unternehmens), sans qu'elles puissent être assimilées à une diffa-

(301) Larenz, t. II (7e éd.) p. 423.

(302) Nipperdey, Rechtsgutachten zum Zeitungsstreik, 1953, pp. 34 et sv.

(303) BGHZ, 3, 28.

(304) BGHZ, 14, 304 (défense faite à une entreprise de pompes funèbres d'exercer son activité dans une cimetière privée).

(305) Cf. Larenz, t. II (7e éd.), pp. 422-423.

(306) RGZ 58, 24; 94, 248; 141, 336; BGilZ 2, 387; 38, 200. 
mation ou à un acte contraire aux bonnes mœurs (307).

En particulier, la jurisprudence estime que la publication et la diffusion des appréciations négatives sur certains produits d'une entreprise, fondées sur un test comparatif accompli par un institut ou par une revue (308), constitue selon les circonstances une atteinte illicite, au droit à l'exploitation d'une entreprise (309). Il est vrai que les conclusions tirées de ces tests, en qualifiant ceitains produits de «défectueux» ou de «non recommandables», sor:t susceptibles d'exercer une influence dommageable sur la vente des marchandises ainsi dépréciées. Par contre, les produits concurrents, dont la qualité a été jugée meilleure, occuperont une place avantageuse sur le marché. Cependant, dans un systèmo d'économie fondé sur la libre concurrence, on peut admettre que les producteurs doivent supporter la comparaison de leurs produits avec ceux des autres entreprises, examinés d'une façon objective et dans les mêmes conditions et qu'ils doivent tolérer les critiques justifiées (310) D'ailleurs, la presse sert l'intérêt général en publiant de telles appréciations. En effet, devant la diversité de nombreux produits offerts aux consommateurs, ceux-ci, qui n'ont ni les possibilités matérielles, ni les connaissances techniques nécessaires pour les comparer, ont grand intérêt à connaître les recommandations des experts qui ont établi les comparaisons.

La publication des résultats de tests de marchandises et des appréciations fondées sur ces résultats, ne doit pas être considérée comme illicite, lorsque les examens sont accomplis avec le soin nécessaire par des experts qualifiés et que les jugements portés sont fondés sur ces examens en usant d'une façon impartiale les

(307) BGHZ 3, 279; (V. pour ce cas supra note 293); BGH Vers R. 61. 843.

(308) En Allemagne, c'est surtout la revue «Die Deutsche Mark» qui s'occupe de ces tests. Aux Etats - Unis, en Angleterre et en Hollande les unions de consommateurs, en France l'Institut de Consommation font des publications de ce genre. Cf. E. Helle Über öffentliche vergleichende Waren-Tests und die Grenzen ihrer Zulaessigkeit, NJW, 1962, p. 1177.

(309) OLG Stuttgart JZ 61, 380 (test relatif aux balances); LG Düs\$心?. dorf, WRP 63, 27 (test relatif aux vêtements); LG Düsseldorf, BB 62, 935 (test relatif aux machines à laver). BGH, NJW, 1963, 104 (critique de mode à la télévision); OLG Stuttgart, NJW 1964, 595 test relatif aux automobiles Fiat Europa); OLG Celle NJW 1964, 1804 (test de VW 1500).

1310) Cf. Larenz, t. II (7e éd,) p. 423. 
mêmes critères et en évitant l'emploi d'expressions dénigrantes qui ne sont pas objectivement nécessaires (311). Les appréciations négatives doivent être justifiées par des faits constatés (312). Il ne faut pas faire de généralisations et déclarer après l'examen d'un seul produit d'une entreprise, qu'elle vend des marchandises de mauvaise qualite (313). L'inexactitude du jugement de valeur donné peut reposer sur une erreur de raisonnement ou sur une déduction non conforme à l'expérience de la vie (314). Par exemple, lorsqu'on compare les marchandises appartenant à différentes catégories de prix, on peut aboutir à un jugement trompeur. Même si l'on indique les prix, il est à craindre que des lecteurs non attentifs lisent seulement le résuitat négatif. Le test doit servir seulement les intérêts des consommateurs; la vente par la revue qui fait le test d'une grande quantité de ses exemplaires à l'entreprise dont les produits sont mieux classés, constitue une réclame comprative servant à favoriser la concurrence d'autrui et sera considéré comme un acte de concurrence contraire aux bonnes mœurs dans le sens de l'art. 1 er de la Loi sur la concurrence déloyale (315). Pour l'admissibilité d'un test, il n'est pas nécessaire de comparer tous les produits du même genre qui existent sur le marché (316). D'autre part, l'examen d'une seule pièce des articles de grande valeur fabriqués en série (aintomobiles) serait en règle générale suffisant; car, les producteurs qui vendent des marchandises ainsi fabriquées garantissent que toutes les unités sont de même qualité (317).

c) La trcisième catégorie consiste en des communications faites au sujet d'un commerçant ou d'une entreprise, conformes

(311) Cf. Helle, NJW, 1952, p. 1178; Hefermehl, Der Warentest in rechtlicher Sicht, GRUR, 1962, pp. 611 et sv..

(312) Ainsi pour dire qu'une marchandise présente danger de vie, il faut qu'il soit établi clairement qu'elle comporte un défàut très grave met. tant en péril la vie de celui qui l'utilise (OLG Stuttgart, NJW. 1964, p. 597).

(313) Helle, NJW, 1962, p. 1178.

(314) Helle, NJW, 1962, p. 1178.

(315) Helle, NJW, 1962, p. 1180.

(316) D. Schultz, Vergleichender Warentest und Recht am eingerichteten und ausgeübten Gewerbebetrieb, NJW, 1963, pp. 1801-1802. D'un avis contraire Bollack, Zur Probiematik der Warenauswahl beim Warentest, NJW, 1963, pp. 986 et sv.

(317) OLG Celle, NJW 1964, p. 1807. D'un avis contraire Hefermehl, GRUR 1962 , p. 617. 
certes à la vérité, mais dont on peut tirer la conclusion qu'on ne saurait leur faire crédit. Il est à mentionner à titre d'exemples, les affirmations telles que «X ne paye pas ses dettes à temps» ou que «déclaration de sa faillite a été demandée» (318). Une semblable communication constitue une atteinte illicite au droit à l'exploitation d'une entreprise, à moins qu'un intérêt majeur de celui qui la fait ou la reçoit ne la justifie et qu'elle ne soit exprimée sous unc forme qui ménage l: mieux possiblo l'intérêt de l'entreprise incriminée. Cependant, la demande de la mise en faillite, sans en faire part à des tiers, n'est pas illicite, même si elle a été formulée sans s'être assurée que les conditions de la faillite se trouvaient réalisées.

d) La quatrième catégorie comprend les cas d'invitation au boycottage d'une entreprise, faite dans des buts étrangers à ía concurrence par exemple dans des buts politiques (319). dentes :

e) Le cas suivant n'entre dans aucune des catégories précé-

Un particuiier qui faisait construire un bâtiment au voisinage d'un magasin, avait fait déposer plusieurs fois et pour de longues durées des matériaux sur le trottoir devant les vitrines dudit magasin, obligeant ainsi les passants à suivre un autre trajet ei rendant ainsi sans effet la réclame que le magasin faisait dans ses vitrines. Le Tribunal supérieur do Düsseldorf a jugé (320) qu'il y avait là une atteinte illicite au droit à l'exploitation d'uise entreprise, pour autant que le dérangement causé dépassait la mesure de ce qu'on devait supporter selon l'usage.

La jurisprudence qui reconnaît le droit à l'exploitation d'une entreprise a été i'objet de diverses critiques émanant de la doctrine (321). En effet, la nature et l'étendue de ce droit ne sont pas bien définies.

Si c'était un droit particulier de la personnalité protégeant le libre développement de celle-ci dans son activité lucrative, on aurait

(318) BGHZ 8, 142;36, 18.

(319) BGHZ 24, 205.

(320) NJW, 61, 1925

(321) Cf. Larenz, t. If (7 éd;) pp. $423-424$; Esser, p. 849; Schultz, NJW, 1963, pp. 1802 et sv. D'un avis contraire: Schippel, Das Recht an eingerichteten und ausgeübten Gewerbebetrieb, 1956, p. 2. 
dû alors protéger aussi l'activité professionnelie non commerciale d'un médecin praticien (322) ou d'un avocat. On pourrait se demander par exemple, si un médecin a la faculté d'intenter une action en dommages - intérêts contre celui qui a répandu le bruit qu'il appliquait un traitement qui n'est pas encore suffisammeni éprouvé selon l'avis de ses confrères? Or, ce n'est pas l'activité lucrative et professionnelle comme telle, mais l'activité d'une en treprise organisée qui est protégée par le droit en question. Donc, l'intérêt du chef d'entreprise au développement de sa personnalité occupe une place secondaire en face de l'intérêt patrimonial qu'il a à faire travailler le capital investi et à le voir protégé contre les dépréciations provenant de la cessation ou de la limitation de l'exploitation. Il serait ainsi plus exact peut - être de qualifier le droit à l'exploitation d'une entreprise de droit patrimonial ayant pour objet l'activité non troublée de l'entreprise (323). Ce droit serait un droit absolu assurant un domaine d'activité exclusive d̀ son titulaire, dans les limites légales, notamment celles concernant la concurrence. Or, selon certains auteurs (324), un tei droit accordant aux individus un domaine fixe d'activité, protégé par les actions en défense et en dommages - intérêts, irait à l'encontre des principas fondamentaux d'une économie dirigée vers la libre concurrence (Marktwirtschaft). D'autant plus que les limites du droit à l'exploitation ne sont pas bien précises; la reconnaissance de ce droit équivaut à l'admission d'une nouvelie clause générale (325). Les essais de la jurisprudence pour lui tracer certaines

(322) La cabine de consultations d'un médecin n'est pas' considérée comme une entreprise commerciale, à moins qu'il ne s'agisse d'une clinique privée (OLG Karlsruhe, NJV, 1964, 2374).

(323) Dans ce sens Larenz, t. II (7e éd.), p. 421; Brecher, Das Unternehmen als Rechtsgegenstand, 1953, pp. 130 et sv.

(324) Esser, p. 849; Raiser, JZ, 1961, p. 469.

(325) Larenz, t. Ir, p. 424. Selon iSchultz (NJW, 1953, pp. 1802 et sv.), en reconnaissant le droit à l'exploitation d'une entreprise, on substitue au principe de la liberté d'action en vertu duquel tout acte qui n'est pas défendu est permis, le principé de l'interdiction selon lequel tout acte qui n'est pas autorisé est défendu; mis celı n'est pas compatible avec le droit en vigueur qui est basé sur le principe de la liberté d'action, n'ayant ses limites que dans l'ordre juridique conforme à la Constitution ainsi que dans les bonnes mœurs et dans les droits dcs autres; les intérêts qui ne sont pas érigés en droits subjectifs ne doivent pas étre protégés. 
limites en recourant à la notion d'atteinte directe et à l'appréciation des biens et intérêts en question dans chaque cas particulier ne paraissent pas suffisants. Comme le démontrent les problèmes résultant des tests comparatifs de divers produits, il faut encore poser des limites déduites d'une économie basée sur la libr' concurrence (326). Esser est d'avis (327) que seules les diverses formes spéciales sous lesquelles se manifeste le droit à l'exploitation d'une entreprise, doivent être protégées contre les atteintes illicites en qualité de droits particuliers.

En Suisse, la doctrine mentionne parmi les droits de la personnalité, le droit au libre exercice d'une activité économique ou le droit à l'exercice non troublé d'une industrie (328). Quant au Tribunal fédéral, il a reconnu de tout temps que chacun possède le droit de faire respecter et de mettre en valeur sa personnalité dans les rapports économiques, en d'autres termes, de laisser s'épanouir sa personnalité économique (329). Ce droit ne sembie pas être limité comme en droit allemand à l'exploitation d'une entreprisc: organisée; il s'étend également à d'autres activités économiqusis. Par contre, en droit suisse, la protection de ce droit contre les non concurrents ne paraît pas être aussi étendue qu'en drcit allemand $(330)$.

Le Tribunal fédéral déduit le droit au libre exercice de la personnalité dans la vie économique, de la liberté du commerce et de l'industrie garantie par la Constitution fédérale (art. 31) et des dispositions du $\mathrm{CC}$ destinées à la protection de la personnalitê (331). Cette jurisprudence s'est déveioppée surtout en matičre

(326) Larenz, t. II, p. 424.

(327) P. 849.

(328) Cí. K. Specker, Die Persönlichkeitsrechte thèse de Zürich 1911, pp $80-81$; M. Regamey, La protection de la personnalité en droit civil. thèse de Laussanne, 1920 pp. 24-25; Egger, Kommentar, 2e éd, ar'. 28, nos. 63 et sv.; Simonius, Travaux de l'Association Henri Capitant, II. 1947 , pp. 307,308 ; von Tuhr, t. I. p. 328 .

(329) Cf. ATF 86 II 365 ou JdT, 1961, pp. 172 - 173 (l'arrêt Giesbrecht c. Vertglas du 20 dés. 1960), où l'on peut trouver une liste des arî́:s du Tribunal fédéral qui reconnaissent ce droit.

(330) V. Supra notes 292 et le texte relatif aux notes 309 et 320.

(331) JdT 1961, p. 173. 
de boycottage. Selon le Tribunal fédéral (332), «celui qui, par des mesures collectives, se propose d'empêcher durablement ou temporairement, autrui de prendre part au jeu de la libre concurrence ou qui met des entraves à cette compétition, ou encore qui impose au concurrent les conditions de sa participation, celui - là porte atteinte aux intérêts personnels de cet individu et à son droit à la liberté du commerce et de l'industrie. Mais cette liberté ne lui confère pas le droit à une existence économique assuréa (333); elle ne le protège point contre les conséquences d'une compétition économique qui se déroule selon régles de ia bonne foi, où il se heurte scit à un autre compétiteur, soit à un ensemb!e de concurrents». Tant dans le derni=r état de la jurisprudence que d'après la nouvelle Lol sur les cartels «le boycott est illicite parce qu'il viole le droit du lésé au libre exercice de sa personnalité dans la vie économique. Mais le refus d'entretenir de relations d'affaires, même s'il a sa cause dans une convention, n'est pas déjà en soi inadmissible; il ne l'est que dans la mesure où il prive un tiers de la possibilité d'exercer une activité normale, en supprimant sa liberté économique ou en la limitant d'une maniére excessive; une telle atteinte exige, de par sa nature même, une certaine intensité, une entrave «notable» à l'activité économique» (334). Le Tribunal fédéral a voulu ainsi restreindre la portée de sa jurisprudence qui admet en principe l'iilicéité de tout boycott (335), en posant la condition du caractère notable de l'atteinte. Il recourt d'autre part, à l'instar du BGH, à l'appréciation des biens et intérêts en présence pcur déterminer

(332) JdT 1961, p. 373.

(333) ATF 5i2 II 383 ou JdT 1927, p. 258.

(334) JdT 1965, p. 377.

(335) Avant le changement de sa jurispruderce en 1960 par l'ariêt «Giesbrecht c. Verglas», selon. le Tribunal fédéral le boycottage était en soi un moyen de combat licite dans la lutte pour la vie économique; il ne devenait illicite ou immoral que si le but qu'il se proposait ou les moyens qu'il employait étaient contraires au droit ou aux mœurs; ou encore lorsqu'il y avait une disproportion évidente entre l'étendue du dommage causé et l'importance du but visé». Cf. à ce sujet la note de jurisprudence d'E. Thilo dans le JdT. 194Q. pp. 98 et sv. Le TF a déclaré illicites, comme le BGH l'a fait aussi, les boycotts employés comme moyen de contrainte pour atteindre des buts non économiques, notamment pour parvenir à des fins politiques (cf. ATF 54 II 146 ou JdT 1928, p. 516). 
l'illicéité d'un boycott, en énonçant les considérants suivants (336): «Le juge doit décider dans cas chaque cas particulier lequel des äroits de la personnalité qui s'affrontent (337) prévaut selon l'ordre juridique établi. Ce faisant, il sera amené à paser les itotérêts protégés en présence... Les intérêts économiquement plus importants ne sont d'ailleurs pas toujours décisives. Le boycotteur n'agit pas licitement aussitôt que les avantages recherchés par lui l'emportent sur le dommage qu'il inflige au boycotté. Celui - là sell qui se propose de servir par le boycottage des intérêts bien fondés, n'agit pas illicitement s'il ne peut les sauvegarder d'une autre $\mathrm{ma}^{-}$ nière».

Comme on peut ie constater dans la jurisprudence, le droit à libre mise en valeur de la personnalité dans la vie économique ne tend pas à assurer un monopole à son titulaire. Ainsi le Tribunal fédéral a déclaré que (338), «toute position à laquelle quelqu'un est arrivé en exerçant son activité commerciale, ne jouit pas d'une protection juridique. Chacun doit supporter les préjudices subis dans l'exploitation de son entreprise organisée, tant qu'ils ne résuitent pas des actes de ses concurrents ou d'autres personnes, qui sont défendus par les lois spéciales régissant catte matière. Cela réside dans la nature des choses. Exercer une activité commerciale signifie l'aspiration aux résultats qui peuvent être volatilisés par l'activité du même genre des autres personnes».

En France, c'est le droit de propriété incorporelle sur un fonds de commerce (339) qui correspond dans une certaine mesure à la notion germanique du droit à l'exploitation d'une entre. prise organisée. A la différence des systèmes juridiques allemardミ et suisse, ce n'est pas un droit particulier de la personnalité, mais tin droit puremsnt patrimonial (340). Selon Ripert (341), «la propriété

(336) JdT, 1961, pp. $174-175$.

(337) II s'agit du droit à la libertẻ des conventions et à celle des associations du boycotteur et du droit au libre exercice de l'activité économique du lésé.

(338) GRUR 1963, p. 270. Cf. Aussi supra le texte relatif à la note 333.

(339) D'après Ripert - Durand - Roblot (Traité élémentaire de droit commercial 4 e éd. Paris 1959 , no, 454), cette propriété ne se conserve que par l'exploitation.

(340) Ripert. Durand-Roblot, no. 453.

(341) No. 453. 
sur le fonds de commerce est en réalité un droit de clientèle.. Le commerçant n'a pas le droit exclusif d'exploiter une clientèle pulsqu'il n'a pas de monopole et qu'il est toujours exposé à voir la clientèle se détourner de lui. Mais en fait il détient des élements qui lui permettent de compter sur le maintien d'une clientèle et éventuellement sur son développement». Ripert (342) reconnaît une action en concurrence déloyale de nature réelle au propriétaire du fonds pour défendre ce fonds contre toute personne qui troublerait l'exercice de son commerce et détournerait sa clientèle. Il est d'avis «qu'il ne faut pas considérer seulement cette action comme une forme de l'action en responsabilité délictuelle». Or, Ripert ne parle pas d'une action en dommages - intérêts qui résulterait d'une atteinte illicite au droit de propriété sur le fonds de commerce. Il semble qu'en l'état actuel du droit français', pour la réparation des préjudices subis dans l'exploitation d'un fonds, on se contente de recourir à une action en dommages -intérêts fondée sur un acte de concurrence illicite (343), sans rechercher s'il ya une atteinte illicite au droit de propriété sur le fonds de commerce. C'est la formule générale de l'art. 1382 du CC français qui permet peut-être aux juristes français de se dispenser d'une telle recherche.

39. Droit à la place de travail (Recht am Arbeitsplatz.) Le. droit à la place de travail est une notion créée et soutenue par une partie de la doctrine allemande (344) et ne semble pas ancore trouver la faveur de la jurisprudence. D'ailieurs, dans la doctrine aussi l'existence et la nature de ce droit sont très controversées. Même ceux qui reconnaissent un tel droit, ne sont pas unanimément d'accord, lorsqu'il s'agit de la définir. Selon certains

(342) No. 455 .

(343) Cf. Savatier, Traité de responsabilité civile, nos. 48 et sv., en particuliex pour le boycott (la mise à l'index) nos. 58 et 64 .

(344) Cf. Fabricius, ACP, 1961, pp. 305 et sv.; Hedemann, Der Arbeitsplat: als Rechtgut, RdA 1953 pp. 121 et sv.; Herschel. Die Betriebszug hörigkeit als geschütztes Rechtsgut, RdA, 1960, pp. 121 et sv.; Nip perdey dans Hueck - Nipperdey, Lehrbuch des Arbeitsrechts, 6e éd. 1957 , t. II. pp. 120 , 634 et sv.

Forma : 25 
auteurs (345), c'est un droit relatif à l'ensemble du domaine d'activité affecté à l'employé dans l'exploitation, avec tous les droits ei devoirs qui en découlent. D'autres (346) le définissent comme un droit fondé sur un contrat de travail valable, conférant la prétentioni d'appartenir à l'exploitation et d'exercer une activité conforme à cette appartenance.

Le droit à la place de travail est reputé être l'un des autres droits sonstige $R$ echte prévus par le $\S 823$ al. 1 du BGB (347). On veut accorder ainsi une protection aux employés et ouvriers qui travaillent dans une entreprise, contre la cessation de l'exploitation et contre la perte de leurs places. Ce droit constituerait dans un certain sens le corollaire au droit à l'exploitation du chef d'en.. treprise. On cite comme exemples (348) des atteintes illicites au drcit à la place de travail un lock-out socialement inadéquat, certains cas de congé donné par l'employeur (349), le fait d'empêcher ceux qui veulent travailler pendant une grève, incendies provoquées par l'employeur, par un autre employé ou par un tiers et entraînant la cessation de l'exploitation.

Les auteurs qui s'opposent à l'admission d'un droit à la plèe de travail (350) déclarent que la place de travail n'est autre en récilité que la position de l'employé qui découie du rapport contractuel

(345) Molitor, Grund und Grenzen des Weisungsrechts, RdA 1959, p. 7.

(346) Hueck - Nipperdey, t, II, p. 637, note 26. Selon Fabricius (p. 307) la place de travail est le domaine d'acivité affecté dans l'exploitation à un employé, se rapportant d'une façon objective à l'organisation de l'exploitation et fixé normalement du point de vue de la fonction $f i$ de l'espace, par un contrat de travail, avec les droits et les devoirs qui en découlent.

(347) Cf. les auteurs cités supra à la note 344.

(348) Cf. Fabricius p. 312 , note 133 ; p. 314 , note 156 ; p. 315

(349) Selon l'opinion dominante les congès injustifiés étant réglementés exclusivement par la Loi sur la protection contre le congé, l'employé congédié d'une manière socialement injustifiée ne peut pas intenter une action en dommages - intérêts contre l'employeur en invoquant le $\S 823$ al. 1 du BGB pour la protection de son droit à la place de travail. Four plus de détails cf. Fabricius, pp. 3110 - 314 .

(350) Nikisch, Arbeitsrecht, 2e éd. 1959, t. II, p, 127; Hueck dans Huecl Nipperdey, Lehrbuch des Arbeitsrechts 6e éd 1959, t I, p. 348 noto 3 et. les autres auteurs cités par Fabricius. à la page 275 , note 6 . 
de travail. Or, ce droit, étant ainsi un droit relatif, ne peut pas se ranger parmi les autres droits du $\S 823$ al. 1 du BGB.

D'autre part, on émet des doutes sur la nature non patrimonial du droit à la place de travail (351) ; ce droit semble servir plutôt les intérêts patrimoniaux de l'employé que le développement de sa personnalité dans la vie économique or, la protection directe des intérêts patrimoniaux, sans qu'une norme légale protectrice soit violée (dans le sens du $\S 823$ al. 2 du BGB) serait contraire à l'intention déclarée du législateur.

En droit suisse, on mentionne (352) parmi les droits de la personnalité, un droit à la liberté de travail dont le contenu n'est pas très précis et ne correspond pas tout à fait au droit à la place de travail. On trouve chez certains auteurs (353) des passages relatifs à la notion du droit pour les ouvriers à la mise en valeur non troublée de leur force de travail, qui peut être lésé par un lock-out ou par des postes de surveillance de grève.

En droit français, on rencontre dans certains ouvrages la notion du droit au travail, considéré comme un droit de la personnalité et défini comme le droit d'exercer une activité professionneile permettant d'obtenir les moy'ns de vivre (354). Mais on ne trouve pas de cas d'application de ce drcit analogues aux exen:ples donnés par les juristes allemands, exepté peut-être dans certaines restrictions apportées au droit patronal de licenciement individuel ou collectif pour des causes de suspension tenant a

(351) Esser, p. 849.

(352) Egger, art. 28, no. 28; Regamey, p. 25.

(353) Specker, pp. $80-81$.

(354) Marty-Raynaud, Droit civil, t. I, no. $332 / 3$, p. 483 . Cf, aussi Camerlynck-iGl. Lyon-Cien, Précis de droit du travail, Paris 1965, nos. 70 et sv.. pp. 61 et sv. Selon ces derniers auteurs, le droit au travail signifie d'une part, le droit d'obtenir un emploi dirigé vers l'Etat; d'autre part, il oblige l'employeur dans une certaine mesure de ga. rantir la stabilité du travailleur. Nerson (Les droits extrapatrinioniaux p. 305) paraît être opposé à l'admission d'un droit au travail comme un droit subjectif privé-Le droit au travail faisait l'objet de l'un des colloques du 5 ème Congrès international de droit comparé, tenu à Upsala en Août 1966. 
l'entreprise et ouvrant droit aux dommages-intérêts; mais cette action semble être de nature contractuelle (355).

40. Protection de certaines situations juridiques relevant du droit de la famille: a) Droit de puissance paternelle. - Le droit des parents découlant de la puissance paternelle (ou de la puissance parentale comme on dit en allemand: (die elterliche Gewalt) est considéré par la jurisprudence (356) et par la doctrine (357) allemandes comme un autre droit absolu protégé par le $\S 823$ al. $1 \mathrm{du}$ BGB. Il n'ya a pas de doute qu'une violation de ce droit peut consister, par exemple, dans la détention de l'enfant par les tier. ou dans les interventions injustifiées de ceux-ci au droit des parents de donner l'éducation nécessaire à leurs enfants. Ainsi, le Tribunal supérieur de Cologne (358) a jugé comme une violation de ce droit d'éducation tout commerce d'un homme contre la volonté des parents avec leur fille mineur. Toutefois, une action tendant à défendre au tiers d'avoir des relations avec la fille mineur n'est admissible que si cette défense repose sur des causes objectives et bien fondées (359). Il n'en est pas ainsi, lorsqu'une jeune fille qui approche l'âge de sa majorité est résolue, après ses vingt et un ans accomplis, à épouser un homme contre la volonté de ses parents. D'autre part, le fait de causer des dépenses aux parents en provoquant des lésions corporelles à leur enfant ne constitue pas une atteinte à leur droit de garde (Sorgerecht); on n'approuve pas ainsi dans la doctrine (360) une décision du Tribunal de Bremen (361), d'après laquelle les frais de voyage et d'hôtel effectués par les parents pour visiter leur enfant à l'hôpital où il a été transporté après un accident, devaient être remboursés comme le résultat d'ure atteinte illicite au droit de garde; or, comme on le remarque avec raison, ni la nécessité de faire des dépenses n'empêche les parents d'exercer leur droit de garde, ni mêmes les lésions provoquées chez

\footnotetext{
(355) Cf. Camerlynck - G. Lyon - Caen, pp. 62-63 et 114.

(356) Cf. RG dâns JW, 13, 202; 25377 et les arrêts des tribunaux d'instance cités infra aux notes $358,359$.

(357) Larenz, t. II (7e éd.) p. 411; Esser, p. 845; Fabricius. p. 301.

(358) Monatsschrift für Deutsches Recht (MDR) 63, 594.

(359) OLG Koblenz, NJW, 1958, pp. $951-952$.

(360) Larenz, t. II (7e éd.), p. 411.

(361) MDR 61, 599.
} 
l'enfant ne constituent une violation de ce droit. Le BGH (362) considère ce genre de dépenses comme faisant partie du dommage subi par l'enfant lui-même.

En droit suisse, on parle de l'existence d'un droit particulier de la personnalité des parents découlant du rapport de parenté, un droit tendant à développer leur personnalité dans leurs relations avec leurs enfants (363). Les parents peuvent intenter une action en dommages-intérêts contre les personnes qui retiennent l'enfant sans y être autorisées (364). Une action qui tend à faire interdire à un tiers d'avoir avec l'enfant mineur des rapports personnels est possible (365).

En droit français, les parents, en invoquant leur droit de garde, peuvent réclamer des dommages-intérêts à la personne qui a détourné l'enfant (366) et faire condamner celle-ci à une astreinte pour la forcer à restitution. D'autre part, en exerçant son droit de contrôie, le père peut agir en dommages-intérêts contre l'instituteur de son enfant, qui a violé la neutralité religieuse ou qui a tenu de propos contraires aux mœurs ou aux convenances (367). Enfin, les parents ont le droit de régler comme ils l'entendent les relations de leurs enfants et de leur interdire de fréquenter telle ou telle personne (368); mais dans les ouvrages français on $n$ : rencontre pas de décisions qui défendent, sous astreinte, d'entrutenir des relations avec l'enfant.

42. b) Droit au maintien non troublé de l'union conjugale. Un autre droit, relevant du droit de la famille, que l'on veut protéger en se fondant sur le $\S 823$ al. 1 du BGB, est le droit de chacun des époux au maintien non troublé de l'union conjugale (Recht jedes Ehegatten auf ungestörten Fortsbestand der Ehe). La question de savoir si l'on doit reconnaître un tel droit de nature absolue est très

(362) Vers. R. 61, 272; 64, 532,

(363) Cf. Egger. Familienrecht, 2e éd. Zurich 1943, art. 273, no. 7; ATF 4 ? II 151.

(364) Egger, art. 273, no. 12.

(365) Egger, art. 275, no. 5.

(366) Nancy, 25 janv. 1873, D. 73.2.11; Planiol-Ripert-Savatier, Traité Pratique no. 331 et note 3 à la p. 408 .

(367) Planiol-Ripert-Savatier, no. 336.

(368) Planiol-Ripert-Savatier, no. 337. 
controversée en droit allemand. Certains auteurs (369) sont d'avis que le mariage denne lieu à des devoirs strictement personnels qui ne peuvent pas être violés par des tiers; par conséquent, les droits qui en découlent ont un caractère relatif comme les droits de creance. D'autres (370) soutiennent que la position juridique ( $R$ e chtsposition) des époux devrait être protégée également contre les tier:s, même si elle ne faisait pas l'objet d'un droit subjectif. Quelques - uns (371) vont encore pius loin et reconnaissent à chacun des époux un droit subjectif de nature absolue (372), au maintien non troublé de l'union conjugale; ce droit est déduit du droit général de ia personnalité et de l'art. 6 al. 1 de la Constitution qui prévoit la protection du mariage et de la famille.

Même parmi ceux qui affirment l'existence du droit en question, il règne des divergences de vue sur les effets de sa violation. Ainsi selon une partie de ces auteurs (373), l'époux qui subit un dom. mage matériel par suite de troubles causés à sa vie conjugale ne saurait intenter une action en dommages - intérêts ni contre son conjoint. - fautif, ni contre le tiers complice de celui - ci; car une pareille action serait contraire à la nature morale du mariage. Une autre catégorie de juristes (374) admet une action en dommages - intérêts seulement contre le tiers, sans l'admettre pourtant contre le conjoint fautif. Conformément à une autre opinion (375), l'action en indemni .

(369) Von Tuhr, Allgemener Teil des Deutschen Bürgerlichen Recht: t. I, 1914, p. 145; Enneccerus-Lehmann. Schuldrecht, 15e éd. 1958, p. 942; Berg, Ehestörungsklage und Schadenersatzansprüche wegen Ehestörung JuS 1961, pp. 137 et sv.

(370) Beitzke, Familienrecht, 9e éd. 1960, p. 47; Bosch, Fam RZ 5 (1958), pp. 101 et sv.; Esser, p. 845.

(371) Coing. JZ, 1952, p. 690; Boehmer, Zur Ehestörungsklage, ACP 1956, pp. 181 et sv., en particulier pp. 200 _ 201; Larenz, t. II (7e éd.), p. 411; Fabricius, ACP, 1961, pp. 316 et sv.; H. Lehmann, Deutsches Familienrecht, 3e éd. 1960, p. 69; Staudinger-Engelmann, Komm. 9: éd. p. 1775; Planck - Flad, Komm. 4e éd. 1928, p. 1718.

(372) Il y a également des juristes qui parlent du caractère mixte, présentant des aspects absolu et relatif du droit en question: K. H. Schwab, NJW, 1956 p. 1150; Magis, Schadenersatz und Unterlassungsanspruch bei Verletzung der ehelichen Treue, thèse de Bonn 1935, pp. $13-25$.

(373) Tels que Staudinger-Engelmann, Planck-Flad, Lehmann.

(374) K.H. Schwab, op. cit.

(375) Boehmer, p. 190, Beitzke et Bosch. 
té droit être accordée sans réserve contre le tiers, et seulement apris la dissolution du mariage contre le conjoint fautif. Enfin, l'avis a été aussi soutenu (376) qu'une indemnité pouvait être exigée même du conjoint fautif pendant la durée du mariage.

Dans la doctrine on a essayé de déterminer le contenu du droit au maintien non troublé de l'union conjugale et les atteintes à ce droit qui peuvent être illicites (377). A cette fin, on a pris comme point de départ, deux exigences qui ressortent de l'union conjugale, la première étant l'exclusivité du domaine sexuel et la seconde la nécessité de vivre en commun. Ainsi les tiers peuvent porter atteinte au droit en question, en ayant des relations adultères ou analogues à celles - ci avec l'un des époux ou en empêchant ou interron;pant la vie en commun d'une manière illicite, par exemple en enlevant l'un des conjoints. On cite comme exemples pratiques du dommage matériel dont on peut demander la réparation au moyen d'une action fondée sur la violation du droit au maintien non troublé de l'union conjugale, les cas suivants (378): Les frais médicaux occasionnés à l'époux trompé par une maladie due aux vexations qu'il a subies ou qu'il a contractée du fait des relations douteuses de son épouse, les frais du procès de divorce ou du procès concernant le désaveu de l'enfant dont le tiers est le père (379) (379a). Le dommage du mari peut consister aussi dans le fait qu'iì a été privé des services

(376) Par Fabricius, p. 334.

(377) Gf. Fabricius, pp. 321 et sv.

(378) Cf. Boehmer, ACP 1956, pp. 187 st 193.

(379) Cf. OLG Oldenburg, MDR 1953, p. 170, no. 108; OLG Hamm, JZ 1953, pp. 757 et sv. qui admettent une telle demande. Par contre. le RG avait nié (RGZ, 72, 132) l'existence d'un rapport de causalité adéquate entre le trouble apporté au mariage et fes dommages de ce genre; car, ll estimait que l'époux trompé avait subi ces dommages en intentant de son propre gré les procès en question.

(379a) Pour les frais d'accouchement le BGH reconnât (BGHZ, 26, 220) à l'époux qui désavoue l'enfant une action en pajement de l'indú contre le véritable père (BGB $\$ 812$ ). Quant aux frais d'entretien de l'tnfant, ils peuvent être réclamés à son véritable père en appliqua:t par analogie le $\S \mathbf{1 7 0 9}$ al. 2 du BGB qui réglemente le droit de recours de la mère et des parents de cette dernière qui ont entretenu l'enfant illégitime (BGHZ 24, 9; 26, 218). 
de sa femme ou qu'il a été obligé d'engager un détective pour obtenir les preuves nécessaires $(380)$.

Quant à l'état de la jurisprudence allemande en ce qui concerne l'admissibilité d'une action en dommages - intérêts pour ies troubles apportés à l'union conjugale, bien que certains tribunaux d'instance (381) reconnaissent une telle action, le BGH la refuse (382) constamment. La Cour fédérale motive sa jurisprudence par le caractère relatif des rapports conjugaux, par la nature morale des devoirs résultant du mariage et par le fait que les effets de la violation de ces devoirs sont réglementés d'une façon exclusive par les dispositions du droit de la famille. Or, comme on le démontre dans la doctrine (383), ces arguments ne résistent pas à un examen sérieux. En effet, on admet aujourd'hui généralement que l'union conjugale doit être protégée également contre les atteintes des tiers (384). D'autre part, la violation des devoirs moraux peut entraîner parfois des préjudices patrimoniaux. En outre, l'affaiblissement du respect pour les valeurs morales que l'on constate de nos jours, nécessite la substitution des sanctions juridiques aux sanctions morales (385). Enfin; la réglementation exclusive du droit de la famille vise seulement les rapports internes des époux; le tiers qui porte atteinte à l'union conjugale ne doit pas pouvoir bénéficier de cette réglementation pour échapper au paiement des dommages - intérêts (386). Mème selon les auteurs (387) qui sont

(380) OLG Wien, Fam RZ 1955, pp. $177-178$.

(381) Cf. les décisions des tribunaux d'instance citées supra aux notes 379 et 380 et OLG Celle Fam RZ 64, 366

(382) BGHZ, 23, 215, 281; 25, 211.

(383) Cf. Boehmer, ACP 1956, pp: 188-194; Fabricius, ACP 1961, pp. 322 - 335; Larenz, t. II ( 7 e éd.) pp. $410-411$.

(384) D'ailleurs le RG ( $R G Z, 71,88 ; 72,130 ; 151,164$ ) avait souscrit à la conception absolue du mariage. Le BGH avait admis aussi à l'occasion d'une action en cessation du trouble (BGHZ, 6, pp. 365 et sv.) l'existence d'un domaine de la vie conjugale devant être protégé d'une manière absolue, également contre les atteintes des tiers; mais ce domaine était restreint au domicile conjugale. $V$. infra note 393 .

(385) Cf. Fabricius, ACF 1961, p. 328.

(386) Boehmer, ACP 1955, pp. 190, 192.

(387) Comme Fabricius, ACF 1961, pp. 329 et sv. 
partisans d'une action en indemnité contre l'époux fautif pendant le mariage, la réglementation du droit de la famille n'exclut pas tout a fait l'application des règles de la responsabilité civile entre les époux; à leur avis, puisqu'un époux peut demander des dommages - intérêts pour lésions corporelles causées par son conjoint pourquoi ne pās lui reconnaître le même droit en cas de toubles apportés à l'union conjugale (338). En dehors de toute cette argumentation que nous venons de reproduire, Esser (389) indique une autre direction pcur la solution du problème de la réparation des dommages résultant des troubles apportés à l'union conjugale; selon lui, cette solution doit êtra recherchée dans le rapport de l'illicéité; en d'autres termes, on doit examiner si le but des dispositions du Code pénal concernant l'adultère ou de l'art. 6 al. 1 de la Constitution fédérale pro. tégeant l'union conjugale visent également la réparation des dommages dont il s'agit et on doit déterminer ainsi les domaines respectifs du droit de la famille et des règles du droit des obligations concernant la responsabilité civile.

Du point de vue pratique, la reconnaissance d'une action en réparation morale et d'une action en cessation de trouble présente plus d'intérêt que l'admission d'une action en réparation du dorimage matériel, en cas de troubles apportés à la vie conjugale. Comme nous l'avons souligné plus haut (390), le § 847 du BGB limite la réparation morale seulement aux cas d'atteintes portées à certains biens personnels. Bien que le BGH ait étendu dans ces dernières années le domaine de la réparation morale aux autres violations du droit général de la personnalité, il n'admet pas un droit particulier de la personnalité au maintien non troubié de l'union conjugale (391). Toutefois, on constate dans la doctrine (392) une

(388) Selon Boehmer (p. 191), tant que le lien conjugal n'est pas dissoris de telles actions en dommages - intérets ne sont pas admissibles.

(389) P. 846.

(390) Cf. supra no. 30 .

('391) Cf. toutefois BGHZ 6, 360. V. supra note 384 .

(392) Cf. Boehmer, ACP 1956, pp. 198 et sv. D'un avis contraire Larenz, t. II (7e éd.) p. 411, note 1; Gernhuber, Lehrbuch des Familienrèchts, $\S 17, \mathrm{I}, \mathbf{3}$ 
tendance à accorder la réparation morale également pour les troubles apportés à la vie conjugale; comme fondement de cette réparation, on préconise ou bien de considérer le maintien non troublé de la vie conjugaie comme un aspect du droit général de la. personnalité, voire comme un droit particulier de la personnalité, ou bien de reconnaître dans la liaison entretenue avec le tiers une atteinte au droit à l'honneur de l'époux trompé.

Une action en cessation du trouble (Ehestörungsklage) tendant à interdire les relations contraires au devoir de fidélité que l'un des époux entretient avec un tiers a été refusé par le RG (393), aussi bien contre le conjoint fautif que contre le tiers complice. Les motifs de ce refus étaient les mêmes que ceux qui étaient avancés contre l'action en dommages - intérêts. Par contre, les tribunaux d'instance (394) et le BGH (395) ont approuvé une action en cessation du trouble, lorsque le trouble ne concernait pas sieulement les rapports personnels des époux, mais atteignait les locaux où se déroulait la vie conjugale (raeumlich - gegenstandlicher Bereich des ehelichen Lebens); en d'autres termes, ces tribunais ont décidé que surtout la femme pouvait demander l'éloignement de la concubine de son mari, du domicile conjugal ou du bureau ou du m:gasin annexes. Les décisions en question étaient fondées sur le besoin de protéger la situation de la femme comme maîtresse et dirigeante de ia maison. Le BGH considérait (396) l'introduction de la concubine dans la maison familiale comme une atteinte grave à l'honneur et à la dignité de l'épouse, lésant l'épanouissement de sa personnalité auquel sont destinés le mariage et la famille et la bles sant ainsi au cceur de son existence morale et sociale. Selon le BGH (397), l'épouse peut également demander l'expulsion d'une gouvernante reçue à ia maison contre sa volonté, lorsque cette gouver-

(393) RGE 71, 85 et sv.; 151, 160 et sv.

(394) Cf. les décisions citées par Boehmer à la p. 202 note 81 .

(395) BGHZ 6, 360 et sv.

(396) BGHZ 6, 365.

(397) Fam RZ 1956, p. 50. 
nante, par son comportement, porte gravement atteinte à la dignité dans sa qualité de maîtresse de maison.

La jurisprudence du BGH qui limite l'action en cessation da trouble seulement aux cas où le mari emmène une autre femme au domicile conjugal, a attiré les critiques de la doctrine (398). Car, le mari peut très bien avoir des relations coupables graves avec une tierce personne même en dehors du domicile conjugal. D'autre part, cette jurisprudence semble protéger seulement la femme contre la concubine de son mari, mais laisse le mari sans protection contre le: agissements de sa femme qui ébranlent les fondements de l'union conjugale. On reproche encore à cette jurisprudence de transporter les principes qui régissent les rappcrts internes des époux au rapport externe qui lie l'un de cæux - ci à un tiers. En effet, la restriction de la protection contre le tiers est motivée par le fait que le $\S 888$ al. 2 du Code de procédure civile exclut toute mesure d'exécution forcée pour obliger les époux à accomplir leurs devoirs personneis. Or, il est illogique que le tiers complice du conjoint infidèla puisse se prévaloir de cette disposition édictéa en vue de protéger l'union cor. jugale.

En droit suisse, selon le Tribunal fédéral (399), «le tiers qui entretient avec un époux des relations adultères ou contraires aux lois de mariage porte atteinte aux intérêts personnels de l'autro». Dans la doctrine on affirme (400) même l'existence d'un drnit particulier de la personnalité tendant au maintien non troublé de l'union conjugale. La jurisprudence (401) et la doctrine (402) sont

(398) Cf. Boehmer, ACP 1956, pp. $203-206$.

(399) ATF 78 II 289 ou JdT, 1953, p. 491.

(400) Cf. Egger Kommentar art. 28, no. 27; von Tuhr, p. 328 texte relatif à la note 39 ; Simonius, Travaux de l'Association Henri Capitant. $t$. II, 1947, p. 30\%, in fine.

(401) ATF 35 II 575; 43 II 309; 78 II 289: 84 II 329; Cour d'appel de Berne, SJZ, 23, 332; Trib. sup. de Zürich, SJZ, 24, 11.

(402) Grossen, ZSR, N.F. 79 (1960), p. 1C8a; W. Padruth, Die Ehestörungskla ge, thèse de Berne 1954, pp. 109 et sv.; Egger, art. 151, no. 11; IP. Lemp, Familienrecht, 1. Abt.: Das Eherecht, Berne 1963, art. 159, no. 18. 
unanimes à admettre que les troubles apportés au mariage peuvent donner lieu à une action en dommages - intérêts pour le dommage matériel et à une action en réparation du tort moral. Par cont:e, le Tribunal fédéral s'est prononcé (403) contre l'admissibilité d'une action en cessation du trouble en cette matière. Cett $€$ jurisprudence n'a pas trouve l'approbation d'une partie de la doctrine (404).

L'action en indemnité fondée sur les troubles causés à la vie conjugale na peut être intentée que contre le tiers, mais non contre le conjoint fautif (405). Il n'est pas permis de demander non plus une condamnation solidaire du conjoint fautif et du tiers; car, les mesures protectrices de l'union conjugale sont énumérées d'une façon restrictive par les articles 169 et sv. du CC suisse. En effet, d'après l'art. 169, lorsqu'un des époux néglige ses devoirs de famille ou expose son conjoint à péril, honte ou dommage, sur la demande de la partie lésée, le juge cherche à ramener l'époux coupable à ses devoirs et, s'il n'y réussit pas, prend les mesures prévues par la loi pour sauvegarder les intérêts de l'union conjugale. Or, parmi ces mesures, une condamnation en dommagesintérêts ou à la réparation morale ou à la cessation de tout commerce avec un tiers n'est pas mentionnée.

Les auteurs suisses donnent (406) des exemples semblables à ceux des juristes allemands en ce qui concerne les dommages matériels à réparer. Ils mentionnent notamment les dommages résultant de troubles causés à la santé de l'époux par l'infidélité de son conjoint et les préjudices qu'il éprouve par la diminution de son crédit. Dans une affaire intéressante le Tribunal fédéral a décidé (407) la réparation du dommage résultant pour l'époux trompé de la révocation d'une représentation que lui avait accordée la firme de son beau - père et de la rupture d'autres relations d’affaires qui la suivirent. Le Tribunal supérieur de Zurich (408)

(403) ATF 78 II 289 ou JdT, 1953, pp. 492 et sv.

(404) Cf. notamment Padrutt, pp. 138 et sv.; Lemp, art. 159, no. 18. D'un avis contraire Grossen, ZSR 1960, pp. 112a-114a

(405) Cf. Padrutt, p. 126.

(406) Cf. Padrutt, p. 130.

(407) ATF 43 II 314.

(408) SJZ, 24, 12. 
a tenu compte des fraîs de détective en calculant les dommages - in . térêts.

L'époux atteint dans ses intérêts personnels ne peut réclamer une somme d'argent à titre de réparation morale que si cela se justifie par la gravité particulière du préjudice et de la faute; tel n'est pas le cas lorsque l'union conjugale était déjà troublé dtpuis plusieurs années au moment de l'intervention du tiers et que celui - ci ne s'est pas comporté envers l'époux offensé d'une façon particuliêrement blessante (409). Suivant les circonstances, la réparation du tort moral peut être réclamée au tiers même en cas ù réconciliation des époux (410).

L'action qui vise à interdire tout ou partie des relations entre le tiers et le conjoint oublieux de ses devoirs paraît irrecevable au Tribunal fédéral (411); car, une action en abstention n'est admissible que si l'acte à interdire peut être suffisamment déterminè pour que le juge saisi d'une action pénale pour le délit d'insoumission puisse se rendre compte immédiatement s'il y a infraction à l'interdiction; or, il n'est pas possible au juge de circonscrire ave: précision les actes, qui en dehors de l'adultère, sont propres à troubler la paix du ménage. Toujours selon le Tribunal fédéral (412), «on pourrait, sans doute, déterminer clairement ce qui est interdit en défendant purement et simplement au défendeur d'avoir avec le conjoint du demandeur n'importe quel contact personnel... Mais de cette façon on risquerait d'étendre l'interdiction à des choses permises, car on ne saurait voir un acte contraire aux lois du mariage et par conséquent une atteinte aux intérêts personnels d'un époux dans n'importe quel rapport verbal ou écrit entre son conjoint et le tiers avec lequel il eut à un moment donné des relations irrégulières». Quant à l'action tenđant seulement à la prohibition de l'adultère, le Tribunal fédéral l'écarte (413), parce que l'art. 214 du Code pénal exprime l'intention du législateur d'exclure

(409) ATF 78 II 297 ou JdT 1953, pp. $496-498$.

(410) ATF 78 II 299 ou JdT 1953, p. 498; ATF 35 II 576; Tribunal supérieur de Zurich, SJZ, 24, 11.

(411) JdT, 1953, pp. $492-493$.

(412) JdT, 1953, p. 493.

(413) JdT 1953, p. 494. 
l'intervention des autorités judiciaires aussi longtemps que les époux vivent ensemble (414). D'ailleurs, indépendamment de cette considération, le Tribunal fédéral estime que (415) la réglemen. tation légaie de la protection de l'union conjugale (art. 169 et sv. CC) ne permet pas au juge de prendre des mesures non prévues par la loi; ainsi, selon le Tribunal fédéral, le juge ne paut pas, sous la menace de peines en cas d'infraction, faire défense à l'époux en faute de commettre de nouveaux adultères pas plus qu'à son con:plice. Or, ce raisonnement du Tribunal fédéral ne paraît pas être très exact (416). Car, les articles 169 et sv. ne visent en réalité que le rapport interne des époux. Au surplus, suivant le mêrne raisonnement on n'aurait pas dû accorder une action en réparation morale contre le tiers pendant la durée du mariage; pourtant, le Tribunal fédéral a décidé du contraire (417).

En droit français, d'après la jurisprudence (418) et la doctrine (419), le divorce et la séparation de corps ne constituent pas les seules sanctions du devoir de fidélité conjugale; il y a lieu d'accorder aussi, en se basant sur l'art. 1382 du CC, une indemnité pécuniaire à l'époux victime de la trahison de son conjoint (420). L'adultère étant un fait dommageable et fautif constitue un délit civil en même temps qu'un delit pénal (421). Les dommaiges - intérêts sont accordés au mari même lorsque l'adultère n'est pas établi et que la femme peut seulement se voir reprocher des relations com:-

(414) La peine prévue par cette disposition ne peut être infligée à l'époux adultère et à son complice que si l'adultère a conduit au divorce ou à la séparation de corps des époux.

(415) JdT 1953, pp. $495-496$.

(416) Cf. Padrutt, pp. 138 et sv. les auteurs cités supra à la note 404 .

(417) JdT, 1953, p. 498.

(418) Cf. les décisions citées par Planiol-Ripert-Rouast, "Traité pratique de droit civil français, t. II, 2e éd., Paris 1952 p. 269, note 1.

(419) Planiol - Ripert - Rouast, no. 346; J. Caillé, De l'action en dommages intérêts pour adultère, thèse de Rennes 1925; Demogue, Traité des obligations, t. IV, nos. 408 et 420 .

(420) En droit français on n'a pas besoin de créer un droit particulier de la personnalité servant à protéger l'union conjugale contre les trourle。 des tiers.

(421) Le mari peut etre condamné aux dommages -intérêts, même s'il n'd pas entretenu la concubine dans la maison conjugale et s'il ne peut pas par conséquent être poursuivi du point de vue pénal (art. 339 CC). Cf. Planicl, Ripert-Rouast, p. 270). 
promettantes ou scandaleuses (422). L'action en dommages - intérêts vise surtout la réparation du dommage moral (423); mais suivant l'opinion de certains auteurs (424), elle peut tendre aussi à la réparation du dommage matériel.

A la différence des droits allemand et suisse l'action en dommages - intrérêts peut être intentée aussi pendant la durée du mariage contre l'époux fautif ou contre celui - ci et le tiers complice, tenus solidairement responsables (425). En cas de pardon de l'é poux offensé, survenant après la constatation judiciaire de l'adultère et en cas de relations scandaleuses l'action peut être dirigíe seulement contre le tiers (426).

Les tribunaux français ont été très rarement saisis d'une demande ayant pour objet de faire ordonner au conjoint la cessation des relations coupables sous la menace d'une astreinte (427). On ne cite qu'un seule décision (428) faisant droit à une telle demande, bien que l'astreinte reste théoriquement possible pour sanctionner les devoirs de famille (429).

43. Protection des droits de créance contre les atteintes illicitcs des tiers. - Ainsi que nous l'avons exposé plus haut (430), selor. la doctrine dominante en Allamagne, les droits de créance restent en dehors des autres droits (sonstige Rechte) protégés par le $§ 823$

(422) Cf. Planiol - Ripert - Rouast, p. 270, note 1; Caillé, pp. 91 - 93.

(423) Planiol-Ripert-Rouast, pr 270 texte relatif à la note 2 .

1424) Marty-Raynaud, Droit civil, t. I, Paris 1961, p. 686; Padrutt, p. 75.

(425) Padrutt, pp. 78 et 86; Caillé, p. 125.

(426) Padrutt, pp. 79 - 81. En cas de pardon avant la constatation judiciaire de l'adultère, si on intentait l'action seulement contre le tiers, l'époux fautif, mais pardonné serait compromis, dans la société; ce qui sereit contraire au but de pardon. Tandis que, si l'adultère a été constaté ou si les relations scandaleuses ont eu lieu, l'époux fautif est déjà compromis aux yeux du public. (Padrutt, p. 81).

(427) Cf. Planiol-Ripert-Rouast, no 348; Grossen, ZSR 1960, pp. 110a-11la.

(4.28) Trib. Castel-Sarrazin, 8 avril 1864, D. 1846.3 .46 et 'Toulouse 29 juin 1864, D. 1864.2.174.

(429) Cf. P. Kayser, L'astreinte judiciaire et la responsabilité civile, Rev. trim de droit civil, 1953, pp. 209-246. Selon Padrutt (p. 84) une action en cessation est possible aussi contrei le tiers.

(430) Cf. supra les notes 46 et 177 , ainsi que les textes qui y sont relatifs. 
al. 1 (430a); car, ce ne sont pas des droits absolus, semblables au droit de propriété; ils ne peuvent être invoqués que contre le débiteur et ne sauraient être violés que par celui-ci, mais non par les tiers. En effet, les droits de créance assurent à leur titulaire une position juridique qui lui permet de demander au débiteur l'accomplissement d'une prestation déterminée. Ils ne sont pas des droits de maîtrise (431). Le créancier ne peut exercer aucune maîtrise sur la personne du débiteur, ni sur sa prestation, ni encore sur l'objet de cette prestation; il ne peut pas exiger d'un tiers qu'il accomplisse la prestation qui lui est due; c'est pourquoi un tiers n'a pas la possibilité de violer un droit de créance. Par contre, le débiteur peut se comporter d'une manière contraire à son obligation, par l'exécution tardive ou par la mauvaise exécution, ou enfin en rendant par sa faute l'exécution impossible. Mais les effets de ces différentes sortes d'inexécution sont réglementés par les $\S \$ 276$ at sv. du BGB. Par conséquent, il n'y a pas lieu de considérer l'inexécution d'une obligation comme la violation d'un autre droit au sens du $\S 823$ al. 1.

Toutefois, bien qu'un tiers ne puisse pas violer en principe le bien juridique qui attache le débiteur au créancier, il peut exercer une influence de fait sur le débiteur ou sur l'objet de la prestation (432). Il en est ainsi lorsque le tiers incite le débiteur d l'inexécution, ou lorsqu'il détruit ou endommage l'objet de la prestation. Dans de pareils cas, même selon la doctrine dominante, le créancier peut réclamer des dommages-iritérêts au tiers si les conditions du $\S 826$ ou celles du $\S 823$ ail. 2 sont réalisées (433). Le $\S 826$ est appliqué surtout dans les cas où on induit les $€$ mployés d'autrui à trahir la confiance de leur employeur (434) ou lorsqu'on accorde ou offre des avantages aux mandataires ou emplcyés d'un

(430a) L'affirmation de M. Weill ( $\mathrm{La}_{\text {a }}$ relativité des conventions en droit privé franłais. Paris 1939, p. 418, note 1) seion laquelle, «l'expressi: «tout autre droit» (sonstiges Recht) engloberait d'après la doctrine allemande les droits d'obligations» nous paraît trop généralisée.

(431). Cf. Larenz, t. II (7e éd.), pp. 409-410. D'un avis contraire von Tuhr. Allg. Teil, t. I, $\xi 6$.

(432) Cf. Fabricius, ACP 1961, p. 280.

(433) Cf. Esser, p. 845; Fabricius, ACP 1951, pp. 284-285 et 302; Groh, Sittenwidrige Erfüllungsvereitelung, dans Festgabe zum 50 jaehrigen Bestehen des Reichsgerichts, t. II, 1929, pp. $122-142$.

(434) Cf. RGZ 134,55. 
tiers pour les inciter à manquer à leur devoir (435). Quand de pareils actes tombent sous le coup d'une disposition pénale, il esi possible de recourir également au $\S 823$ al. 2 pour intenter une action en dommages - intérêts contre le tiers. Cette action peut être fondée parfois aussi sur certaines dispositions de la Loi concernant la concurrence déloyale. D'autre part, le créancier est autorisé à invoquer la violation de sa possession et à se prévaloir ainsi du $\S 823$ al. 1 (436), s'il se trouve en possession de l'objet (437) de l'obligation endommagé par le tiers (438).

Il existe aussi dans la doctrine des essais tendant dans une certaine mesure à faire bénéficier les droits de créance eux-mêmes, de la protection prévue au $\S 823$ al. 1 pour les autres droits. Ainsi. selon Larenz (438a) et quelques autres auteurs (439), il manque aux droits de créance une fonction d'exclusion par rapport à un objet; c'est la raison pour laquelle les interventions dommageables des tiers dans l'accomplissement de la prestation ne constituent pas une violation du droit de créancs; toutefois, dans certaines circonstances, il est possible pour un tiers d'intervenir par un acte de disposition dans la situation juridique du créancier en ce qui concerne l'appartenance de la créance à celui-ci. En effet, les droits de créance, comme tous les autres droits subjectifs, appartiennent nécessairement à une personne déterminée, de sorte que leur appartenance à toute autre personne est exclue. Dans ce sens, le créancier parle de «sa créance» (440). Ainsı, tout droit subjectif est exclusif du point de vue de son attribution à un sujet et présente un caractère

(435) Cf. BGH dans NJW, 1962, 1099.

(436) Cf. supra les notes $167-169$ et le texte qui y est relatif.

(437) Par exemple le locataire d'une chose.

(438) Cf. Fabricius, ACP 1961, p. 303.

(438a) T.I (7e éd.), § 29, III, pp. $341-342$; t. II (7e éd.), pp. $409-410$.

(439) Cf. Löbl. Die Geltendmachung fremder Forderungsrechte im eigenen Namen, ACP 129, 257 et sv., en particulier pp. 294 et sv.; von Caemmerer, Bereicherung und unerlaubte Handlung, dans Festschrift für Rabel, 1953, p. 355; Westermann, Lehrbuch des Sachenrechts, § 2, 1, 2, p. 8; Stoll, ACP 1962, p. 212.

(440) Certains auteurs comme Leonhard (Allgemeines Schuldrecht des BGB, 1929 , pp. 60 et sv.) vont jusqu'à qualifier cette appartenance de droit de propriété sur une créance. Contra Larenz, t. 1, p. 341.

Forma : 26 
absolu (441). Il est possible par conséquent de considérer la position juridique du créancier en ce qui concerne la compétence que lui confère son droit (Rechtszustaendigkeit) comme uı autre droit du $\S 823$ al. 1, protégé contre les atteintes non autorisées des tiers. En principe, un tiers ne saurait, en disposant de la créance d'autrui, porter atteinte au droit du créancier (442), car son acte de disposition est sans effet et laisse intacte le droit du créancier. Ainsi, le débiteur qui paye entre les mains d'un tiers (lequel se fait passer pour le créancier ou exhibe une fausse procuration) ne sera pas libéré par ce payement, malgré sa bonne foi. C'est seulement par exception qu'un tiers peut, en disposant sans droit d'une créance ou d'un papier - valeur éteindre le droit du créancier. Voici quelques exəmples de ces cas exceptionnels: Conformément aux $\S \S 407$ et 403 du BGB (443), le débiteur est valablement libéré si, avant qu'il ait connaissance de la cession de la créance, il paie de bonne foi entre les mains du précédent créancier ou, dans le cas de cessions multiples, entre les mains d'un cessionnaire auquel un autre a le droit d'être préféré. D'autre part, le porteur illégitime d'un titre au porteur (444) ou un non héritier légitimé par un certificat d'héritier (445) peuvent recouvrer une créance avec effet libératoire pour le débiteur. Dans tous ces cas; le véritable créancier peut, en vertu du $\S 823$ al. 1, actionner en dommages - intérêts celui qui a disposé de sa créance en la recouvrant.

Fabricius (446) admet également une action en dommages intérêts, basée sur le $\S 823$ al. 1, dans les cas où un tiers dispose de la créance d'autrui avec effet libératoire. Mais il fonde son opinion sur une autre argumentation que celle de Larenz. En effet. d'après Fabricius (447), le $\S 823$ ai. 1 ne vise pas seulement la protection des droits absolus; à son avis (448), si l'intérêt attacké

(441) D'un avis contraire: Esser, $\S 202,1$. b, p. 845; Enneccerus - Lehmann, $\S 1$, II, la.

(442) Cf. von Tuhr, Partie générale du code fédéral des obligations, $t$. I, p. 327 .

(443) Art. 167 du CO suisse.

(444) Cf. BGB $\S \S 793$ et 808 .

(445) Cf. BGB $\S \S 2366-2367$.

(446) ACP 1951, pp. 285 et sv; 305 et si.

(447) ACP 1961, p. 295.

(448) Cf. plus haut note 160. 
par un sujet de droit à un bien faisant l'objet de ce droit est typiquement reconnaissable du point de vue social comme nécessitant protection, on doit accorder le bénéfice du $\S 823$ al. 1 à ce bien, en le considérant comme un autre droit protégé par cette disposition. Ainsi, les biens qui remplissent la condition de (sozialty pische Offenkundigkeit) peuvent profiter de la protection du $\$$ 823 al: 1, même s'ils ne font pas l'objet d'un droit absolu (449). Toujours selon Fabricius (450), les tiers peuvent également violer un droit de créance; ce qui doit être admis une fois qu'on reconraât l'applicabilité du $\S 826$ pour la réparation de certains dommages causés au créancier par un tiers. Toutefois cet auteur arrive à peu près à la même conclusion que Larenz, en ce qui concerne la protection des droits de créance contre les atteintes des tiers; car, il n'estime applicable le $\S 823$ al. 1 que dans les cas où un tiers dispose de la créance avec effet extinctif ou retient ou détruit sans droit un papier - valeur dans lequel est incorporé un droit de créance (451), empêchant ainsi le créancier de faire valoir son droit. En ce qui concerne d'autres atteintes aux droits de créance, Fabricius (452) pense qu'en principe le bien juridique à protéger n'est pas typiquement reconnaissable comme digne de protection contre les interventions des tiers.

En droit suisse, comme en droit allemand, selon l'opinion dominante (453), les droits de créance, étant des droits relatifs,

(449) ACP, 1961, p. 295. D'un avis rapproché: Leonhard pp. 545, 550, 554, Pour la critique de la théorie de Fabricius: cf. Larenz, t. II (7e éd.) p. 409, note 1; ce dernier reproche à Fabricius de méconnâtre que le BGB ne prend en considération que la violation des droits et non celle des intérêts. Cf. aussi supra note 160 .

(450) ACP 1961, p. 284. Par contre, d'après Groh (op. cit. pp. 125, 126) le $\S 826 \mathrm{BGB}$ protège le patrimoine du creancier, et non son droit de créance contre les atteintes contraires aux bonnes moeurs.

(451) Cf. RGZ 158, 248 (protection du droit de l'actionnaire incorporé dans une action d'une société anonyme). Le RG a admis également (RGZ. 100,278 ) quie le droit à la part d'une SARL pouvait être protégé comme un autre droit prévu par le $\S 823$ al. 1 .

(452) ACP 1961, pp. $301-304$.

(453) Cf. von Tuhr, Partie génèrale, $\S 46$, II, pp. $326-327$; Oser-Schönenbenger, art. 41, nos. $15-19$; Becker, art. 41, no. 39; Oftinger, Schweizerisches Haftpflichtrecht, t. I, pp. $114-115$; le Tribunal fédéral: BGE 25 II 852; 52 II $375 ; 53$ II $332 ; 63$ II 21/22, 88; 74 II 26. 
ne peuvent être violés que par le débiteur qui n'exécute pas son obligation. L'inéxécution d'une obligation ne constitue pas un acte illicite au sens de l'art. 41 du CO et ses effets sont réglementés par les articles 97 et $\mathbf{s v . ~ d u ~ C O . ~ L e ~ t i e r s ~ q u i ~ e m p e ̂ c h e ~ l e ~ d e ́ b i t e u r ~}$ d'accomplir son obligation, notamment en détruisant la chose due cu en l'endommageant, commet un acte illicite à l'égard du créancier dont le droit relatif ne crée pour le tiers aucune obligation. Le créancier ne peut donc s'en tenir qu'au débiteur, conformément aux articles 97 et sv. du CO; il n'a pas d'action contre le tiers en vertu de l'art. 41. Cependant, si le créancier possède l'objet de l'obligation, on admet qu'il peut, en invoquant sa qualité de possesseur, réclamer des dommages - intérêts au tiers. D'autre part, lorsque le tiers incite le débiteur à contrevenir à ses obligations contractuelles, l'art. 41 al. 2 du CO suisse qui correspond au $\S 826$ du BGB ou les articles 1 (e) et (f) de la loi fédérale sur la concurrence déloyale sont applicables. Enfin, on accorde au créancier l'action de l'art. 41 al. 1, lorsqu'un tiers dispose de la créance avec effet extinctif. Les exemples d'un tel acte de disposition sont semblables à ceux donnés en droit allemand; notamment l'art. 167 du CO suisse correspond aux $\S 407$ et 408 du BGB et prévoit la libération du débiteur qui, en cas de cession d'une créance, paie de bonne foi entre les mains du créancier précédent et en cas de cessions multiples entre les mains d'un cessionnaire auquel un autre a le droit d'être préféré.

Selon l'opinion dominante en Suisse (454), un tiers qui offre un prix plus élevé et se fait céder la chose vendue, mais nón encore délivrée (445) à un autre, ou qui débauche l'employé d'un concurrent, ne lèse pas les droits de la créance de l'acheteur ou de l'employeur précédent, même s'il sait que la chose ou les services étaient promis à ceux-ci; il peut laisser au débiteur le soin de s'expliquer avec le premier créancier. Des circonstances particulièrement graves

(454) Cf. von Tuhr, t. I, p. 327; Oser-Schönenberger, art. 41, no. 15.

(455) En droit suisse, à la différence du droit français, le contrat de vente ne transfère pas la propriété de la chose vendue à l'acheteur; il faut encore effectuer un acte de disposition consistant dans la remise de la possession (en particulier la tradition) pour que l'acheteur acquière la propriété. 
teront seules admettre une atteinte aux bonnes mœeurs dont découle, en cas de dommage intentionnel, le droit de réclamer au tiers des dommages - intérêts en vertu de l'art. 41 al. 2. Ces circonstances résident notamment dans le but poursuivi ou dans les moyens employés (par exemple intention de nuire par pur esprit de vengeance, tromperie du marchand) (546).

Il existe toutefois certains auteurs suisses qui soutiennent que l'art. 41 al. 1 du CO est applicable en cas d'intrusion des tiers dans les rapports contractuels. Ainsi, selon A. Gelpke (457), les intérêts du créancier découlant de son droit de créance peuvent être violés par des tiers et cette violation constitue une illicéité au sens de l'art. 41 al. 1 du CO. L'action en indemnité du créancier ne sera pas fondée sur la violation de son droit de créance, mais su: l'atteinte portée à son intérêt qui est digne d'une protection juridique (458). L'auteur admet l'existence d'une lacune dans la loi on ce qui concerne la protection de l'intérêt du créancier tendant à la non intrusion des tiers dans ses rapports contractuels; cette lacune doit être combiée par le juge conformément à l'art. 1 al. 2 du CC suisse, en pesant les intérêts respectifs du créancier et du tiers qui intervient. Quant à C.P. Mercier (459), il préconise d'assurer la protection du créancier qui ne doit pas être entravé dans ses rapports contractuels, en lui reconnaissant un droit de personnalité (460). L'objet de ce droit consiste dans le respect par le tiers de la sphère des rapports contractuels. Mercier (461) oppose au droit du créancier de pouvoir conclure librement des contrats avec tout le monde, le droit de même nature qui appar-

(456) BGE 52 II 375 ou JdT 1927: pp. $261-262$.

(457) Die Verletzung eines vertraglichen Rechts durch einen Nicht-Vertragsbeteiligten, thèse de Zurich 1919 , pp. 32 et sv., pp. 58 et sv.

(458) Gelpke (pp. 51-52, 60) admet pour le créancier l'existence d'un intérêt digne de protection en cas de destruction de l'objet de vente et en cas de débauchage de son employé, mais non dans les cas de double vente; c'est justement cette différence de traitement qui a été critiquée par Oser-ISchönenberger, art. 41, no. 18.

(459) Faut-il admettre l'existence du jus ad rem en droit civil suisse, thèse de Lausanne, $1929, \mathrm{pp} .157$ et sv.

(460) Le Tribunal fédéral (BGE 52 II 375) ne parait pas admettre un tel droit de personnalité.

(461) P. 160 . 
tient au tiers; il déduit de cette confrontation des conclusions qui céterminent les conditions, sous lesquelles l'intervention du tiers sera illicite. Ainsi, à son avis (462), «le tiers est responsable du dommage qu'il a causé, pourvu que son acte ait exercé une influence déterminante sur l'inéxécution du premier contrat, dont il connaissait l'existence, mais il ne porte pas atteinte au droit de la personnalité protégeant la sphère des rapports contractuels, s'il ignore le premier engagement, ou s'il ne fait qu'accepter une proposition toute prête que lui fait le débiteur de conclure un contrat ${ }_{\text {. }}$

En droit français, la jurisprudence (463) ainsi que la majorité des auteurs (464) admettent la responsabilité délictuelle du tiers qui participe sciemment à la violation d'une obligation. Le principe de la relativité des obligations et des conventions ne fait pas obstacle à une telle responsabilité. Car, «si les tiers ne sont pas pcisonnellement obligés par le contrat, rien ne les autorise à porter une atteinte consciente aux droits du créancier. En le faisant, ils ne manquent pas sans doute à un devoir contractuel, mais au devoit général de ne pas nuire à autrui, comme source d'une responsabilité délictuelle. Pour le nier, il faudrait découvrir, dans l'art. 1165, le principe d'un véritable droit de nuire consciemment à autrui. Or le seul droit donné aux tiers par ce texte est de ne pas rechercher si des engagements ont été pris. C'est d'ailleurs pour eux une situation avantageuse quant à la preuve, puisqu'ils ne seront respcnsilbles que si l'on établit leur mauvais a foi, c'est-à-dire leur connaissanee de la promesse qu'ils ont aidé à violer» (465). Pour lEs auteurs affirmant que la faute implique la violation d'un droit et non simplement la lésion des intérêts de la victime (466), lıs droits de créance, étant des valeurs comprises dans le patrimoine comme les droits réels, doivent être aussi protégés comme ces derniers, contre les

(462) P. 161.

(463) Cf. les décisions citées par Savatier. Traité de la responsabilité civile, t. I, p. 187, note 3. Cf. aussi A. Weill, La relativité des conventions en droit privé français, Paris 1939. no. 254 où se trouve uâe analyse de la jurisprudence.

(464). Savatier, t. I, nos. 144 et sv.; Mazeaud-Tunc, t. I, no. 144; Weill, no; 231 et sv., en particulier nos. 247 et sv.

(465) Savatier, t. I, no. 144, p. 187.

(466) Cf. Weill, no. 238, p. 416. 
atteintes des tiers (467). D'ailleurs, le contrat conçu en tant que fait social est opposable erga omnes (468); «le même sujet passif universel se retrouve dans le droit réel et dans le droit de créance, sujet tenu du devoir d'abstention» (469).

Les théories de Hugueney et de Demogue, expliquant la responsabilité du tiers par sa participation à la faute contractuelie du débiteur n'ont pas trouvé l'approbation de la doctrine dominante (470). Selon P. Hugueney (471), la responsabilité du tiers étant certainement délictuelle, celle de l'auteur principal (c'est-à-dire du débiteur qui viole son obligation) doit également se transformer en responsabilité délictuelle. Par contre, Demogue (472) estime que la nature contractuelle de la responsabilité du débiteur influe sur la nature de celle du tiers et la rend également contractueile.

Quant aux cas d'application de la responsabilité du tiers complice de la violation d'une obligation contractuelle, d'abord cette responsabilité est reconnue expressément par l'art. 23 a) liv. 1 du Code du Travail (Loi du 5 février 1932) en cas de débauchage d'un salarié par un autre employeur. D'ailleurs, même déjà avant la Loi du 5 février 1932, la jurisprudence rendait responsable l'employcux. qui méconnaît sciemment les droits d'un autre, en lui enlevant son employé (473). D'autre part, «la promesse de vente ou de location qui n'engendre de responsabilité contractuelle que pour le promettant, fait aussi naître une responsabilité délictuelle chez lui qui, de mauvaise foi, se fait vendre, louer ou hypothéquer la chose promise à autrui» (474).

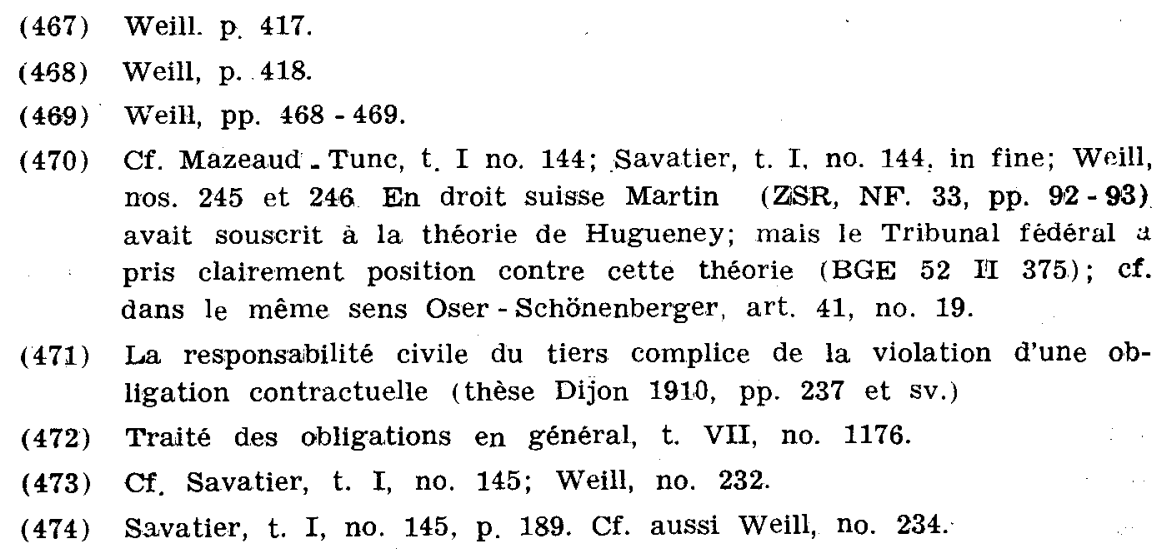


La jurisprudence qui ne se contente pas de la connaissance du contrat précédent (475) et exige le concert frauduleux entre le tiers et le débiteur en matière de contrats soumis à transcription, a attiré les critiques de la doctrine (476).

L'inobservation d'une clause fixant d'une manière licite des prix minimums, entraîne à côté de la responsabilité contractuelie du vendeur qui l'a acceptée, la responsabilité délictuelle du client, qui achète ou revend, en connaissance de cause, au-dessous du prix limite (477).

La responsabilité délictuelle du tiers n'est pas engagé seulement lorsqu'il est complice du débiteur violant son obligation, mais aussi dans les cas ou le tiers, sans complicité avec le débiteur, apporte de son propre chef un trouble de fait à l'inexécution du contrat (478). "Ainsi le voleur qui empêche un transporteur ou un autre débiteur de corps certain s'exécuter, doit réparation, soit au créancier lésé par cette inexécution, soit au débiteur condamné envers ce créancier» (479).

44 - Nouvelles théories qui ne considèrent pas suffisante, pour établir l'illicéité, la lésion d'un droit ou d'un bien absolu. - Nous avions souligné plus haut (480) que, d'après l'opinion dominante en droit allemand, un acte ayant pour effet la violation d'un droit absolu ou de l'un des biens pərsonnels protegée par le $\S 823$ al. 1, doit être qualifié d'illicite, à moins qu'il n'existe un fait justificatif. Or, récemment, on a apporté certaines restrictions importantes à cette manière de voir.

(475) La condition de «violation de l'obligation en connaissance de son existence» peut être expliquée par le manque de publicité des droits de créance; tandis que ies droits réels sont plus apparents que les droits de créance.

(476) Cf. Savatier, t. I, no, 146.

(477) Cf. Savatier, t. I, no. 145, p. 188; IVeill, no. 233. En Suisse, dans un de ses arrêts, le Tribunal féderal (BGE 52 II 375) n'a pas í. mis la responsabilité de ''acheteur qui ne respecte pas le prix minimum imposé.

(478) Cf. Savatier, t. I, no. 147 bis; Mazeaud-Tunc, t. I, no. 143.

(479) Savatier, t. I, no. 147 bis.

(480) Cf. supra no. 28. 
En premier lieu, même ceux qui reconnaissent comme critère de l'illicéité la violation d'un droit absolu, se sentent obligés de faire des réserves (481) en ce qui concerne les nouveaux droits crées par la jurisprudence, tels que le droit général de la personnalité et les divers droits particuliers qui en découlent ainsi que le droit à l'exploitation d'une entreprise. En raison de l'imprécision du contenu des droits en question, le juge ne peut, sans faire d'autres recherches, prononcer l'illicéité d'un acte qui a eu une influence désavantageuse sur l'objet de ces droits. Il doit d'abord fixer l'illicéité de l'atteinte en recourant à d'autres critères pour en conclure à violation du droit. Par contre, lorsqu'il s'agit des droits et des biens classiques prévus expressément au $\S 823$ al. 1 , tels que la propriété ou la vie, le corps, la santé, la liberté de mouvement, on peut facilement constater l'existence d'une lésion de ces droits et biens afin d'en déduire l'illicéité de l'acte qui a porté préjudice à leur objet. Selon Larenz (482), la détermination de la violation des droits et biens classiques est une question de constatation des faits et non une question d'appréciation nécessitant de porter un jugement de valeur (483). Ainsi, par exemple, lorsqu'on détruit la chose appartenant à autrui, l'acte de destruction viole le droit de propriété de ce dernier; cet acte est en principe illicite; la preuve de l'existence d'un fait justificatif ne ferait qu'écarter le caractère illicite de la violation de la propriété. Tandis que pour déterminer, si une affirmation de la presse porte atteinte au droit à l'honneur de la personne visée, le juge doit confronter l'intérêt de celle-ci avec l'intérêt du public à être informé à son sujet; s'il estime que l'information est fondée sur un intérêt légitime, le jugement de valeur qu'il prononce n'ôtera pas seulement le caractère illicite à la violation du droit à l'honneur, mais il signifiera qu'il ne s'agit même pas d'une violation du droit en question. Donc, la méthode se rapportant à l'effet de l'acte sur le bien juridique protégé afin de déterminer l'illicéité doit être restreinte, selon les tendances

(481) Cf. Larenz, t. II (7e éd.). pp. 424-425; Lehmann, Festschrift für Hedemann, 1958, pp. 188 et sv.; OLG Stuttgart, JZ, 62, p. 93.

(482) T. II (7e éd.), p. 425.

(483) Pourtant parfois les limites de la propriété ne sont pas non plus toujours trés précises; il suffit de penser aux limites de la proprieté immobiliére découlant des régles de voisinage. 
nouvelles de la doctrine allemande, aux droits et biens classiques mentionnés expressément au $\$ 823$ al. 1.

D'autre part, d'après certaines théories récentes, lorsqu'il s'agit d'atteintes non intentionnelles, même si celles-ci sont portées a des droits et biens classiques, le critère de la viclation du droit ou du bien ne suffit pas à déterminer l'illicéité; pour pouvoir prononcer l'iilicéité de pareils actes, il faut encore établir la transgression d'une norme de conduite spéciale posée par l'ordre juridique ou l'inobservation des règles générales de diligence. Ces conceptions se ramènent dans leurs grandes lignes à deux théories. Suivant la première, préconisée par Nipperdey (484), pour déterminer l'illicéité de tous ies actes non intentionnels, il faut, en plus de la violation ou parfois de la mise en danger d'un droit ou d'un bien obsolu, rechercher si ces actes contreviennent à une norme de conduite ou aux règles générales de diligence; cette théoriø ne fait donc pas de distinction entre les actes non intentionnels qui ont comme effet direct ou indirect la violation d'un droit. Tandis que la seconde théorie considère catte recherche complémentaire comme nécessaire seulement pour les actes non intentionnels qui ont pour effet indirect la violation d'un droit ou d'un bien juridique. tiels :

Résumons maintenant ces théories dans leurs traits essen-

a) La théorie de Nipperdey. Selon cet auteur (485), la notion d'illicéité exprime un jugement de valeur désapprobateur sur un acte déterminé. Elle doit être distinguée de la notion de faute qui est également l'expression d'un jugement de valeur désapprobateur supposant nécessairement un acte illicite; mais ce jugement se rapporte à la question de savoir si l'on peut reprocher personnellement à l'agent son acte. C'est pourquoi un acte peut être illicite, sans être à la fois fautif, ainsi par exemple lorsque l'agent était incapable de discernement áu moment ou il a commis cet acte. La qualification désapprobatrice d'illicéité peut être rattachée à deux facteurs différents relatifs aux circonstances de l'acte: D'une part, l'acte peut être jugé d'après les conséquences qu'il a entraînées

(484) Cf. Enneccerus - Nipperdey, Lehrbuch des Bürgerlichen Rechts, t. II, vol. 2, 15e éd. Tübingen 1960, $\S 209$, pp. 1207 et sv.

(485) Enneccerus - Nipperdey, T. I, vol. 2, pp. $1277-1285$. 
par rapport aux intérêts (486) auxquels l'ordre juridique attache une valeur; d'autre part, l'acte peut être apprécié en soi par rapport à une injonction ou une interdiction de l'ordre juridique en tant que conforme ou contraire à une norme (normgemaess, $n$ or $m$ widrig). L'opinion encore dominante pour déterminer l'illicéité prend en considération seulement le jugement de valeur. désapprobateur concernant le résultat de l'acte ( Erfolgsunwert). Or, cette manière de voir est insoutenable. Car, d'une part, un certain nom. bre de dispositions édictant une responsabilité ne se fondent pas seulement sur le résultat de l'acte (487). D'autre part, la théori: de l'illicéité se rapportant au résultat, ne saurait expliquer l'illicéi. té de la lésion des biens juridiques par omission. En effet, il est généralement admis qu'une omission n'est illicite que s'il y a un lien de causalité entre elle et la violation du bien juridique et si elle constitue l'inobservation d'un devoir qui tend à prevenir le résultat. Or, comme on le voit, le jugement d'illicéité ne peut pas se rapporter seulement au résultat de l'omission: il faut encore re. chercher si cette omission constitue un comportement contraire à une norme qui ordonne de prendre certaines mesures pour empêcher le dommage de se produire. La situation est semblable en cas de violation de biens juridique, due à la négligence. Selon le $\S 276$ al. 1 du BGB, celui qui n'observe pas la diligence exigée dans les rapports sociaux ( wer die im Verkehr erforderliche Sorgfalt ausser Acht laesst ), agit d'une manière négligente. La mesure de diligence requise par cette disposition n'est pas déterminée d'après la personnalité de l'agent, mais au moyen d'un critère objectif, c'est-à-dire, selon les exigences des rapports sociaux. En droit pénal, suivant la conception qui a prévalu, l'inobservation des exigences générales de diligence n'est pas une question relative à la faute, mais à l'illicéité. Il «st regrettable qu'on n'utilise pas également en droit civil les résultats des recherches des pénalistes. En effet, pour répondre à la question de savcir si i'agent a observé la diligence, requise par les rapports sociaux, on apprécie son acte d'après une norme de conduite générale déterminée en partant du comportement

(486) En les lésant ou les mettant en dangér.

(487) Par exemple, selon le $\S 826$ la responsabilité pour les dommages causés au patrimoine comme tel supposent un acte contraire aux bonnes mœurs et l'intention de nuire. 
d'un homme prudent et raisonnable; on n'examine donc pas si l'un peut reprocher personnellement à l'agent de ne pas avoir observé la diligence commandée par les circonstances. La notion de faute ne peut être évoquée ici, car l'agent concret n'est pas pris en considération. La réponse affirmative à la question de savoir si le devoir général de diligence est enfreint, n'appelle qu'un reproche consistant à dire que l' «on» aurait dû se conporter autrement. Mais c'est un jugement d'illicéité ( Rechtswidrigkeitsurteil), parce qu'on établit ainsi d'une façon objective le caractère de l'acte contraire à un devoir. Enfin, la théorie de l'illicéité se rapportant au résultat ne permet pas de résoudre d'une façon satisfaisante les problèmes relatifs aux cas où les activités et installations dangereuses autorisées par l'ordre juridique causent la violation des biens juridiques; car, même si la diligence commandée par les rapports sociaux ou même le maximum de diligence humainement possible, est observé, le résultat causé et par conséquent l'activité qui a entraîné ce résultat, aurait dû être illicite selon la théorie classique; or, ceci n'est pas conforme à la réalité.

D'après Nipperdey (488), tout ce qui précède démontre que le jugement d'illicéité ne saurait être fondé seulement sur le résultat. de l'acte, mais qu'il convient de prendre aussi en considération la non conformité de cet acte à une injonction ou à une interdiction de l'ordre juridique. Par conséquent, l'illicéité peut être définie comme la violation ou la mise en péril d'intérêts juridiquement reconnus, par des actes contraires aux injonctions ou aux interdictions de l'ordre juridique. Les devoirs des sujets de droit par rappori aux intérêts méritant la protection peuvent être établis de deux manières: d'une part, les normes juridiques posent des interdictions qui ordonnent l'abstention des actes visant la violation des intérêts en question; d'autre part, elles édictent des injonctions qui prescrivent, en accomplissant certains actes - qui ne visent pas un résultat désapprouvé et même qui sont parfois désirables - de prendre les précautions nécessaires pour éviter cortains effets accessoires de ces actes consistant dans la violation des intérêts protégés. S'agissant de cette dernière catégorie d'actes, il faudrait déterminer la mesure de la diligence exigée. La limite extrême de

(488) Enneccerus - Nipperdey, Lehrbuch, t. I,, volume 2, p. 1286 et sv. 1294 et sv. 
cette diligence découle de la nature même de l'injonction qui est une norme de conduite: il ne peut pas être question des exigences de diligence que personne n'est en mesure de remplir. Les violations des biens juridiques, qui sont inévitables, ne peuvent être donc considérées comme contraires aux injonctions et comme illicites. En outre, les exigences du droit qui est un ordre de la vie en commun ne peuvent pas s'orienter seulement vers ces limites extrêmes. Cet ordre, dans le souci de protéger les biens juridiques dans la plus grande mesure possible, ne doit pas imposer des restrictions insupportables en ce qui concerne les rapports sociaux et le développement de la personnalité. 'Si l'homme devait s'abstenir de tout acte qui pourrait avoir comme conséquence éventuelle la violation d'un bien juridique, on le condamnerait à l'inactivité. C'est pourquoi, l'ordre juridique, en fixant les limites du devoir de diligence, doit tenir comptè de l'idée de la vie sociale en commun et desi risques qui lui sont attachés. Il ne peut prescrire qu'un comportement conforme aux exigences auxquelles on peut soumettre un homme normal, ordinaire et raisonnable placé dans le cadre de la vie sociaie en commun et dans la situation concrète à juger; en d'autres termes, on peut attendre de celui qui agit, qu'il mette en péril les biens d'autrui dans une mesure adéquate du point de vue social. Cei principe d'appréciation a trouvé son expression particulièrement au $\S 276$ al. 1 phr. 1 du B.G.B. Les violations non intentionnelles des biens juridiques ne sont par conséquent illicites que si elles ont été effectuées sans observer la diligence requise dans les rapports sociaux. Cette théorie se rapproche ainsi, du moins apparemment, de celle de la négligence objective. Mais Nipperdey qui considère l'inobservation de la diligence objective comme une question d'illicéité, préconise (489) la prise en considération de l'individualité de l'agent, en vue de déterminer la mesure de diligence nécessaire pour établir l'existence d'une faute non intentionnelle. Il revient donc à la conception subjective de la faute: celui qui ne possède pas les qualités et les capacités nécessaires pour prendre les précautions exigées, ne serait pas en faute, s'il n'est pas état de se rendre compte de sa déficience; on ne pourrait donc pas le déclarer fautif, en disant qu'il aurait dû savoir qu'il ne possedait pas les qualités nécessaires.

(489) Enneccerus - Nipperdey, Lehrbuch, t. I., vol, 2, $\S$ 213. III, 2, p. 1321 et sv. 
Le B.G.H. a également admis (490), la théorie de Sozialadäquanz en matière de circulation routière. Selon la Cour Suprême, l'acte dommageable d'un usager de la route n'est pas illicite, lorsque celui-ci s'est ccmporté d'une façon correcte du point de vue des injonctions et des interdictions concernant la circulation routière, mêrnt s'il a lésé un bien absolu protégé par le $\S 823$ al. 1.

La théorie de Nipperdey a suscité des critiques (491). Les adversaires de cette théorie font remarquer, d'abord, l'existence de certaines dispositions du B.G.B. qui permettent d'intenter une action en cessation de trouble en cas de violation ou de mise en péril d'un droit absolu, même si l'on ne se trouve pas en présence d'une fautc (intention ou négligence objective); si l'on subordonne encore une telle action, qui ne dépend que de l'illicéité de l'acte, à l'inobservation d'une diligence objective en cas d'actes non intentionnels, la protection des droits absolus s'en affaiblirait. D'autre part, confor. mément au $\$ 277$ al. 2, on admettait l'existence d'un cas ce légitime défense, lorsqu'il y avait atteinte à un droit absolu, sanis rechercher si l'agresseur avait respecté ou non une injonction de diligence. Enfin, le $\S 276$ al. 1 phr. 2 du B.G.B. définit expressément la négligence et non l'illicéité.

b) Certains auteurs, parmi lesquels se trouve Larenz, en tenant compte de ces critiques, ont tempéré la théorie de Nipperdey (492). A leur avis, un acte non intentionnel portant atteinte à un bien ou droit absolu n'est illicite que lorsque la violation du droit constitue la conséquence directe de l'acte; il n'est pas nécessaire alors de rechercher, si cette atteinte contrevient encore à une norme de conduite, en particulier à la norme de diligence générale. C'est seulement lorsque la violation du droit absolu est la consiquence indirecte d'un acte non intentionnsl que l'on doit cxaminer, si cミt acte est contraire d'une façon objective à un devoir de diligirrce. Larenz (493) illustre sa théorie avec les exemples suivants lorsqu'une infirmière injecte à un malade un liquide qui causera un effet

(490) B.G.H.Z., 24, 21.

(491) Cf. surtout Hans Stoll, JZ 1958, p. 137 et Unrechtstypen bei Verletzung absoluter Rechte, $\mathrm{ACF}^{\prime} 162,205$; Larenz, t. II, 7ème éd. p. 427 - 423.

(492) Cf. Larenz, t. II, pp. $428-430$.

(493) T. II, pp. $428-429$. 
mortel, dans la croyance erronée mais excusable qu'il s'agit d'un médicament inoffensif, elle commet un acte illicite, sans qu'on puisse lui reprocher, l'inobservation de la diligence nécessaire. Dans ce cas, le malade menacé peut recourir à la légitime défense, ou bien un tiers peut intervenir en invoquant le cas de nécessité, s'ils s'apei. çoivent de l'erreur de l'infirmière qui est de bonne foi. Par contre, celui qui fabrique des produits somnifères, qui ne peuvent être vendus que sur l'ordonnance, ne tue pas d'une maniere illicite la personne qui s' $\epsilon$ st procurée ce produit sans ordonnance et qui s'est suicidée en en avalant une forte dose, lorsque cel produit a été remis à pharmacie d'une façon régulière. Mais s'il y avait une négligence objective de la part du fabricant, en facilitant l'obtention de son produit sans ordonnance, son comportement serait illicite.

Toujours selon Laren\% (494), la conséquence de l'acte est directe, lorsqu'elle réside dans le processus d'accomplissement de l'acte ou lorsqu'elle constitue avec lui un ensemble inséparable d'après les conceptions tirées de l'expérience de la vie.

(494) T. II pp. $429-430$. 